Illinois State University

ISU ReD: Research and eData

Theses and Dissertations

6-9-2015

\title{
An Approach To An Agave Problem: The Bioremediation Of Agricultural Waste By Yeast Fermentations
}

Joshua Michael Jarodsky

Illinois State University, jmjarod@ilstu.edu

Follow this and additional works at: https://ir.library.illinoisstate.edu/etd

Part of the Agriculture Commons, Biochemistry Commons, and the Chemistry Commons

\section{Recommended Citation}

Jarodsky, Joshua Michael, "An Approach To An Agave Problem: The Bioremediation Of Agricultural Waste By Yeast Fermentations" (2015). Theses and Dissertations. 509.

https://ir.library.illinoisstate.edu/etd/509

This Thesis is brought to you for free and open access by ISU ReD: Research and eData. It has been accepted for inclusion in Theses and Dissertations by an authorized administrator of ISU ReD: Research and eData. For more information, please contact ISUReD@ilstu.edu. 


\section{AN APPROACH TO AN AGAVE PROBLEM: THE BIOREMEDIATION OF AGRICULTURAL WASTE BY YEAST FERMENTATIONS}

Joshua M. Jarodsky

\section{Pages}

The agricultural waste products created by industries, such as the Tequila manufacturing industry, create thousands of tons of waste material every year. This agricultural waste often becomes an environmental and ecological problem for fields and surrounding areas. The purpose of this study is to determine the potential of using the yeast Kluyveromyces marxianus 7-1 and Kluyveromyces marxianus 8-1 to ferment the leaf waste from the harvesting of the Agave tequilana as a form of bioremediation. Fermentations (anaerobic, under constant shaking, and at room temperature) were monitored for colony forming units, $\mathrm{pH}$ of fermentation broth, concentration of reducing sugars, and protein concentration as a function of fermentation time. Yeast products formed during the fermentation such as enzymes (inulinases), protein, and the yeast cells are considered important due to their current market value and use as feedstock for other fermentations with Yarrowia lipolytica, Saccharomyces cerevisiae, and 
Rhodotrula glutinis (not the focus of this study). Endogenous compounds in the Agave tequilana leaves are also of interest to these studies such as potential natural ultraviolet absorbing compounds (mycosporine-like-amino acids).

It was determined that both Kluyveromyces marxianus 7-1 and Kluyveromyces marxianus 8-1 are able to grow on the leaves of the Agave tequilana with similar growth curves, as determined by colony forming units. Kluyveromyces marxianus 7-1 experienced a shorter lag time making it the "better" choice for an industrial application. It was demonstrated that the protein and reducing sugar concentrations have an inverse relationship with colony forming units as a function of fermentation time. Several interesting ultra violet absorbing compounds were extracted from the leaves of the Agave tequilana and a positive control (seaweed). These compounds were characterized by thin layer chromatography, UV-Vis spectrophotometry, and high performance liquid chromatography with a diode array detector. These studies demonstrate that the leaves of the Agave tequilana, which are currently considered waste, have potential to produce economically valuable products through mycosporine-likeamino acid extractions and fermentation with Kluyveromyces marxianus 7-1 and Kluyveromyces marxianus 8-1.

KEYWORDS: Agave Tequilana, Agricultural Waste, Bioremediation, Kluyveromyces marxianus, Mycosporine-Like-Amino Acids, Yeast Fermentations 
AN APPROACH TO AN AGAVE PROBLEM: THE BIOREMEDIATION OF AGRICULTURAL WASTE BY YEAST FERMENTATIONS

JOSHUA M. JARODSKY

A Thesis Submitted in Partial Fulfillment of the Requirements for the Degree of MASTER OF SCIENCE Department of Chemistry ILLINOIS STATE UNIVERSITY 
(C) 2016 Joshua M. Jarodsky 
AN APPROACH TO AN AGAVE PROBLEM: THE BIOREMEDIATION OF AGRICULTURAL WASTE BY YEAST FERMENTATIONS

JOSHUA M. JARODSKY

COMMITTEE MEMBERS:

Marjorie A. Jones, Chair

Jun-Hyun Kim

Jon Friesen

Stephen Hughes 


\section{ACKNOWLEDGMENTS}

I want to first thank Dr. Marjorie A. Jones, research advisor, for sharing her invaluable wisdom and enthusiasm for the sciences. Also, for her advisement through my undergraduate and graduate programs at Illinois State University and beyond.

Thank you to Dr. Stephen Hughes at the United States Department of Agriculture in Peoria, IL for supplying yeast and resources for my thesis research, as well as acquiring and arranging for a whole fresh Agave tequilana plant from Jalisco, Mexico to be delivered to Illinois State University for my thesis.

I want to thank my loving family for their endless support during my studies.

Finally, I express my gratitude to the faculty, staff, students, and my research lab peers at Illinois State University Department of Chemistry for providing a friendly, stimulating, and challenging learning environment, as well as for the lab space, equipment, instruments, reagents, and materials provided by Illinois State University Department of Chemistry.

J. M. J. 


\section{CONTENTS}

Page

ACKNOWLEDGMENTS

CONTENTS

TABLES iv

FIGURES

CHAPTER

I. INTRODUCTION 1

The Tequila Industry and the Agricultural Waste 1

The Agave tequilana and its Leaves 3

Inulin and Agave tequilana Fructans 4

Fermentation $\quad 6$

Kluyveromyces marxianus $\quad 8$

Mycosporine-Like-Amino Acids $\quad 12$

Bioremediation of the Agave tequilana Agricultural Waste 14

II. MATERIALS AND METHODOLOGY 18

$\begin{array}{ll}\text { Organisms and Storage } & 18\end{array}$

Yeast Starter Cultures and Inoculation 19

Fermentation $\quad 20$

Fermentation Sampling $\quad 22$

Assay for Reducing Sugars $\quad 23$

Concentration of Protein 24

Yeast Inulinase Purification $\quad 25$

Inulinase Activity 27

Mycosporine-Like-Amino Acid Extraction 28

Extract Purification and UV-Vis Spectroscopy 29

Thin Layer Chromatography of Extracts 30

HPLC of Extracts 30 
III. RESULTS AND DISCUSSION

Fermentation Weights $\quad 32$

Fermentation Growth Curves $\quad 33$

Assay for Reducing Sugars $\quad 42$

Fermentation Broth $\mathrm{pH}$ and Protein Concentration 48

Yeast Inulinase Purification and Activity 53

Mycosporine-Like-Amino Acid Extraction $\quad 56$

Mycosporine-Like-Amino Acid Column Purification 56

TLC of Mycosporine-Like-Amino Acid Extracts 57

HPLC of Mycosporine-Like-Amino Acid Extracts 59

$\begin{array}{ll}\text { IV. CONCLUSIONS AND FUTURE WORK } & 62\end{array}$

$\begin{array}{ll}\text { Fermentation } & 62\end{array}$

Reducing Sugars $\quad 65$

Protein Concentration $\quad 66$

Yeast Inulinase Purification $\quad 69$

Mycosporine-Like-Amino Acid Extraction and Purification $\quad 70$

TLC and HPLC of Mycosporine-Like-Amino Acid Extracts $\quad 71$

Final Conclusions $\quad 74$

$\begin{array}{ll}\text { Future Work } & 74\end{array}$

$\begin{array}{ll}\text { REFERENCES } & 76\end{array}$

APPENDIX A: Selection of Reported Structures of

Mycosporine-Like-Amino Acids

(Modified from ref. 46)

81

APPENDIX B: Reported Biosynthetic Routes of Mycosporine-Like-Amino Acids

(Modified from ref. 27)

82

APPENDIX C: The Proposed Generalized Bio-Nylon 6 and Bio-Kevlar Synthetic Pathways

(Modified from ref. 8)

83 


\section{TABLES}

\section{Table}

Page

1. Summary of Fermentation Set, Type, and Weight of Agave tequilana Pieces Used

2. Retention Times, Peak Absorbance, and Peak Area of HPLC Separation of Mycosporine-Like-Amino Acid Extracts From the Skin of the Agave tequilana Monitored at $320 \mathrm{~nm}$

3. Comparison of Fermentations of Kluyveromyces marxianus 7-1 and Kluyveromyces marxianus 8-1 on Various Media 


\section{FIGURES}

Figure

Page

1. Agave tequilana Fructan 5

2. Wild Type Kluyveromyces marxianus (WT), Km7-1, Km8-1 Variants Genomic DNA Fragmentation 10

3. Reported Mycosporine-Like-Amino Acid Core Structure 13

4. Breaking up of Agave tequilana Leaves 21

5. Km7-1: CFU as a Function of Fermentation Time 34

6. Km8-1: CFU as a Function of Fermentation Time 36

7. CFU as a Function of Fermentation Time 39

8. CFU as a Function of Adjusted Fermentation Time 39

9. All Respective Fermentations: Averaged CFU as a Function of Adjusted Fermentation Time

10. All Respective Fermentations: Averaged CFU as a Function of Fermentation Time

11. Control Fermentation: Reducing Sugar Concentration as a Function of Fermentation Time

12. Km7-1 Fermentations: Reducing Sugar Concentration as a Function of Fermentation Time

13. Km8-1 Fermentations: Reducing Sugar Concentration as a Function of Fermentation Time 
14. Averaged Fermentation Reducing Sugar Concentration and CFU as a Function of Fermentation Time

15. Control Fermentations: Protein Concentration as a Function of Fermentation Time

16. Km7-1 Fermentations: Protein Concentration as a Function of Fermentation Time

17. Km8-1 Fermentations: Protein Concentration as a Function of Fermentation Time

18. Averaged CFU and Averaged Protein as a Function of Fermentation Time

19. Silver Stained SDS-PAGE Gel

20. Same Gel as Figure 19 with the Image Converted to Black and White and the Brightness and Contrast Adjusted

21. Overlaid UV-Vis Spectra of Pooled MycosporineLike-Amino Acid Fractions from Dried Seaweed and the Skin of the Agave tequilana

22. TLC of Mycosporine-Like-Amino Acid Extracts from Seaweed (Lanes A and B) and Agave tequilana Skin (Lane C) After Ninhydrin Detection Spray for Amines

23. TLC of Mycosporine-Like-Amino Acid Extracts from Seaweed (Lanes A and B) and Agave tequilana Skin (Lane C) After Sulfuric Methanol Detection Spray for Hydrocarbons

24. HPLC Separation of Seaweed Mycosporine-LikeAmino Acid Extracts $(320 \mathrm{~nm})$

25. HPLC Separation of Agave tequilana Skin

Mycosporine-Like-Amino Acid Extracts $(320 \mathrm{~nm})$ 


\section{CHAPTER I}

\section{INTRODUCTION}

\section{THE TEQUILA INDUSTRY AND THE AGRICULTURAL WASTE}

For the country of Mexico, tequila is a major source of pride and economic wealth. According to IBISWorld, tequila contributes $9.1 \%$ to the distilled beverage industry and had an estimated revenue of $\$ 1.1$ billion USD in 2015 (1). The name and distilled beverage, tequila, is protected by the Declaration for the Protection of the Appellation of Origin Tequila enacted by the Mexican Federal Government in 1977 to legally control the production, labeling, and distribution of tequila in a similar fashion to champagne regulation in France (2).

According to the Consejo Regulador Del Tequila (CRT) (Tequila Regulation Council) of Mexico, a private nonprofit organization emplaced by the Mexican Federal Government in 1994 to regulate every aspect of tequila production, labeling, and distribution, tequila has been made in Mexico for at least the last 300 years (3). The CRT enforce stiff regulations dictating that in order for a drink to be considered tequila it must comply with the Norma Oficial Mexicana (Mexican Official Standard) NOM-006-SCFI-2012, Alcoholic Beverages-Tequila-Specifications and pass inspections of all claims of appellation of origin. For example, section 4.17 of NOM-006-SCFI-2012 requires that at least $51.0 \%(\mathrm{w} / \mathrm{w})$ of the carbohydrates used to make the distilled 
beverage must come from the Agave tequilana in order for it to be considered tequila. Section 4.32 specifies that any facilities that "...to pursue the elaboration of Tequila..." must be in the territories appointed in the Declaration (4).

The CRT has reported that over 240 million liters of tequila were produced in 2015 , which was $20.4 \%$ lower than the last peak in production of 312 million liters reported in 2008 (5). In 2008, over 1.12 million metric tons of Agave tequilana piñas (hearts) were harvested to make tequila and an estimated 0.89 million metric tons were harvested in 2015 (6). Section 4.36 of NOM-006-SCFI2012 states that only the piña of the Agave tequilana can be used for the production of tequila and the leaves cannot (4). The piña makes up $50.0-55.0 \%$ (w/w) of the total plant weight and the rest of the plant (the leaves) is considered waste $(6,7)$.

From the harvest in 2008 using the weights previously listed and assuming $50 \%(\mathrm{w} / \mathrm{w})$ leaf waste, it can be estimated that 1.12 million metric tons of leaf waste material were created and an estimated 0.89 million metric tons in 2015. The leaves are either left in the fields to rot or are dumped in the surrounding areas. Throwing the leaves aside at first seems to be a simple way to return nutrients to the soil of the plantation. While it may seem important for soil health, the buildup of the hundreds of thousands of tons of leaf waste material creates an ecological and environmental problem for the fields and surrounding areas (8). This agricultural waste problem created by the tequila industry needs to be addressed due to the large volume of leaf waste material created every year. 


\section{THE AGAVE TEQUILANA AND ITS LEAVES}

Agave tequilana is a seed bearing flowering vascular terrestrial desert monocotyledon plant. It arranges its long fleshy leaves in a rosette pattern and belongs to the Agavaceae family. Its scientific name is Agave tequilana F.A.C. Weber but goes by other common names such as: agave, Agave tequilana, Agave tequilana azul, blue agave, and Weber's blue agave $(9,10)$. In its native habitat, the central western highlands of Mexico, the Agave tequilana is typically found in arid or semi-arid ecosystems with sandy soils and altitudes of around 1500 meters above sea level (10). The Agave tequilana grown for tequila production require 8-10 years to grow to maturity, can reach over 2 meters tall, and is almost exclusively grown in Jalisco, Mexico (3).

The leaves become blue-green in color when the plant reaches maturity at about 8 years, and are $90-120 \mathrm{~cm}$ long, $8-12 \mathrm{~cm}$ wide at the base, and taper to a point (7). The leaf material, in its native state, is not considered to be good for animal feed because it is very fibrous and hard to metabolize by many organisms. The leaves also have sharp thorns that line the edges and a sharp needle-like thorn at the tip of the leaf. Calcium oxalate is found in the leaves as well. Due to these long spindle raphide shaped crystals, skin exposure can cause contact dermatitis, and calcium oxalate is reported to cause kidney stones when it is ingested (11). It has been reported that the leaves of the Agave tequilana contain, on average, $9.7 \%(w / w)$ reducing sugars $(7)$. This means that with an 
estimated 890,000 tons of leaf waste material created in 2015 , an estimated 86,000 tons of reducing sugars were not utilized but are being wasted.

\section{INULIN AND AGAVE TEQUILANA FRUCTANS}

Inulin is a plant polysaccharide that is a fructan (fructose polymer) with a glucose moiety and has been reported to be the major polysaccharide in Agave tequilana (Figure 1, black colored portion of the molecular structure) $(12,13)$. The core structure of inulin is sucrose ( $\alpha$-glucose-(1-2)- $\beta$-fructose) with an attached $\beta$-(1-2)-fructose oligomer. The fructose oligomer covalently bonds to

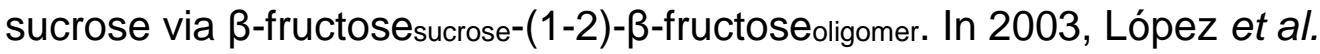
characterized the fructans from an eight year old Agave tequilana plant by GCMS, NMR, and MALDI-TOF-MS. They reported a more complex fructan structure that retains the inulin core (sucrose and $\beta$-(1-2)-fructose oligomer) but also has more branching fructans. It was reported by López et al. that $\beta-(2-6)-f r u c t o s e$ linkages, and fructose- $\beta-(2-6)-$ glucose (Figure 1; black, blue portion of molecular structure, and $\mathrm{n}_{4}=3$ monomers, $\mathrm{n}_{6}=1$ monomer) were also a part of the inulin structure that was extracted from the Agave tequilana (14). A few years later Mancilla-Margalli and López expanded on their previously described fructan from the Agave tequilana, to include more random dispersion of stacking and branching of the fructans along the respective vertical and horizontal axes of inulin. This expanded structure is shown by the black, blue, and red portions of Figure 1 (where $n_{4} \neq 0$ ) and were determined by using GC-MS and TLC (15). The 


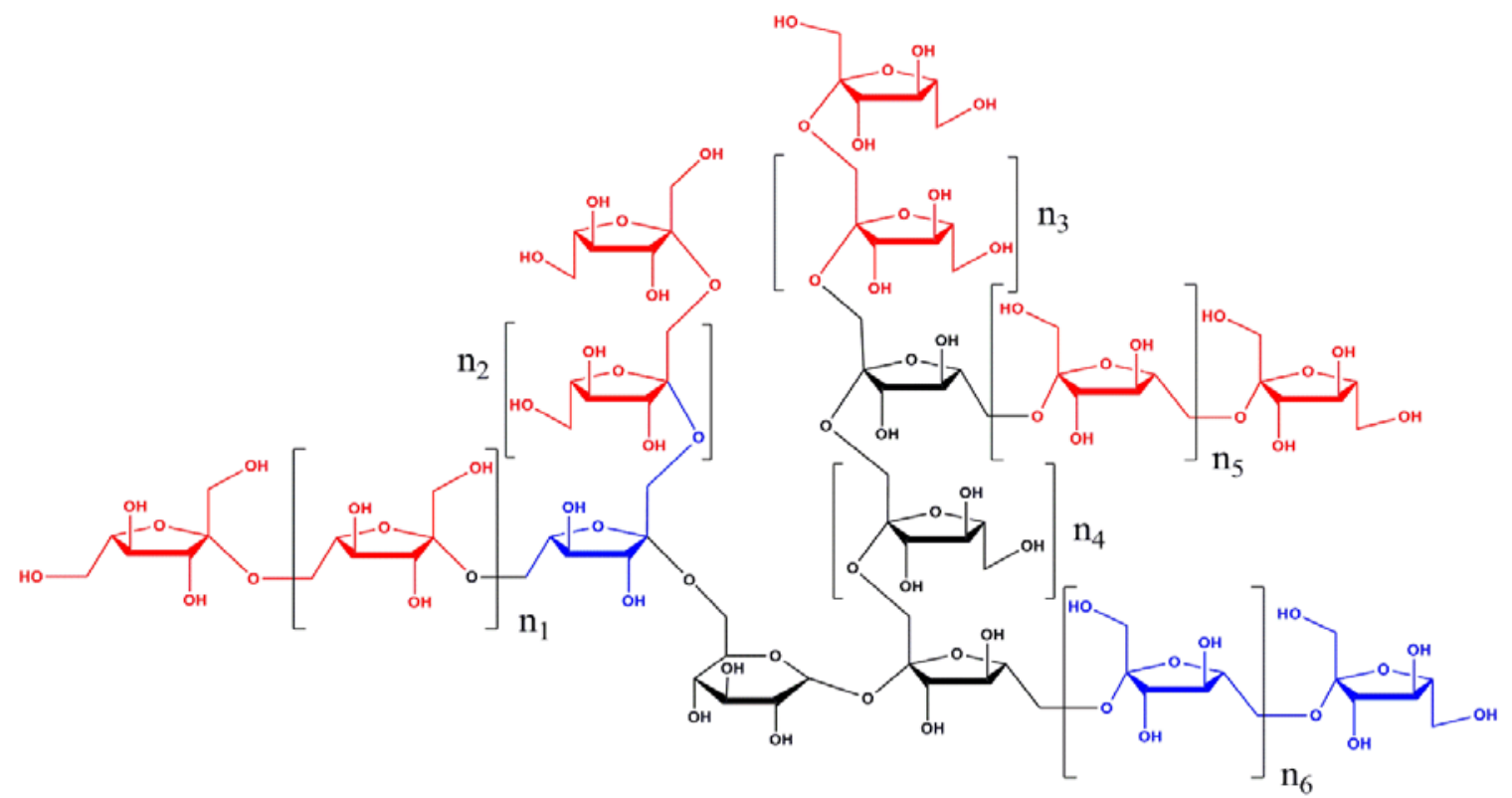

Figure 1. Agave tequilana fructan. Reported inulin structure shown in black (13). The reported structure of fructan in Agave tequilana shown in black and blue $\left(n_{4}=3\right.$ and $\left.n_{6}=1\right)(14)$. Mixed fructan structure variations of which have been reported in the Agave tequilana, by Mancilla-Margalli and López reported structures in black, blue, and red (where $\left.n_{4} \neq 0\right)(15,16)$. $n_{x}$ indicates the brackets, which can have various lengths of monomers reported as $n_{x}=\#$ of monomers.

ratio of glucose to fructose in these fructans, is that fructose is always found in higher portions than glucose (glucose: fructose, $1: n \geq 3$ ). It is important to note that in the tequila industry and the literature, all of the carbohydrates extracted are often considered to be inulin even though only a small portion of the fructans in the Agave tequilana are actually inulin (Figure 1, black portion of the molecular structure) $(13,16)$. 


\section{FERMENTATION}

The degradation of $D$-glucose or other simple carbohydrates ( $D$-fructose, $D$-galactose and $D$-mannose) under anaerobic conditions to obtain energy (adenosine triphosphate, ATP) is how Nelson and Cox define fermentation (17). Yeast are one of many organisms that thrive under anaerobic conditions and almost entirely rely on glycolysis for energy. Most organisms utilize the glycolytic pathway in order to covert glucose to two pyruvates and net 2 ATP through various well studied mechanisms. Glycolysis is often described in two phases; a preparative phase and a payoff phase (17).

The preparative phase often starts with $D$-glucose being phosphorylated at the $\mathrm{C}_{6}$ position by an enzyme, hexokinase, using a phosphate group from ATP releasing adenosine diphosphate (ADP). Glucose-6-phosphate is then rearranged to fructose-6-phosphate by another enzyme called phosphohexose isomerase. Hexokinase from the previous step has also been reported to phosphorylate fructose at the $\mathrm{C}_{6}$ position using ATP as well, creating fructose-6phosphate, thus allowing fructose to enter the glycolytic pathway, and skipping the previous step with phosphohexose isomerase. Using another ATP, phosphofructokinase-1 adds another phosphate group to fructose-6-phosphate producing fructose-1,6-bisphosphate. Aldolase then cleaves fructose-1,6bisphosphate in to two smaller molecules, glyceraldehyde-3-phosphate and dihydroxyacetone phosphate. Dihydroxyacetone phosphate is then rearranged to glyceraldehyde-3-phosphate by triose phosphate isomerase. This is considered 
the end of the preparative phase and, at this point in the glycolytic pathway, 2 ATP have been consumed, and 2 glyceraldehyde-3-phosphates have been produced (17).

The payoff phase starts by oxidizing and phosphorylating each glyceraldehyde-3-phosphate with phosphate and nicotinamide adenine dinucleotide $\left(\mathrm{NAD}^{+}\right)$catalyzed by glyceraldehyde-3-phosphate dehydrogenase, to produce 1,3-bisphosphoglycerate. The byproducts produced from this step are a proton and the reduced form of nicotinamide adenine dinucleotide (NADH). Then 1,3-bisphosphoglycerate donates one of its phosphate groups to ADP to form ATP by an enzymatic reaction with phosphoglycerate kinase to produce 3phosphoglycerate. Phosphoglycerate mutase then rearranges 3phosphoglycerate to 2-phosphoglycerate. Enolase then preforms a dehydration reaction with 2-phosphoglycerate to yield phosphoenolpyruvate. The glycolytic pathway ends with another ATP being generated by pyruvate kinase by removing a phosphate group from phosphoenolpyruvate and thus forming pyruvate. This step is considered the payoff phase because in the preparative phase 2 glyceraldehyde-3-phosphates were produced and thus 4 ATP can be made from the payoff phase for every glucose or fructose that enters for a net gain of 2 ATP (17).

The environment in which the pyruvate is produced dictates its final metabolic fate. Under anaerobic conditions pyruvate gets converted to acetaldehyde by pyruvate decarboxylase, releasing carbon dioxide. Pyruvate 
decarboxylase requires magnesium (II) and thiamine pyrophosphate to complete the previously described step. Lastly, nicotinamide adenine dinucleotide (NAD ${ }^{+}$) is regenerated by the reaction of alcohol dehydrogenase with acetaldehyde, the reduced form of nicotinamide adenine dinucleotide (NADH), and a proton to produce ethanol and water. Thus the overall net reaction (17) of the glycolysis of glucose in yeast under anaerobic conditions is:

Glucose + 2 ADP + 2 Phosphate $\rightarrow$

2 Ethanol +2 Carbon Dioxide $+2 \mathrm{H}_{2} \mathrm{O}+2 \mathrm{ATP}$

Fructose would have the same fate as glucose through the glycolytic pathway as long as hexokinase phosphorylates it, requiring ATP. Alternatively, fructose can be phosphorylated at the $C_{1}$ position by fructokinase also requiring ATP. Then fructose-1-phosphate aldolase splits fructose-1-phosphate into glyceraldehyde and dihydroxyacetone phosphate. Glyceraldehyde-3-phosphate is produced from glyceraldehyde by triose kinase requiring ATP. Dihydroxyacetone phosphate gets rearranged to glyceraldehyde-3-phosphate by triose phosphate isomerase. This process also requires 2 ATP to produce the 2 glyceraldehyde-3-phosphates created at the end of the preparation phase with glucose (17).

\section{KLUYVEROMYCES MARXIANUS}

Fermentations of carbohydrates extracted from the piñas of the Agave tequilana can be carried out using either or both cultured and noncultured 
(spontaneous) yeast to produce tequila (4). The specific strain of yeast used for fermentation and fermentation conditions used for tequila production are unique to each distillery. It has been reported that the cultured yeasts used are typically Saccharomyces cerevisiae and that spontaneous fermentations typically have Saccharomyces cerevisiae as the dominant strain. Although, various species of Kluyveromyces marxianus and Pichia kluyveri are often found in smaller quantities in spontaneous fermentations (18). It has been demonstrated that on an industrial scale, fermentations with only cultured Kluyveromyces marxianus or Pichia kluyveri can perform in accordance with NOM-006-SCFI-2012 standards $(4,19)$. Thus variations of these species of yeast, like the ones of Kluyveromyces marxianus, can be used to address the leaf agriculture waste product problem from harvesting of the Agave tequilana. The leaves have on average 9.7\% (w/w) carbohydrates and have been demonstrated to ferment extractions from the piña of the same plant on an industrial scale (7).

Kluyveromyces marxianus is a homothallic hemiascomycete yeast that has been frequently isolated from dairy environments. It has demonstrated phenotypic traits such as the ability to metabolize a wide range of sugars (inulin, glucose, fructose, sucrose and raffinose), enhanced thermotolerance, secretion of lytic enzymes and a faster growth rate than other eukaryotic microbes. All of these features make Kluyveromyces marxianus an attractive species of yeast for industrial use $(20,21)$. Wild type Kluyveromyces marxianus (NRRL Y-1109) was irradiated for 9 hours with $234 \mathrm{~nm}$ UV-C light at a distance of $14 \mathrm{~cm}$ above the cells in sterile water to mutate its DNA and to achieve a mortality rate of $80 \%$ to 
eliminate any background growth. Two unique and novel mutant strains survived this process which were designated Kluyveromyces marxianus 7-1 (NRRL Y50798, Km7-1) and Kluyveromyces marxianus 8-1 (NNRL Y-50799, Km8-1) (22). Variable nucleotide tandem repeat (VNTR) polymerase chain reaction (PCR),

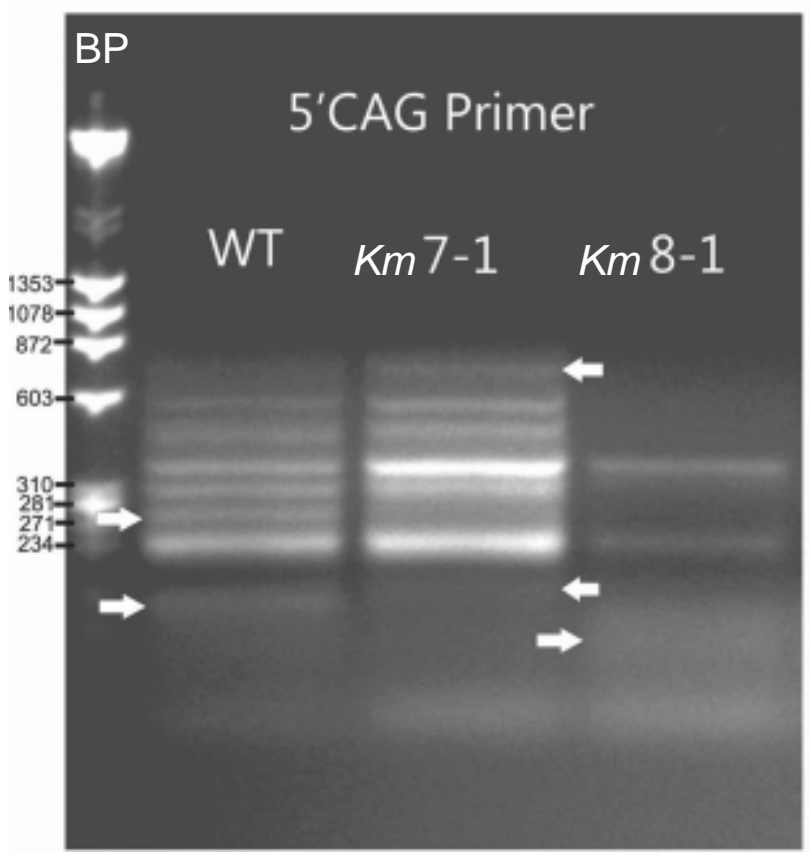

Figure 2. Wild type Kluyveromyces marxianus (WT), Km7-1, Km8-1 variants genomic DNA fragmentation.

Demonstrating that these strains are not the same (indicated by the white arrows). Lane for base pair standards (BP) (22). using a 5'CAG primer,

demonstrated that wild type

Kluyveromyces marxianus,

Kluyveromyces marxianus 7-1 and Kluyveromyces marxianus 8-1 are

different strains from each other.

These strains are considered

different from one another because

the DNA fragmentation patterns are not identical (Figure 2). The exact differences between these strains are unknown and still need to be further explored by comparative

DNA sequencing but this was not the focus of the current research. Particular differences in the presence of a gene in one strain of yeast and the absence observed in the other two are indicated by white arrows (22). Previous work in our lab demonstrated that these yeasts have the ability to metabolize various standard carbohydrates (glucose and inulin) making these strains of interest for this thesis (23). 
The previous work done by Galindo-Leva et al. demonstrated that Kluyveromyces marxianus 7-1 and Kluyveromyces marxianus 8-1 can grow on standard media containing inulin and inulin does not spontaneously degrade under the reported experimental conditions (23). This means Kluyveromyces marxianus 7-1 and Kluyveromyces marxianus 8-1 are likely to be secreting enzymes to degrade the inulin. At least two different enzymes have been reported to degrade inulin, endo-inulinase and exo-inulinase and both have been purified from Kluyveromyces marxianus $(24,25)$. Endo-inulinase (EC 3.2.1.7) is reported to facilitate the hydrolysis of the terminal $\beta$-(1-2)-fructan ends and has a reported molecular weight of $66 \mathrm{kDa}$ when purified from a strain of Kluyveromyces marxianus and reported molecular weight range of 53-200 kDa (24) from other organisms. Exo-inulinase or fructan $\beta$-fructosidase (EC 3.2.1.80), is reported to hydrolyze the non-reducing end of $\beta-(1-2)$ and $\beta-(2-6)-$ fructose of fructans and has a reported molecular weight of $250 \mathrm{kDa}$ when purified from a strain of Kluyveromyces marxianus and reported molecular weight range of 60$250 \mathrm{kDa}(25)$ from other organisms.

In previous work it has been demonstrated that both Kluyveromyces marxianus 7-1 and Kluyveromyces marxianus 8-1 produce $\quad 0.0-2.3 \%(\mathrm{w} / \mathrm{v})$ ethanol on various standard media $(22,23)$. When either Kluyveromyces marxianus 7-1 or Kluyveromyces marxianus 8-1 were grown on commercially available inulin (1\% w/v), no ethanol was detected (23). According to the National Association of Securities Dealers Automated Quotations, better known as NASDAQ, the price of ethanol has been steadily declining since July of 2011 and 
is currently being traded at a ten year low of $\$ 1.37$ USD per gallon in the United States during February of 2016 (26). It can be estimated that the current price of ethanol (February of 2016) has dropped $53.3 \%$ in the last five years and therefore production of ethanol from these yeasts grown on sources of inulin is not of interest to these studies.

\section{MYCOSPORINE-LIKE-AMINO ACIDS}

Several species of plants, fungi, and cyanobacteria have been reported to produce a unique class of compounds called mycosporine-like-amino acids. These organisms have produced this class of compounds in order to prevent the damaging effects of UV rays and over 18 different mycosporine-like-amino acid structures have been described. These compounds have been reported to absorb light from 309-362 nm, which stimulates bond rotation and then excess energy is lost through heat dispersion $(27,28)$. It has been reported that the precursor compound, 4-deoxy-gadusol, is produced from 3-dehydroquinate via the Shikimate pathway (27). The Shikimate pathway is used by plants and other organisms (excluding animals) to produce aromatic amino acids such as tryptophan, phenylalanine, and tyrosine by using one $D$-erythrose-4-phosphate and two phosphoenolpyruvates as starting material (29).

The core structure of mycosporine-like-amino acids is 1,5-dihydroxy-5hydroxymethyl-2-methoxycyclohex-1-en-3-one, also known as 4-deoxy-gadusol (Figure 3, where $\mathrm{R}_{1}=\mathrm{O}$ and $\mathrm{R}_{2}=\mathrm{OH}$ ) (30). The various mycosporine-like-amino 
acid derivatives differ by the side chains attached to $R_{1}$ and $R_{2}$ of Figure 3. Amino acids such as glycine, serine, glutamic acid, taurine, threonine, and valine are common side chains found on 4-deoxy-gadusol and bond covalently through the nitrogen of the amine group along the peptide chain but are not the only side chains seen (27). Other side chains include ethanol, methane, sulfate, and propene, among others, are reported, as well as glycosylated amino acid side chains $(31,32)$. Various reported structures and biosynthetic pathways for mycosporine-like-amino acids are shown in Appendices A and B, respectively.

Mycosporine-like-amino acids have a potential for being used as industrial photostabilizers or sunscreens (28). According to a recent article in Chemical and Engineering News most sunscreens on the U.S. market filter UV-B radiation ranging from 290-<smiles>[R]C1=C(OC)C([R])CC(O)(CO)C1</smiles>

Figure 3. Reported mycosporine-likeamino acid core structure. Various side chains such as amino acids bond covalently through the nitrogen on the amine group at $\mathrm{R}_{1}$ and $R_{2}(27)$ $320 \mathrm{~nm}$ and only a few filter UV-A radiation ranging from $320-400 \mathrm{~nm}$ (33). This is important since it has been reported that UV-A rays penetrate deeper into the skin and are a major contributor to the formation of skin cancer cells (33). Thus novel sources of UV-A absorbing compounds are needed to lead to more effective sunscreens. 


\section{BIOREMEDIATION OF THE AGAVE TEQUILANA AGRICULTURAL WASTE}

To determine the potential of using selected yeast strains (Kluyveromyces marxianus 7-1 and Kluyveromyces marxianus 8-1, respectively) to ferment the agricultural waste from tequila production i.e. the leaves from Agave tequilana, is the purpose of this thesis. These studies will give an important direction for the bioremediation of the hundreds of thousands of metric tons of agricultural waste currently generated by tequila production every year. Not only would this address the ecological and environmental problems caused by the extensive amounts of leaf waste but could provide extra income to the farmers if they sell their leaf waste material to biorefinery sites. Currently, no biorefinery plants are in place to handle the waste from the harvesting of Agave tequilana and companies like GEN 2 Energy Company, Inc., working with the United States Department of Agriculture, are interested in filling this niche industry $(8,34)$.

The United States Department of Agriculture IS interested in products from these fermentations, such as yeast cells, protein in the fermentation broth and any remaining solids, which may be considered valuable feedstock for fermentations with other yeast such as Yarrowia lipolytica, Saccharomyces cerevisiae, and Rhodotorula glutinis (8).The fermentations with Yarrowia lipolytica can produce an oil rich biomass that can be used for the production of ammonia as well as protein for advanced animal feeds. Fibrous leftovers from the fermentation can then be subjected to acid hydrolysis and further fermented with GMAX1, a cellulosic Saccharomyces cerevisiae, which can express a 
peptide sweetener. After this sweetener protein is extracted the remaining solid material could be jet cooked and fermented with the Rhodotorula glutinis to create isoprenes. The Yarrowia lipolytica and Rhodotorula glutinis remaining fermentations could be mixed and then subjected to pyrocracking and hydroformylation. This could convert ammonia, isoprenes, protein, and oils into renewable gasoline and 10-16\% (v/v) aromatic hydrocarbons including benzene, toluene, and xylene. These aromatic hydrocarbons are of interest because they can be used as precursors to bio-nylon 6 (polycaprolactam) and bio-kevlar (proposed synthesis in Appendix C) (8).

The major focus of this thesis is to determine the potential of using Kluyveromyces marxianus 7-1 and Kluyveromyces marxianus 8-1 to ferment the leaves of the Agave tequilana. To do this viable cellular growth was monitored by colony forming units over the course of the fermentation and was compared to growth on standard media from previous work by Galindo-Leva et al. (23).

The utilization of carbohydrates was determined by thin layer chromatography (TLC) and an assay for determining the concentration of reducing sugars and will also be compared to previous work by Galindo-Leva et al. using standard carbohydrates such as sucrose, fructose and inulin $(23,35)$. In 2016, Chemical and Engineering News reported that DuPont and Archer Daniels Midland released their synthesis for making fructose into furan dicarboxylic methyl ester, which can be reacted with 1,3-propanediol to make a novel biologically based packaging polymer (36). Other bioplastics (polyethylene 
furanoate) can be made from furan dicarboxylic methyl esters when further reacted with ethylene glycol. Polyethylene furanoate could then replace a petroleum based plastic (polyester polyethylene terephthalate) used in petroleum based products like bottles. This is exactly what DuPont and Archer Daniels Midland, working with Coca-Cola, are trying to do (36). Thus any fructose left in the fermentation broth after the fermentation ended could be used as feedstock for these bioplastic synthetic routes. The $\mathrm{pH}$ of the fermentation as function of time was also monitored during these studies as well.

Purification of certain proteins from these fermentations, such as yeast inulinase enzymes, is of interest as well because of their economic value. Sigma Aldrich sells purified inulinase from Aspergillus niger for 729.00 USD for $250 \mathrm{mg}$ of lyophilized powder thus making it a potentially profitable enzyme to purify on an industrial scale (37). Purified enzymes were compared to standard inulinase isolated from Aspergillus niger purchased through Sigma Aldrich by their molecular weight determined via SDS-PAGE.

Lastly, endogenous compounds, such as novel UV radiation absorbing compounds in the Agave tequilana leaves, are also of interest to this thesis. The Agave tequilana, being a desert plant, is exposed to extensive hours of solar radiation over its lifetime and must protect itself from the harsh UV radiation from the sun. It is anticipated that a plant growing under these conditions would produce sun screening compounds that absorb at wavelengths not used for 
photosynthesis. Thus, the extraction of novel UV absorbing compounds from the Agave tequilana leaves is of particular interest to this thesis. 
CHAPTER II

\section{MATERIALS AND METHODOLOGY ORGANISMS AND STORAGE}

One mature live whole Agave tequilana plant was shipped fresh from Jalisco, Mexico and delivered to Illinois State University in Normal, IL. Upon receiving the Agave tequilana plant, the leaves were quickly trimmed from the piña and had their thorns removed with a knife. Leaves were cut into two or three sections depending on length and placed in either liquid nitrogen or $-80^{\circ} \mathrm{C}$ freezers for long term storage. The piña was split into several pieces, frozen at $-80^{\circ} \mathrm{C}$ and given to Dr. Stephen Hughes (United States Department of Agriculture, Peoria, IL) for other research.

The strains of yeast, Kluyveromyces marxianus 7-1 (NNRL Y-50798) and Kluyveromyces marxianus 8-1 (NNRL Y-50799), were obtained from Dr. Stephen Hughes from the United States Department of Agriculture, Peoria, IL as colonies on solid agar growth medium. After receiving the yeast, once every month, a few isolated colonies were plucked with a $10 \mu \mathrm{L}$ inoculation loop and each colony was plated on to individual sterile solid agar YPD growth medium in polystyrene sterile petri dishes. The sterile solid agar YPD growth medium used for all experiments in this thesis was made using Bacto ${ }^{\mathrm{TM}}$ yeast extracts $(\mathrm{Y}$; Becton Dickinson and Company), Bacto ${ }^{\mathrm{TM}}$ peptones (P; Becton Dickinson and Company), and dextrose or D-glucose (D; Fisher Scientific). The YPD medium 
was made in a ratio of $10 \mathrm{~g}: 20 \mathrm{~g}: 20 \mathrm{~g}, \mathrm{Y}: \mathrm{P}:$ D per liter of nanopure water for liquid growth medium and with an added $20 \mathrm{~g} \mathrm{Bacto}{ }^{\mathrm{TM}}$ agar (Becton Dickinson and Company) for solid growth medium (23). All media were autoclaved at $250^{\circ} \mathrm{F}\left(121^{\circ} \mathrm{C}\right)$ and $20 \mathrm{PSI}(138 \mathrm{kPa})$ for 21 minutes to sterilize. After a sterile YPD agar plate was streaked with cells, the lid was sealed with parafilm and then placed into an incubation oven. The oven was set to $35^{\circ} \mathrm{C}$ and plates were allowed to grow for 24-48 hours before being placed at $4^{\circ} \mathrm{C}$ for storage until use.

\section{YEAST STARTER CULTURES AND INOCULATION}

All work with cells was conducted using sterile techniques and the Forma Class II A2 Biological Safety Hood (Thermo Electron Corporation). To propagate an abundance of viable yeast cells, 24 hours prior to a fermentation, $5 \mathrm{~mL}$ of sterile YPD liquid medium was placed into a sterile screw cap $15 \mathrm{~mL}$ polystyrene test tube (Fisherbrand) with a sterilized stir bar. Then using a sterile $10 \mu \mathrm{L}$ inoculation loop (Fisherbrand) a few isolated colonies were plucked and transferred into the YPD liquid medium. The inoculation loop was rolled between the fingers along the vertical axis to disperse the yeast into the YPD liquid medium. This was done with both yeast strains into their own respective starter culture tubes. These tubes, $K m 7-1$ in YPD, $K m 8-1$ in YPD and Negative Control (YPD liquid medium only) were grown aerobically in the dark with constant stirring at room temperature for 24 hours. 
To make inoculations with equal cell numbers of the different yeast strains, optical density with a Hewlett-Packard UV-Vis spectrophotometer at 600 $\mathrm{nm}$ was determined using the negative control (YPD liquid medium only) as a blank. Optical density is not based on absorbance, rather light scattering and is used to estimate cellular concentration. This measurement is done at a wavelength that is not typically where biological derived compounds absorb. Prior to spectroscopy in a sterile hood, $500 \mu \mathrm{L}$ were removed from the starter cultures and placed into their own respective sterile $1.5 \mathrm{~mL}$ polystyrene test tubes. Using the negative control (YPD with no yeast cells added) as spectrophotometric blank, the cells were diluted with nanopure water (total volume $1 \mathrm{~mL}$ ) until an optical density of 1.0 absorbance units was achieved. The dilution factors were noted, repeated in the sterile hood using sterile water, and $500 \mu \mathrm{L}$ of this diluted starter was inoculated into each respective fermentation. The negative control starter (YPD with no yeast cells) was not diluted and $500 \mu \mathrm{L}$ of it was directly inoculated into a negative control fermentation.

\section{FERMENTATION}

Random mixtures of upper and lower portions of frozen Agave tequilana leaves were placed into a clean plastic biohazard waste bag (Figure 4A) and then the bag was rolled up and placed into another clean plastic biohazard waste bag. The now double bagged leaves were placed into one more clean plastic biohazard waste bag and rolled up as before. The triple bagged Agave tequilana 
leaf portions (Figure 4B) were then placed on a concrete floor, a few thin towels were placed on top and the leaves were then quickly smashed with a hammer. This was done quickly to break up the leaf material, reduce time for any degradative enzymatic activity, and to create a random distribution of upper and lower leaf material. After the leaf material was broken up, it was transferred to a new clean plastic biohazard waste bag and frozen at $-80^{\circ} \mathrm{C}$ (Figure 4C). Pieces of the frozen Agave tequilana leaves that were small enough to fit into the mouth of the fermenter were picked at random, weighed, placed, into a fermenter $(1.0 \mathrm{~L}$ PRYEX Reusable Media Storage Bottles) with nanopure water and then autoclaved as previously described. The ratio of Agave tequilana leaf pieces:

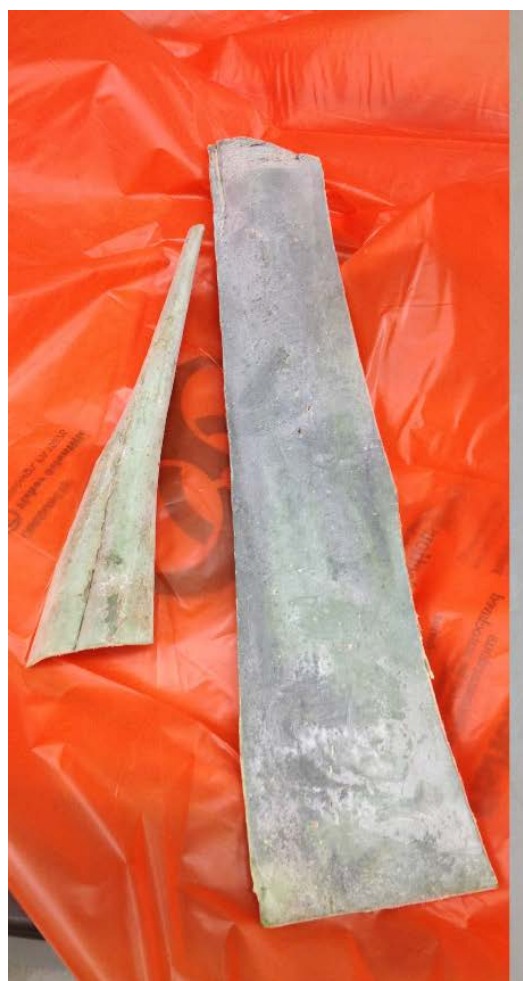

A

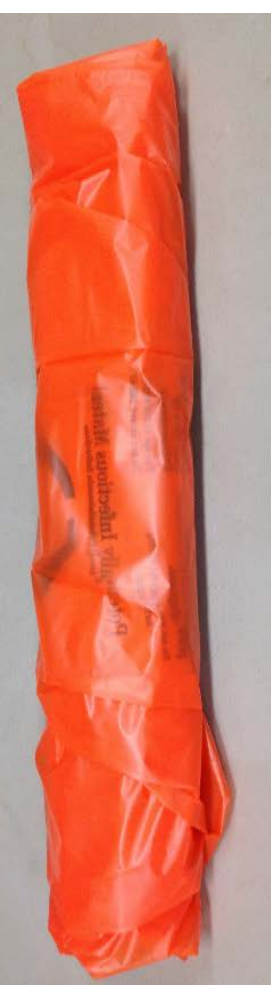

B

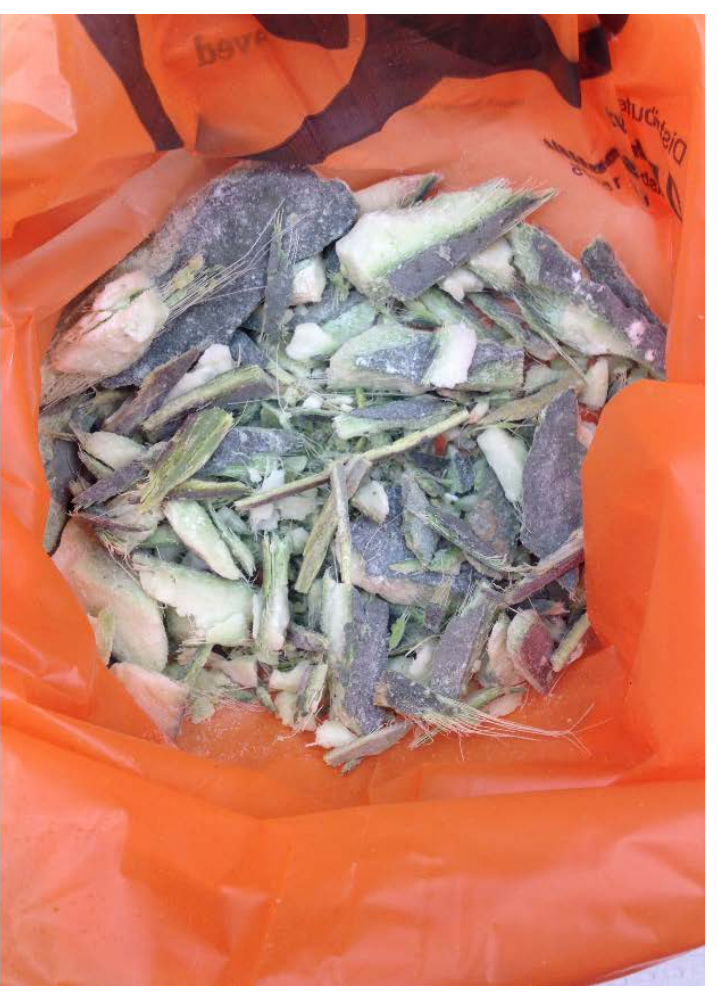

C

Figure 4. Breaking up of Agave tequilana leaves. (A) Two large frozen pieces of Agave tequilana leaves, (B) large leaf pieces wrapped in 3 biohazard bags, (C) frozen broken up Agave tequilana pieces ready to be weighed and added to fermenters. 
nanopure water was 1: $10(\mathrm{w} / \mathrm{v})$. For these experiments $40 \mathrm{~g}$ of Agave tequilana pieces was the target weight per fermentation unless otherwise noted.

After autoclaving, the fermenters' lids were tightly screw down and cooled (in a water bath in a cold room at $4^{\circ} \mathrm{C}$ ) to room temperature. The fermenters were inoculated $(500 \mu \mathrm{L})$ with their respective starter culture in a sterile hood as previously described. A fermentation control containing Agave tequilana and nanopure water was inoculated $(500 \mu \mathrm{L})$ with the negative control starter (YPD liquid medium only). Fermentations were carried out anaerobically at room temperature on a shaker table (New Brunswick Scientific Company, Inc. Series 25 incubator, 200 RPM).

\section{FERMENTATION SAMPLING}

Every 12 hours after inoculation, for 72 hours, samples were taken using sterile technique. For each time point, $3 \mathrm{~mL}$ were taken from each fermentation, and were stored as $1 \mathrm{~mL}$ aliquots at $-80^{\circ} \mathrm{C}$. Before being frozen, $10 \mu \mathrm{L}$ of fermentation broth was diluted (dilution factors of 1, 10, 100, 1000, and 10,000 were used) and then $10 \mu \mathrm{L}$ of the diluted fermentation broth were plated in triplicate on sterile YPD agar plates to obtain colony forming units. Control fermentations (Agave tequilana pieces and nanopure water, no yeast cells) were 
not diluted during plating to allow ease of detection of any microbial contaminates.

Colony forming units (CFU) is a simple way to monitor viable cellular growth. The diluted fermentation broth was spotted on to the center of sterile YPD agar plates. Then a sterile cell spreader (Lazy-L Spreader ${ }^{\mathrm{TM}}$ Sigma Aldrich) was used to evenly distribute the spotted diluted fermentation broth. The plates were then placed into an incubation oven set to $35^{\circ} \mathrm{C}$ and grown until colonies were large enough to count (36-48 hours). After counting the colonies, the CFU data were plotted as a function of time.

\section{ASSAY FOR REDUCING SUGARS}

To determine the consumption of reducing sugars a modified dinitrosalicylic acid (DNS) method developed by Miller was used (35). The frozen fermentation broth samples were thawed and centrifuged (9,000 rpm; 54400xg) for 2.5 mins in a table top Eppendorf Centrifuge (5415 C). After centrifugation all samples were placed on ice until being subjected to the DNS assay. This method was scaled down to $500 \mu \mathrm{L}$ of total sample or dilution of sample and $500 \mu \mathrm{L}$ of the reagent (1.0\% DNS (w/v), 0.2\% sodium bisulfite $(\mathrm{w} / \mathrm{v}), 0.2 \%$ phenol $(\mathrm{v} / \mathrm{v})$ and 2.14\% sodium hydroxide (w/v)). After the sample and the reagent were mixed, the solution was boiled for $5 \mathrm{~min}$, and then cooled on ice to room temperature. After cooling, the samples were analyzed by UV-Vis spectroscopy at $575 \mathrm{~nm}$ in 1 
$\mathrm{mL}$ polystyrene cuvettes. To determine the concentration $(\mathrm{mg} / \mathrm{mL})$ of reducing sugars in the samples a standard curve using fructose (Sigma Aldrich) was used. To test whether this assay was sensitive to all sugars or just reducing sugars, both standard inulin from chicory (a non-reducing sugar, Sigma Aldrich) and fructose (a reducing sugar, Sigma Aldrich) were tested for their respective response to the DNS assay.

\section{CONCENTRATION OF PROTEIN}

To determine the concentration of protein in the fermentation broth as a function of time, frozen samples were thawed and centrifuged $(9,000 \mathrm{rpm}$; 54400xg) for 2.5 mins in a table top Eppendorf Centrifuge (5415 C). The centrifuged samples were placed on ice until an aliquot of the supernatant was harvested and subjected to the Bradford method of determining protein concentration (38). This was done by mixing the fermentation broth as necessary with nanopure water to a total of $800 \mu \mathrm{L}$ in a new $1.5 \mathrm{~mL}$ polystyrene centrifuge tube. Then $200 \mu \mathrm{L}$ of protein assay dye reagent concentrate (Bio-Rad) was added for a total of $1 \mathrm{~mL}$ and then the tube was gently mixed. These mixtures $(200 \mu \mathrm{L})$ were individually loaded in to a 96 well plate, along with protein standards and were evaluated by spectroscopy ( $595 \mathrm{~nm}$ ) by a microplate reader (Bio-Rad iMARK ${ }^{\text {TM }}$ Microplate Absorbance Reader). Plates were read three times, to test the instruments' reproducibility, and the absorbance values were 
averaged. A standard curve was made using various dilutions of standard bovine serum albumin (stock $1 \mathrm{mg} / \mathrm{mL}$ ). These supernatants were also tested for $\mathrm{pH}$ by spotting $10 \mu \mathrm{L}$ on to Whatman $\mathrm{pH}$ indicator paper $(\mathrm{pH}$ 4.5-10; catalog number: 2614991).

\section{YEAST INULINASE PURIFICATION}

After 72 hours of fermentation, the fermentation broth was filtered through a cheese cloth to remove large solids and then this crude filtrate was centrifuged at $1500 \mathrm{rpm}(4160 \mathrm{xg})$ for 10 mins at $4^{\circ} \mathrm{C}$ using a table top centrifuge (Labnet Hermle Z $400 \mathrm{~K}$ ). The supernatant was then gently decanted and added to 2.5 cm dialysis tubing (10 kDA MW cutoff) that had been soaked for an hour in nanopure water. The supernatant was dialyzed against 4 liters of nanopure water overnight at $4^{\circ} \mathrm{C}$ under gentle stirring. After dialysis, the tubing was removed from the 4 liter flask and was hung for 10 mins from a ring stand to allow any solids to drop to one end of the tubing. Using a pipette, $5 \mathrm{~mL}$ of this crude extract was saved for comparison with purified fractions. The dialyzed supernatant was removed and added to diethylaminoethyl (DEAE) beads for a "batch" type anion extraction. The DEAE beads were equilibrated with $5.0 \mathrm{mM}$ phosphate buffer, $\mathrm{pH}$ 6.8 prior to use (39). The beads and dialyzed supernatant were gently mixed on a rocker plate for an hour at room temperature. The beads were allowed to settle and the supernatant was decanted. The beads were washed $(2 x)$ with the same 
buffer and washes were pooled. Afterwards the beads were washed with $5.0 \mathrm{mM}$ phosphate buffer pH 6.8 containing $10 \mathrm{mM} \mathrm{NaCl}$ to elute bound enzyme (39). The salt eluate was then dialyzed against water to remove the excess salt. The dialyzed supernatant crude extract, the DEAE bead decanted supernatant and the dialyzed eluate were tested for their protein concentration by the Bradford method as described above using $5 \mathrm{mM}$ phosphate buffer $\mathrm{pH} 6.8$ for dilutions and as the blank (38). A Hewlett-Packard spectrophotometer 8453 was used and each sample was individually measured for absorbance at $595 \mathrm{~nm}$.

After the concentration of protein was determined; $10 \mathrm{~mL}$ of the DEAE wash and the dialyzed salt eluate were lyophilized. Then the extracts were resuspended in sodium dodecyl sulfate loading buffer ( $1 \mathrm{x})$ and a minimal amount of water to achieve $1-2 \mathrm{mg} / \mathrm{mL}$. The loading buffer contains $200 \mathrm{mM}$ tris $\mathrm{pH} 6.8$, $8 \%$ sodium dodecyl sulfate (w/v), $0.4 \%$ bromophenol blue (v/v), $40 \%$ glycerol $(\mathrm{v} / \mathrm{v})$ and $400 \mathrm{mM}$ dithiothreitol. Sample mixtures were boiled for $5 \mathrm{mins}$ in a water bath and $10-20 \mu \mathrm{L}$ of the samples were loaded into each well. Then the samples were subjected to sodium dodecyl sulfate polyacrylamide gel electrophoresis (SDS-PAGE), at 120V, using the methodology of Laemmli using $12 \%$ gels (40).

Following electrophoresis, the gels were stained in $0.1-0.2 \%(\mathrm{w} / \mathrm{v})$ coomassie blue in $45 \%$ methanol $(\mathrm{v} / \mathrm{v}), 45 \%$ water $(\mathrm{v} / \mathrm{v})$ and $10 \%$ glacial acetic acid $(v / v)$ for an hour. The gels were then destained overnight in $45 \%$ methanol (v/v), 45\% water (v/v) and 10\% glacial acetic acid (v/v). Bio-Rad's Precision plus 
protein $^{\mathrm{TM}}$ Kaleidoscope ${ }^{\mathrm{TM}}$ prestained protein standards $(10 \mu \mathrm{L})$ were used for molecular weight markers and standard inulinase from Aspergillus niger (Sigma Aldrich) was used for comparison. When necessary a modified version of the more sensitive silver staining protocol reported by Kerényi and Gallyas (41) was used. Gels were washed with $200 \mathrm{~mL} 50 \%$ methanol (v/v) for 10 mins and then $200 \mathrm{~mL}$ of deionized water for 10 mins. The gels were then sensitized with $0.02 \%$ sodium thiosulfate $(\mathrm{w} / \mathrm{v})$ in water for one min and then rinsed with several volumes deionized water. After the rinsing, $0.1 \%$ silver nitrate $(w / v)$ in water was added and foil was used to cover the gel from light during the staining for 20 mins. The gels were rinsed again with several volumes of deionized water and incubated with $200 \mathrm{~mL} 2.0 \%$ sodium carbonate (w/v) with $0.04 \%$ formaldehyde $(\mathrm{v} / \mathrm{v})$ to develop the gels. When the gel was developed, the reaction was stopped with $200 \mathrm{~mL} 5.0 \%$ acetic acid (v/v).

\section{INULINASE ACTIVITY}

To evaluate inulinase activity, fractions collected during the process of purification were assayed for inulinase activity. This was carried out by incubating $0.5 \mathrm{~mL}$ of fractions with $2.0 \mathrm{~mL}$ 1.0\% standard inulin from chicory (Sigma Aldrich) (w/v) for 7 days at $35^{\circ} \mathrm{C}$. Samples were tested for inulinase activity by the DNS method (35). Activity is defined as the non-spontaneous degradation of inulin to fructose. Negative controls (no fractions from purification or standard inulinase added) were also evaluated. 


\section{MYCOSPORINE-LIKE-AMINO ACID EXTRACTION}

The extraction of suspected mycosporine-like-amino acids was carried out by a variation of the extraction method reported by Torres et al. (42). Frozen Agave tequilana leaves were partially thawed on dry ice covered in foil in a $9 \times 13$ inch glass baking dish in the cold room $\left(4^{\circ} \mathrm{C}\right)$. The semi frozen Agave tequilana leaves were then carefully grated with a stainless steel box cheese grater (4 sided cheese grater) in the cold room to remove the plants' skin. The grated skin material was weighed and then mixed with $80 \%$ methanol $(\mathrm{v} / \mathrm{v})$ at a ratio $(\mathrm{w} / \mathrm{v})$ of 1:10 (grated skin: $80 \%$ methanol) in a large flask with a ground glass top. This mixture covered in foil was gently stirred for 24 hours with a magnetic stir bar in a cold room. Due to lack of commercially available standards, a positive control extraction was simultaneously carried out using dried seaweed (Hime Brand Roasted Seaweed Sushinori Special Selection), purchased from a local supermarket. Seaweed was used as a positive control because it is reported to contain mycosporine-like-amino acids $(27,31,43)$. The same extraction methods applied to the Agave tequilana were also applied to the seaweed.

After 24 hours, the mixture was vacuum filtered using Whatman $19.0 \mathrm{~cm}$ filter paper. The solids were discarded and the filtrate was transferred to a separatory funnel, where equal volumes of dichloromethane were added to remove chlorophylls and other less polar compounds. Three sequential dichloromethane washes were done, then the methanol top layer was collected and dried under nitrogen gas. Before drying, $1 \mathrm{~mL}$ aliquots were removed. After 
the methanol was removed, extracts were frozen at $-80^{\circ} \mathrm{C}$ and then lyophilized until dry. The dried extracts were weighed and stored at $-80^{\circ} \mathrm{C}$ until analyzed.

\section{EXTRACT PURIFICATION AND UV-VIS SPECTROSCOPY}

A portion of each dried extract was resuspended in $5.0 \mathrm{~mL}$ of nanopure water and subjected to UV/Vis spectroscopy using nanopure water as a blank. Samples were scanned over wavelengths from $200-800 \mathrm{~nm}$ and peaks of interest were picked manually for an initial spectrum prior to purification. Then $20 \mathrm{~mL}$ of methanol was added to the $5.0 \mathrm{~mL}$ of resuspended extract for a final volume of $25 \mathrm{~mL}$ of $80 \%$ methanol $(\mathrm{v} / \mathrm{v})$. The same purification methods applied to the Agave tequilana extracts were also applied to the seaweed.

A $10 \mathrm{~mL}$ aliquot of this mixture was loaded on to a normal phase column (Varian Super Flash silica column) that was washed with $150 \mathrm{~mL}$ of nanopure water and $150 \mathrm{~mL}$ of $80 \%$ methanol (v/v) prior to loading. The column was sequentially eluted with $150 \mathrm{~mL}$ of $80 \%$ methanol (v/v), $150 \mathrm{~mL}$ of $40 \%$ methanol $(\mathrm{v} / \mathrm{v})$ and then $150 \mathrm{~mL}$ of nanopure water. Fractions $(8 \mathrm{~mL})$ were collected in 10 $\mathrm{mL}$ polystyrene test tubes with caps. Fractions were subjected to UV/Vis spectroscopy, and the interesting fractions were pooled, frozen at $-80^{\circ} \mathrm{C}$, and lyophilized. Interesting fractions were defined by demonstrating absorption in the UV region (200-400 $\mathrm{nm})$. The dried extracts were resuspended in a minimal 
amount of nanopure water and subjected to UV/Vis spectroscopy and thin layer chromatography.

\section{THIN LAYER CHROMATOGRAPHY OF EXTRACTS}

For the mycosporine like amino acid extracts, small aliquots $(0.5-7 \mu \mathrm{L}$ total) of the selected fractions were spotted 1-2 $\mu \mathrm{L}$ at a time, on to glass back silica plates for thin layer chromatography (TLC). A mobile phase of 1-butanol: methanol: cyclohexane at a ratio of $7: 4: 2(\mathrm{v} / \mathrm{v} / \mathrm{v})$ was used to separate these extractions. Two different detection sprays were used, 1.0\% ninhydrin (w/v) in ethanol then $5.0 \%$ sulfuric acid in methanol $(w / v)$. The ninhydrin was sprayed on the plate first and then it was gently heated on a hot plate for the detection of any amines present (indicated by a yellow, pink, or purple color) (44). Then the sulfuric acid methanol was sprayed on the plate and the plate was gently heated again looking for charred spots as an indication of any hydrocarbons.

\section{HPLC OF EXTRACTS}

Another separation technique employed to the dried extracts was high performance liquid chromatography (HPLC) with a diode-array detector (DAD). A modified method to separate mycosporine-like-amino acids reported by Carreto et al. in 2001 was used on a Hewlett-Packard Series 1100 LC (45). This system 
was equipped with a degasser (Hewlett-Packard G1322A), quaternary pumping system (Hewlett-Packard Quatpump G1311a), an auto-sampler (Hewlett-Packard ALS G1313A), column heating element (Hewlett-Packard ColComb (G1316A), and a UV/Vis spectrometer (Hewlett-Packard DAD G1315A). A reverse phase Regis Rexchrom ${ }^{\mathrm{TM}}$ ODS (octadecylsilane, $4.6 \mathrm{~mm} \times 150 \mathrm{~mm}$ ) column was used as the stationary phase.

A two part mobile phase was used for these separations, Solvent A) $0.2 \%$ acetic acid (v/v) in water and Solvent B) acetonitrile: methanol: $0.2 \%$ acetic acid $(\mathrm{v} / \mathrm{v})$ at a ratio of 25: 25: $50(\mathrm{v} / \mathrm{v} / \mathrm{v})$ in water (45). Dried extracts (150 mg of Agave tequilana skin extract or $90 \mathrm{mg}$ of seaweed extract) were resuspended into 1.0 $\mathrm{mL}$ of solvent $\mathrm{A}(0.2 \%$ acetic acid $(\mathrm{v} / \mathrm{v}))$. The mobile phase flow rate was set to $0.5 \mathrm{~mL}$ per min with the column temperature at $50^{\circ} \mathrm{C}$. A run time of 45 mins with an initial isocratic hold of solvent A for 15 min, then $70 \%$ solvent A ( $30 \%$ solvent B) at 14 min, 100\% solvent B at 30 mins until the end of the run. Under these conditions $15 \mu \mathrm{L}$ of samples were injected and the DAD was set to record intensity at a specific wavelength $(320 \mathrm{~nm})$ as a function of elution time. 


\section{CHAPTER III}

\section{RESULTS AND DISCUSSION}

\section{FERMENTATION WEIGHTS}

A total of 13 fermentations were carried out during this study; 3 control fermentations (Agave tequilana pieces and nanopure water, no yeast cells), 5 fermentations with Kluyveromyces marxianus $7-1$ and 5 fermentations with Kluyveromyces marxianus 8-1. Three sets of fermentations, summarized in Table 1, were carried out at different times $(A, B, C)$ and the initial weight of Agave tequilana pieces used per fermentation are also shown. The average and standard deviation of fermentation weight for all fermentations was $40.09 \pm 0.04$ $g(n=13)$, Fermentation Set A had an average weight of $40.08 \pm 0.03 g(n=3)$, Fermentation Set B had an average weight of $40.13 \pm 0.02 \mathrm{~g}(\mathrm{n}=5)$ and Fermentation Set $C$ had an average weight of $40.06 \pm 0.04 \mathrm{~g}(n=5)$. The average control fermentation weight was $40.09 \pm 0.05 \mathrm{~g}(\mathrm{n}=3)$, the average Kluyveromyces marxianus 7-1 fermentation weight was $40.08 \pm 0.06 \mathrm{~g}(\mathrm{n}=5)$, and the average Kluyveromyces marxianus 8-1 fermentation weight was $40.11 \pm$ $0.02 \mathrm{~g}(\mathrm{n}=5)$. These data show that the various fermentation weights were within one standard deviation of each other with respect to fermentation type and between sets of fermentations. Thus each fermentation, statistically, started with the same mass of Agave tequilana pieces prior to inoculation. 
Table 1. Summary of Fermentation Set, Type, and Weight of Agave tequilana Pieces Used

\begin{tabular}{|ccc|}
\hline $\begin{array}{c}\text { Fermentation Set } \\
\text { and ID Number }\end{array}$ & $\begin{array}{c}\text { Fermentation } \\
\text { Yeast Type }\end{array}$ & $\begin{array}{c}\text { Total Weight of } \\
\text { Agave tequilana Pieces Used }\end{array}$ \\
\hline$A$ & $\begin{array}{c}\text { Control } \\
\text { (no yeast cells) } \\
\text { Km7-1 }\end{array}$ & $40.05 \mathrm{~g}$ \\
$A$ & Km8-1 & $40.08 \mathrm{~g}$ \\
$A$ & Control & $40.11 \mathrm{~g}$ \\
$B$ & (no yeast cells) & $40.14 \mathrm{~g}$ \\
B1 & $K m 7-1$ & \\
B2 & $K m 7-1$ & $40.12 \mathrm{~g}$ \\
B1 & $K m 8-1$ & $40.16 \mathrm{~g}$ \\
B2 & $K m 8-1$ & $40.14 \mathrm{~g}$ \\
C & Control & $40.13 \mathrm{~g}$ \\
& (no yeast cells) & $40.08 \mathrm{~g}$ \\
C1 & $K m 7-1$ & \\
C2 & $K m 7-1$ & $40.01 \mathrm{~g}$ \\
C1 & $K m 8-1$ & $40.04 \mathrm{~g}$ \\
C2 & $K m 8-1$ & $40.10 \mathrm{~g}$ \\
& & $40.08 \mathrm{~g}$ \\
\hline
\end{tabular}

\section{FERMENTATION GROWTH CURVES}

For all control fermentations (Agave tequilana pieces and nanopure water, no yeast cells) carried out during this work, no CFU were observed. This demonstrates the sterility of the sampling technique and the sterility of the fermentations during these experiments over the entire course of the fermentation. Thus also demonstrating that any CFU observed on the respective solid YPD agar plates containing diluted fermentation broth with either Kluyveromyces marxianus 7-1 or Kluyveromyces marxianus 8-1 fermentations are from the respective yeasts in the fermentation and not from other organisms. 
When all the fermentations containing Kluyveromyces marxianus 7-1 CFU are plotted against time (Figure 5), 3 of the 5 fermentations (Km7-1 (B2), $K m 7-1(\mathrm{C} 1)$, and Km7-1 (C2)) entered log phase at the same time (after 12 hours of fermentation) and demonstrated similar growth rates. All fermentations with this strain of yeast entered log phase (maximum rate of growth) by 12 hours into the fermentation and reached stationary phase by 36 hours into the fermentation, except for the Km7-1 (B1). This set entered stationary phase after 48 hours of fermentation and demonstrated the slowest growth kinetics $\left(1.78 \times 10^{6}\right.$ viable cells per hour) observed in this strain of yeast determined by the slope of the log phase. This indicates that this fermentation is likely an outlier fermentation, since its growth curve is so different from the other fermentations carried out with this strain of yeast in these studies (Figure 5). The $K m 7-1$ (B1) fermentation demonstrated a maximum CFU of $5.70 \times 10^{7}$ viable cells per $\mathrm{mL}$. The $\mathrm{Km} 7-1$ (A) fermentation had the fastest growth kinetics (largest slope in log phase) of

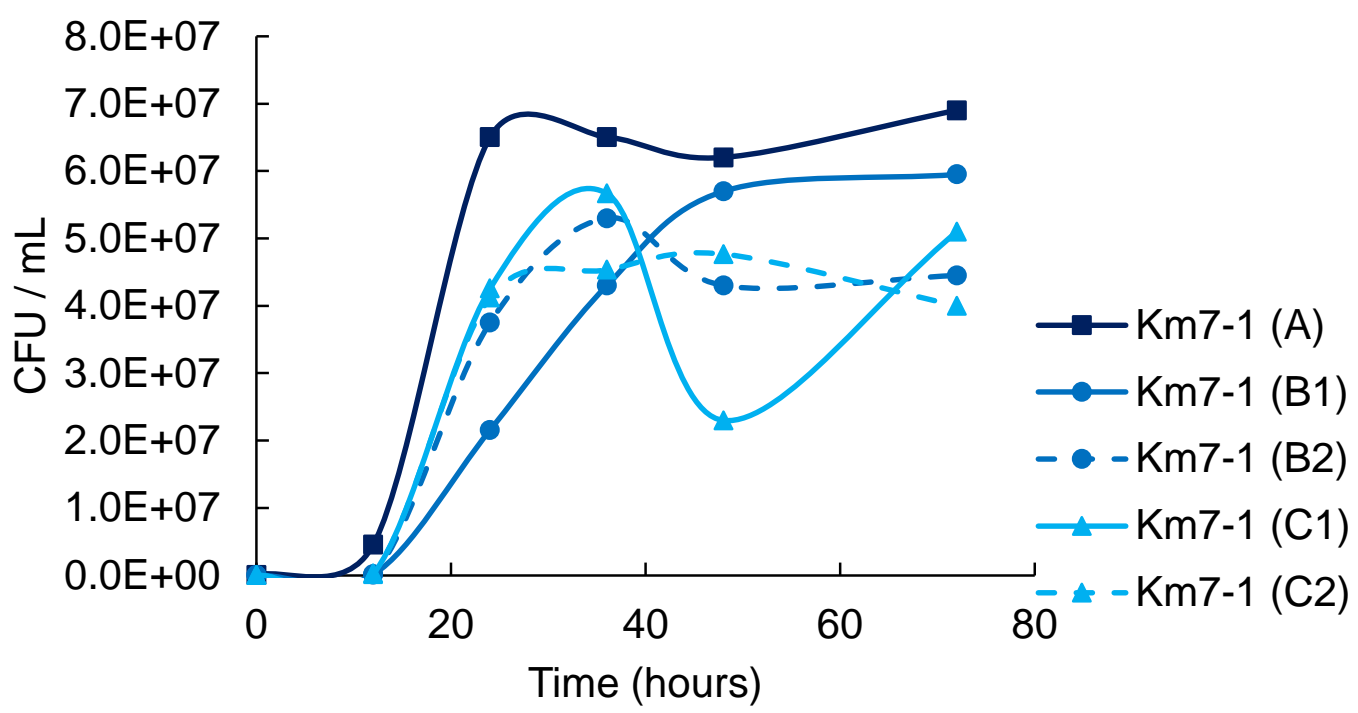

Figure 5. Km7-1: CFU as a function of fermentation time. 
$5.04 \times 10^{6}$ viable cells per hour and also the highest CFU $\left(6.50 \times 10^{7}\right.$ viable cells per $\mathrm{mL}$ ) observed with this strain of yeast. The other Kluyveromyces marxianus 7-1 fermentations had similar growth kinetics (slope during log phase) of $3.11 \mathrm{x}$ $10^{6}$ viable cells per hour (Km7-1 (B2)), $3.53 \times 10^{6}$ viable cells per hour (Km7-1 (C1)), and $3.42 \times 10^{6}$ viable cells per hour (Km7-1 (C2)) during log phase. The Km7-1 (B2), Km7-1 (C1), and Km7-1 (C2) fermentations had CFU maxima of $5.30 \times 10^{7}$ viable cells per $\mathrm{mL}$ at 36 hours, $5.66 \times 10^{7}$ viable cells per $\mathrm{mL}$ at 36 hours, and $4.12 \times 10^{7}$ viable cells per $\mathrm{mL}$ at 24 hours, respectively. The large drop in CFU observed in the Km7-1 (C1) fermentation seen at 48 hours is likely an experimental outlier due to operator error since the next time point at 72 hours is nearly the same CFU seen at the CFU maximum at 36 hours. This is also supported by the asymptotic growth patterns seen by all the other fermentations carried out with this same strain of yeast in this study. One other fermentation with this strain in these studies demonstrated a dip in CFU after the CFU maximum was observed. This fermentation was $K m 7-1$ (B2). However, this drop in CFU was approximately $1.0 \times 10^{7}$ viable cell per $\mathrm{mL}$ compared to the approximate drop of $2.9 \times 10^{7}$ viable cells observed in the $K m 7-1$ (C1) fermentation. Variations in growth kinetics and maximum CFU are likely due to two factors: natural variation in metabolizable substrates in the different Agave tequilana pieces or that using the same optical density for inoculations does not mean the exact number of viable cells are being inoculated between these fermentations. 
When all the fermentations containing Kluyveromyces marxianus 8-1 CFU are plotted against time (Figure 6), 4 of the 5 fermentations (Km8-1 (B1), Km8-1 (B2), Km8-1 (C1), and Km8-1 (C2)) entered log phase at the same time (log phase by 24 hours). In these experiments, the $K m 8-1$ (A) fermentation had the shortest lag phase and thus entered log phase the earliest, which was observed after 12 hours of fermentation (Figure 6). The Km8-1 (A), Km8-1 (B1), Km8-1 (B2), Km8-1 (C1), and Km8-1 (C2) had a lag phase of 12 hours (except for (Km81 (A)) before the fermentations demonstrated initial growth kinetics of $5.59 \times 10^{5}$

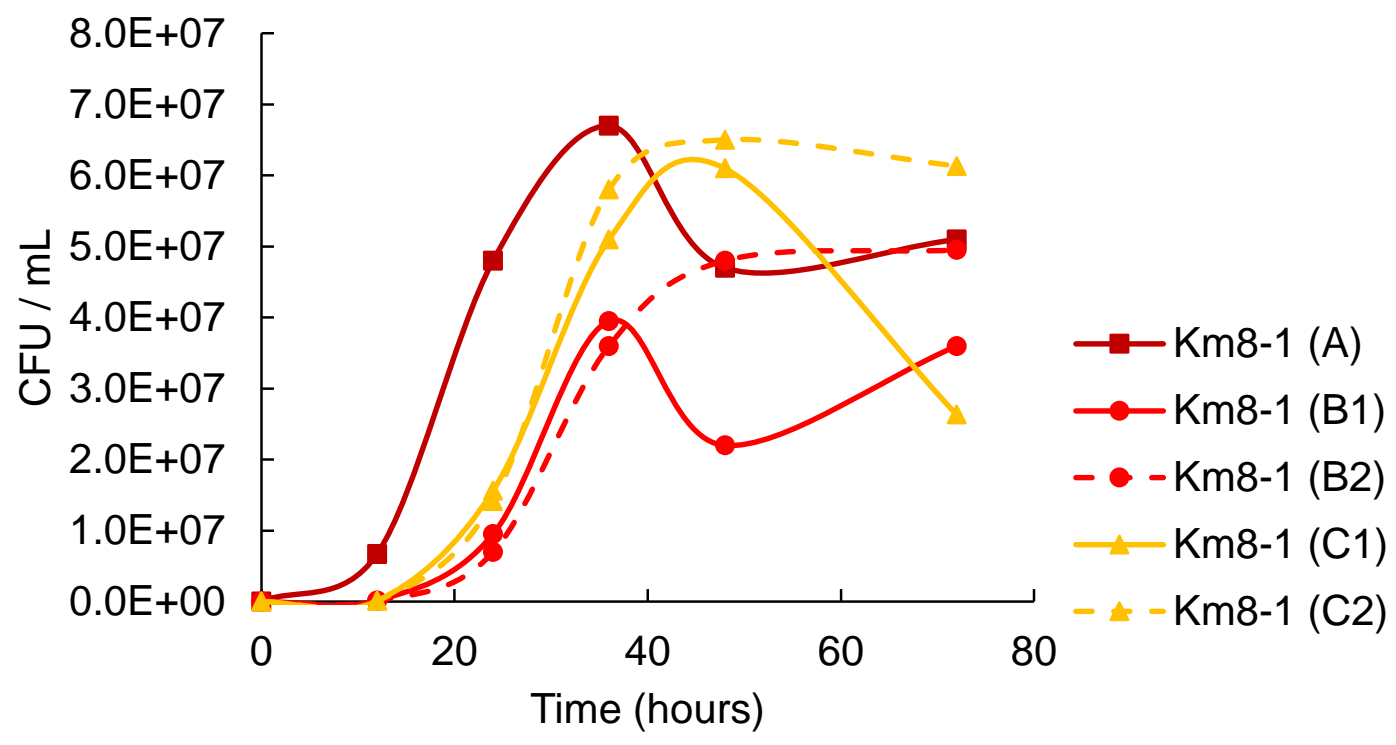

Figure 6. Km8-1: CFU as a function of fermentation time.

viable cells per hour, $7.7 \times 10^{5}$ viable cells per hour, $5.73 \times 10^{5}$ viable cells per hour, $1.29 \times 10^{6}$ viable cells per hour and $1.17 \times 10^{6}$ viable cells per hour, respectively, during the early log phase (between 12-24 hours of fermentation, except $K m 8-1(\mathrm{~A})$, which was between 0-12 hours). The $K m 8-1$ (A), Km8-1 (B1), Km8-1 (B2), Km8-1 (C1), and Km8-1 (C2) fermentations had an observed log growth kinetics (slope of log phase) of $3.44 \times 10^{6}$ viable cells per hour, 
$2.50 \times 10^{6}$ viable cells per hour, $2.41 \times 10^{6}$ viable cells per hour, $2.94 \times 10^{6}$ viable cells per hour and $3.66 \times 10^{6}$ viable cells per hour, respectively, during the early log phase. These fermentations, Km8-1 (A), Km8-1 (B1), Km8-1 (B2), Km8-1 (C1), and Km8-1 (C2), had CFU maxima of $6.70 \times 10^{7}$ viable cells per $\mathrm{mL}$ at 36 hours, $3.95 \times 10^{7}$ viable cells per $\mathrm{mL}$ at 36 hours, $4.80 \times 10^{7}$ viable cells per $\mathrm{mL}$ at 48 hours, $6.50 \times 10^{7}$ viable cells per $\mathrm{mL}$ at 48 hours, and $6.10 \times 10^{7}$ viable cells per $\mathrm{mL}$ at 48 hours respectively. These fermentations show more variation in the trend seen after the respective fermentation stationary phase than the fermentations with Kluyveromyces marxianus 7-1. The Km8-1 (A), Km8-1 (B1), and Km8-1 (C1) fermentations demonstrated a dip in CFU after the observed CFU maximum. For the $K m 8-1(\mathrm{~A})$ and $K m 8-1$ (B1) fermentations the dip in CFU was approximately $2.00 \times 10^{7}$ viable cells in 12 hours. The Km8-1 (C1) fermentation dip was approximately $4.00 \times 10^{7}$ viable cells in 24 hours, with is twice as much in twice the time as the $K m 8-1$ (A) and $K m 8-1$ (B1) fermentations. The Km8-1 (B2) and Km8-1 (C2) fermentations demonstrated an asymptotic trend after the maximum CFU was observed. It was observed that both $\mathrm{Km} 8-1$ (B2) and Km8-1 (C2) fermentations reached their asymptotic stationary phase after 48 hours of fermentation. For this set of fermentations with Kluyveromyces marxianus 8-1, it is unclear if the dip in CFU was an error in sampling or error in inoculation or the actual growth curve trend exhibited by these yeast, since a majority of the fermentations carried out in these studies with this strain of yeast (3 of 5) demonstrated this trend. The minority (2 of 5) exhibited the asymptotic 
trend also seen in the majority of the Kluyveromyces marxianus 7-1 fermentations (4 of 5) in this study.

When all the Kluyveromyces marxianus 7-1 and Kluyveromyces marxianus 8-1 fermentations are plotted together (Figure 7) a clear difference in fermentation trends by the respective yeast becomes apparent. When the outlier Km7-1 (B1) fermentation and the shorter lag phase $K m 8-1$ (A) fermentations are ignored, then the faster growth kinetics (large slope of log phase) of Kluyveromyces marxianus 7-1 becomes apparent. Interestingly, when the fermentation times are adjusted and plotted so that the log phases of the respective fermentations occur at the same time (Figure 8), it is apparent that the growth kinetics are not so different from one another. Other than the Km7-1 (A) and $K m 7-1$ (B1) fermentations, the fermentations in this study have almost the same growth kinetics (Figure 8, between 12-24 hours of fermentation). When the adjusted fermentation time plot (Figure 8 ) is averaged $(n=5)$ with respect to the strain of yeast (Figure 9), then it is apparent that these yeast grow nearly identically. The errors bars in Figure 9 are a standard deviation from the mean CFU $(n=5)$. The overlap between the error bars of the growth curves of the Kluyveromyces marxianus 7-1 and Kluyveromyces marxianus 8-1, further demonstrate the nearly identical growth. Kluyveromyces marxianus 7-1's 


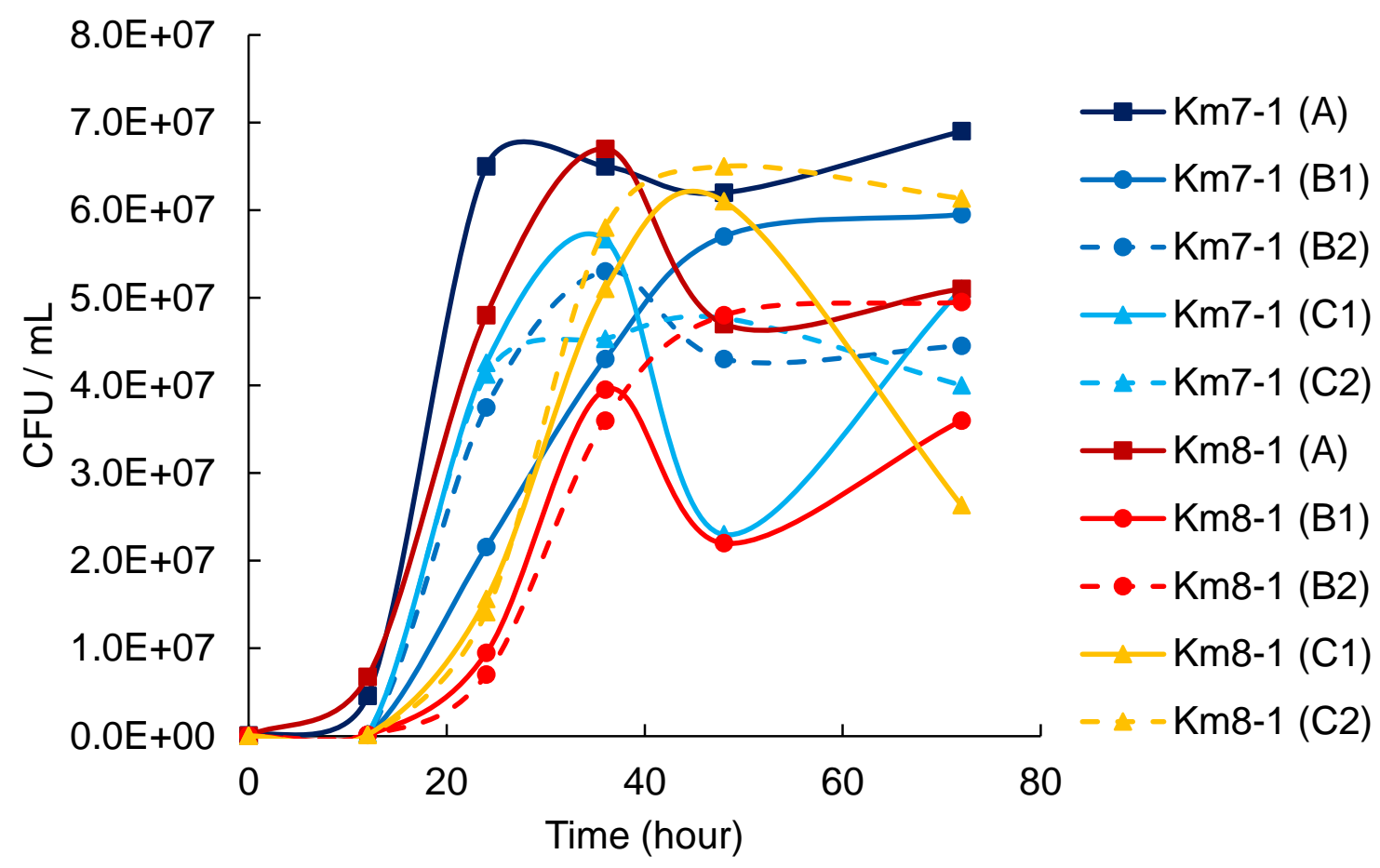

Figure 7. CFU as a function of fermentation time.

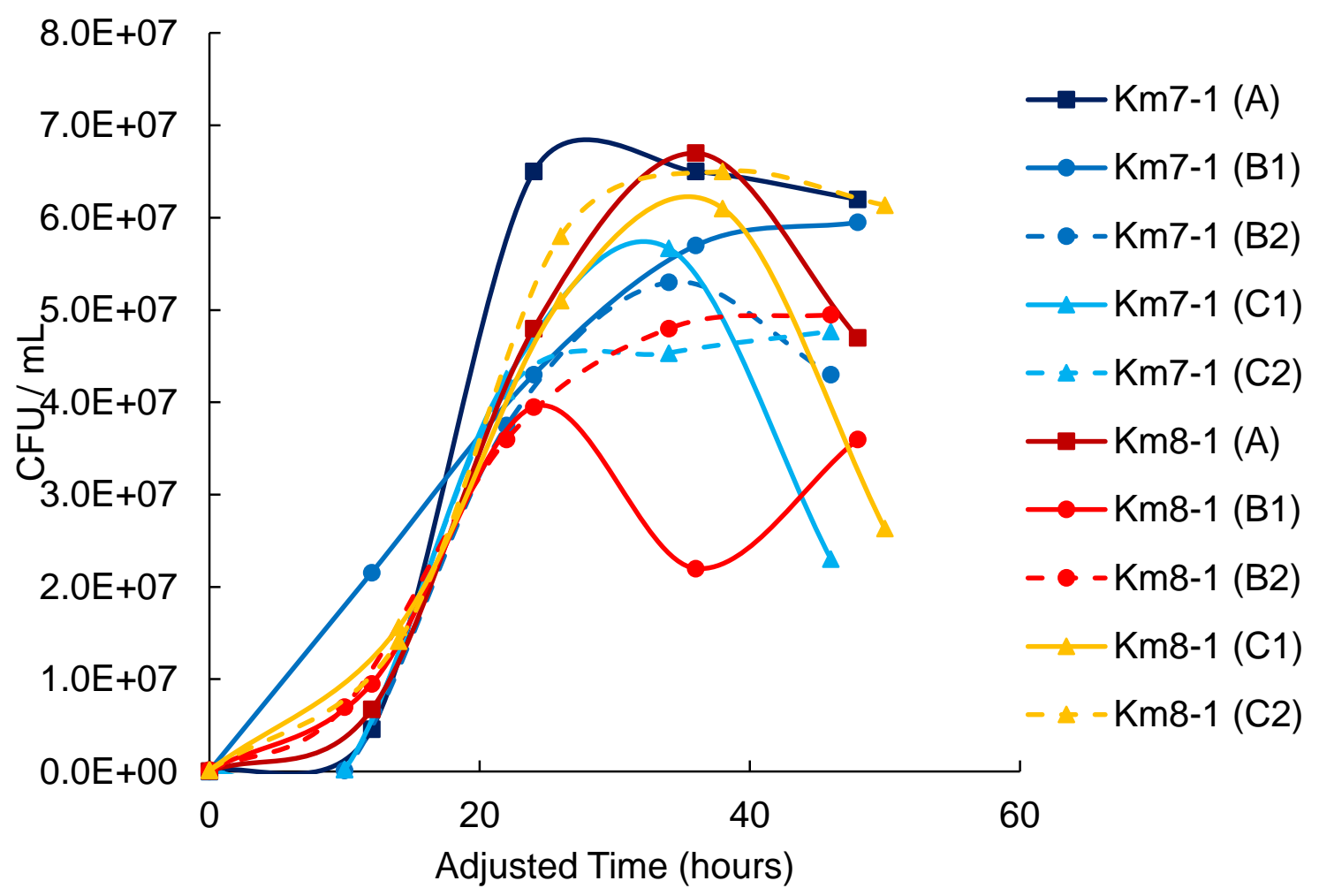

Figure 8. CFU as a function of adjusted fermentation time. 
Average CFU maximum was $5.47 \times 10^{7}$ viable cells per $\mathrm{mL}$ and Kluyveromyces marxianus 8-1's average CFU maximum was $5.22 \times 10^{7}$ viable cells per $\mathrm{mL}$ (4.57\% difference). When using the adjusted fermentation growth curves, Kluyveromyces marxianus 7-1's growth kinetics were $3.87 \times 10^{6}$ viable cells per hour and Kluyveromyces marxianus 8-1's growth kinetics were $2.00 \times 10^{6}$ viable cells per hour (20.7\% difference) during log phase. When the fermentations CFU are averaged with respect to the strain of yeast and when the fermentation time is not manipulated (Figure 10), then it appears that both strains of yeast reach their respective $\mathrm{CFU}_{\max }$ at 36 hours into the fermentations. Kluyveromyces marxianus 7-1's average CFU maximum was $5.47 \times 10^{7}$ viable cells per $\mathrm{mL}$ and Kluyveromyces marxianus 8-1's average CFU maximum was $5.31 \times 10^{7}$ viable cells per $\mathrm{mL}$ (2.90\% difference). The errors bars (standard deviation, $\mathrm{n}=5)$ for the respective yeast strains in Figure 10 demonstrate that both yeast strains reach the same CFU maximums at stationary phase after 36 hours of fermentation. In both Figures 9 and 10, after the CFU maximum was observed at 36 hours of fermentation, a drop in CFU was also observed 12 hours later. 


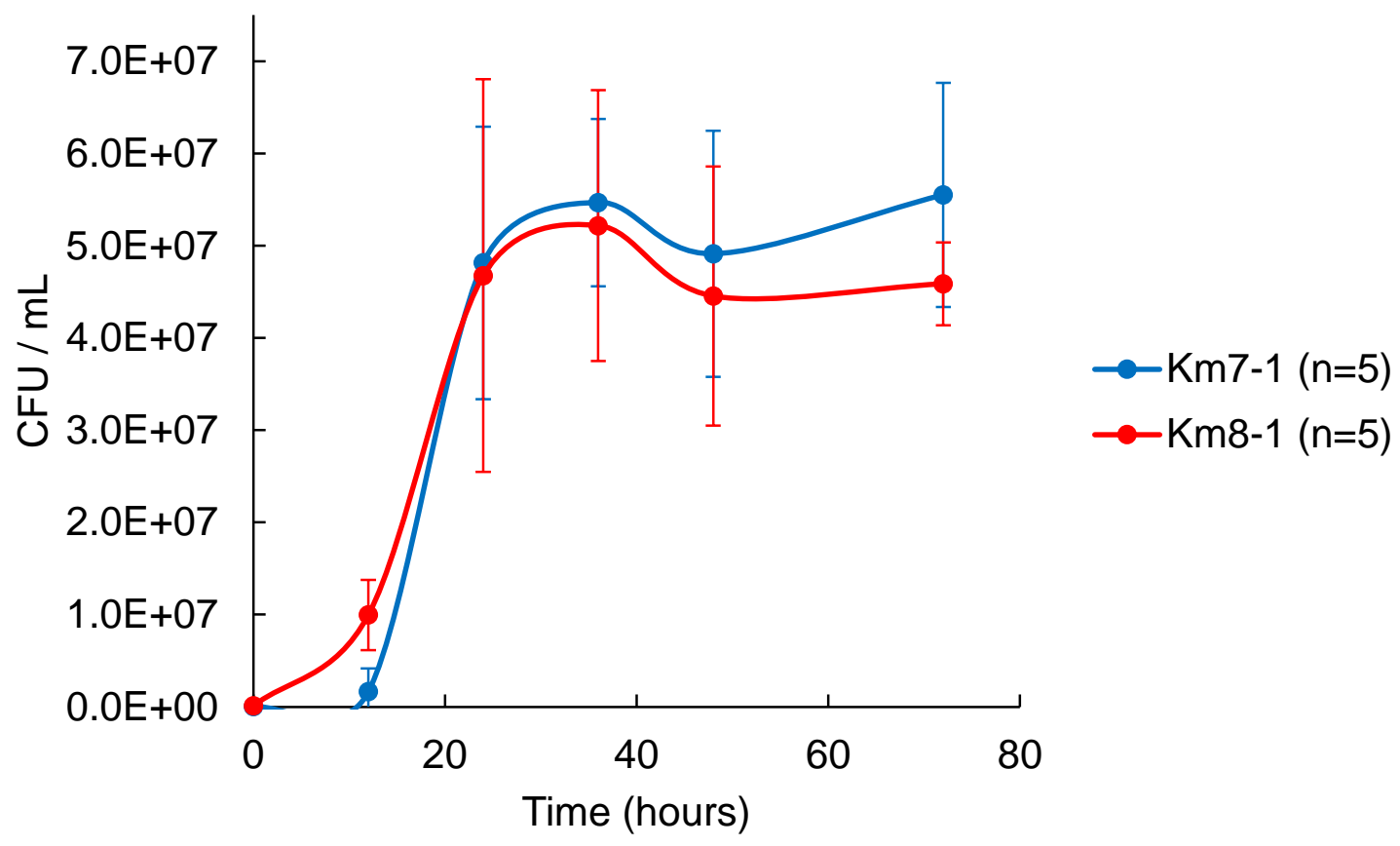

Figure 9. All respective fermentations: averaged CFU as a function of adjusted fermentation time.

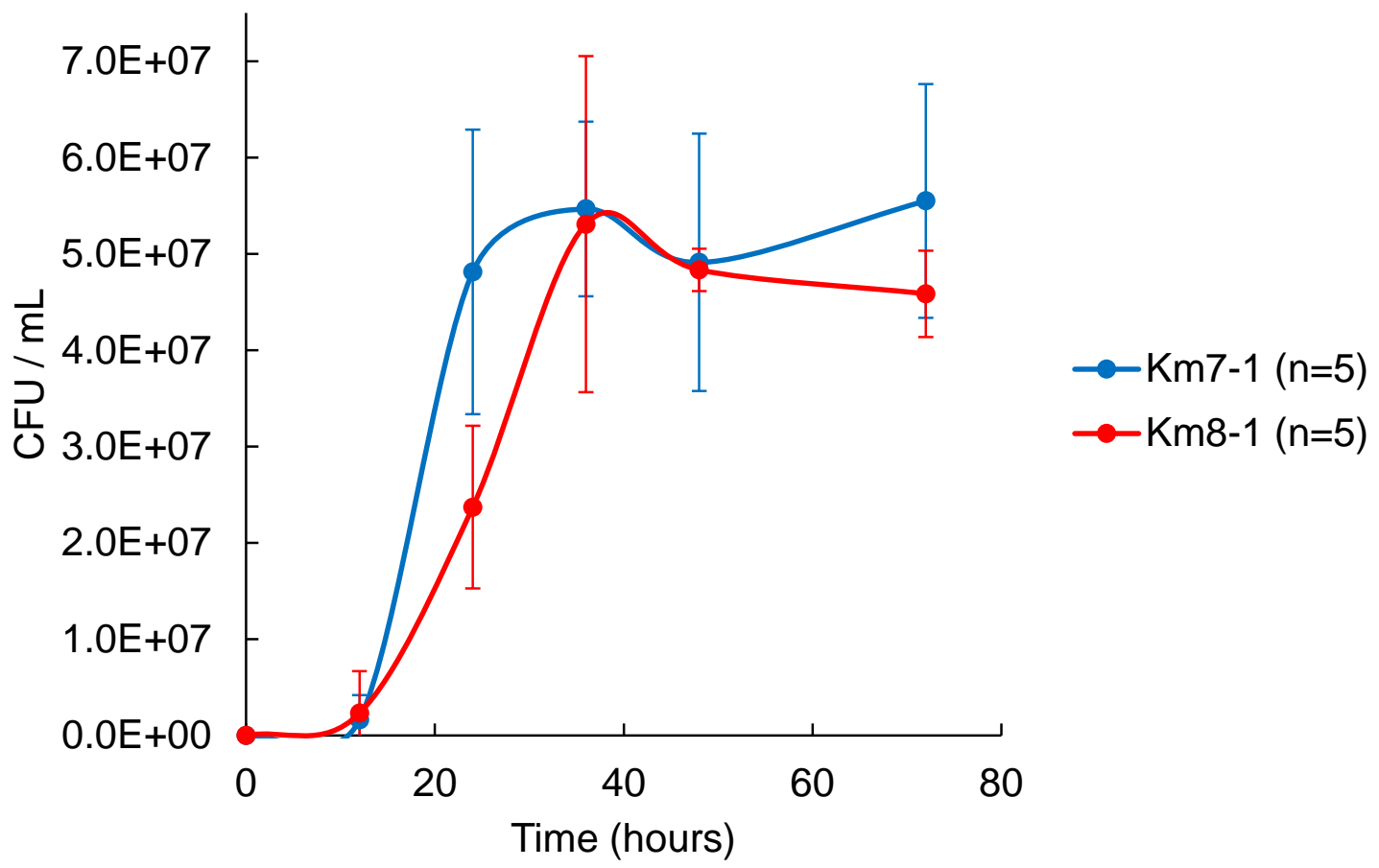

Figure 10. All respective fementations: averaged CFU as a function of fermentation time. 


\section{ASSAY FOR REDUCING SUGARS}

When standard inulin (a non-reducing sugar) and fructose (a reducing sugar) were tested using the DNS assay only the fructose demonstrated an absorbance value at $575 \mathrm{~nm}$ while the inulin demonstrated a similar absorbance as the blank (water and DNS reagent). Thus the DNS assay is only sensitive to the reducing sugar found in the samples and not the non-reducing sugars such as fructan polymers. The reducing sugar concentration for the Control fermentation broths (Agave tequilana pieces and water, no yeast added) demonstrated some variation (Figure 11), which is expected with natural variation between the different leaf pieces and different parts of the Agave tequilana leaf (upper or lower portions). This also indicates that reducing sugars are available from the leaves of the Agave tequilana. Overall during the course of the

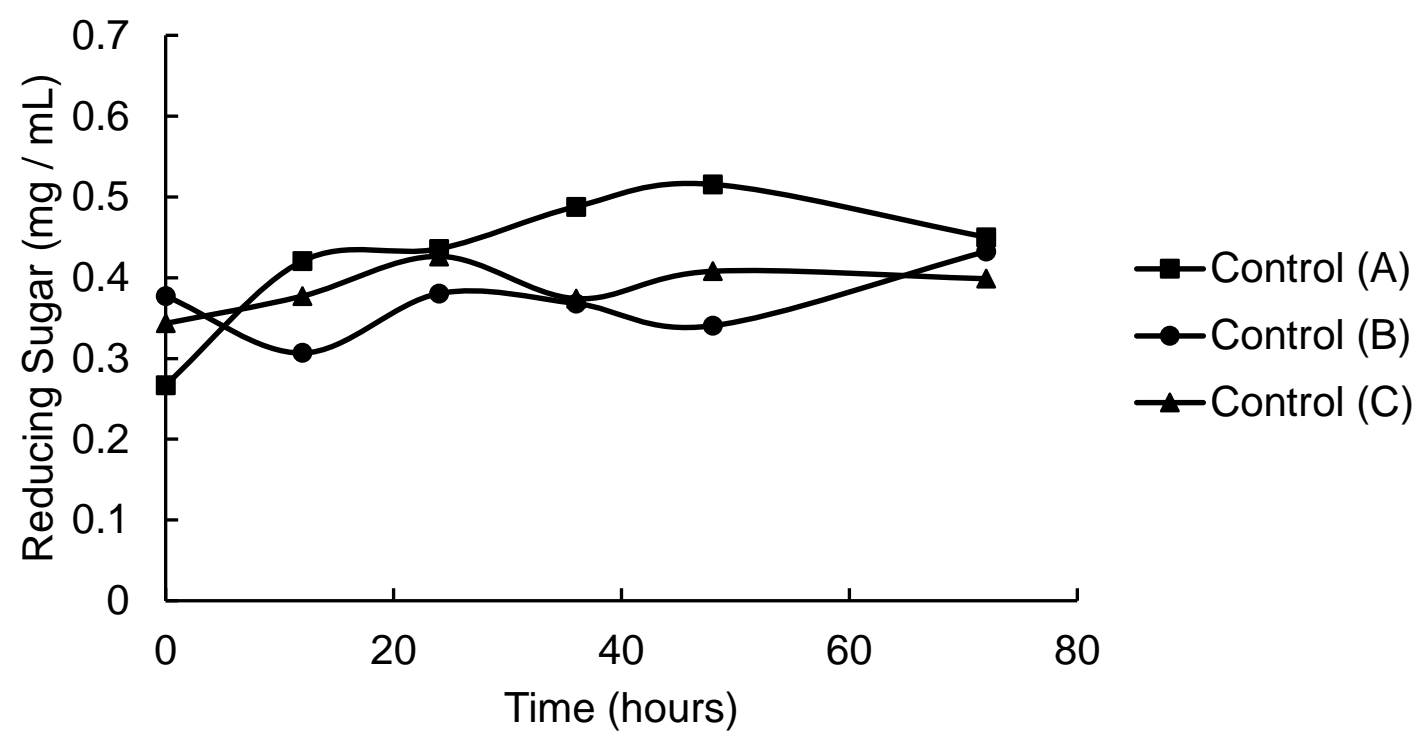

Figure 11. Control fermentation: reducing sugar concentration as a function of fermentation time. 
respective Control fermentations (Figure 11, Control (B) and Control (C)) the reducing sugar concentration remained fairly constant, with a slight positive slope. The Control (A) fermentation demonstrated an increase in the reducing sugar concentration from an initial concentration of $0.27 \mathrm{mg} / \mathrm{mL}$ reducing sugars to an observed maximum of $0.51 \mathrm{mg} / \mathrm{mL}$ reducing sugars (Figure 11).

When the reducing sugar concentration of the respective Kluyveromyces marxianus 7-1 fermentations are plotted as a function of time (Figure 12), 4 out of 5 fermentations (Km7-1 (B1), Km7-1 (B2), Km7-1 (C1), and Km7-1 (C2)), demonstrate the same trend over the same time frame. The initial reducing sugar concentrations for the Km7-1 (B1), Km7-1 (B2), Km7-1 (C1), and Km7-1 (C2) fermentations were $0.36 \mathrm{mg}$ per $\mathrm{mL}, 0.35 \mathrm{mg}$ per $\mathrm{mL}, 0.33 \mathrm{mg}$ per $\mathrm{mL}$, and 0.33 $\mathrm{mg}$ per $\mathrm{mL}$, respectively. All of these fermentations begin to demonstrate a reduction in the concentration of reducing sugars at 12 hours into the fermentation. After 36 hours of fermentation the final reducing sugar concentrations becomes asymptotic at their respective lowest concentrations observed. The final reducing sugar concentrations for the $K m 7-1$ (B1), Km7-1 (B2), Km7-1 (C1), and Km7-1 (C2) fermentations were $0.04 \mathrm{mg}$ per $\mathrm{mL}(89.6 \%$ reduction from initial), $0.10 \mathrm{mg}$ per $\mathrm{mL}(72.2 \%$ reduction from initial), $0.014 \mathrm{mg}$ per $\mathrm{mL}$ (95.5\% reduction from initial), and $0.02 \mathrm{mg}$ per $\mathrm{mL}$ (95.1\% reduction from initial), respectively. The data collected for the $K m 7-1(\mathrm{~A})$ fermentation are clearly an outlier for this assay. Although the initial $\mathrm{mg}$ per $\mathrm{mL}$ was the same as the other fermentations, it does not follow the same trend as the other four 
fermentations for Kluyveromyces marxianus 7-1 with this assay in this study (Figure 12) and is likely due to an error in running the assay. Therefore it will be ignored for the rest of the reducing sugar analyses with Kluyveromyces marxianus 7-1.

When the reducing sugar concentration of the respective Kluyveromyces marxianus 8-1 fermentations are plotted as a function of time (Figure 13), 3 out of 5 of the respective fermentations (Km8-1 (B1), Km8-1 (B2), and Km8-1 (C1)) follow the same trend observed by the majority (4 of 5) of Kluyveromyces marxianus 7-1 fermentations observed in Figure 12. The initial reducing sugar concentrations for the Km8-1 (A), Km8-1 (B1), Km8-1 (B2), Km8-1 (C1), and Km8-1 (C2) fermentations were $0.26 \mathrm{mg}$ per $\mathrm{mL}, 0.46 \mathrm{mg}$ per $\mathrm{mL}, 0.37 \mathrm{mg}$ per $\mathrm{mL}, 0.31 \mathrm{mg}$ per $\mathrm{mL}$, and $0.32 \mathrm{mg}$ per $\mathrm{mL}$, respectively. It was observed that in these fermentations after 12 hours of fermentation the reducing sugar concentration began to decrease. After 48 hours of fermentation the lowest concentrations of reducing sugars were observed. The final reducing sugar concentration after 72 hours of fermentation for the Km8-1 (A), Km8-1 (B1), Km8-1 (B2), Km8-1 (C1), Km8-1 (C2) fermentations were 0.05 mg per mL (81.4\% difference from initial), $0.01 \mathrm{mg}$ per $\mathrm{mL}$ (98.1\% difference from initial), $0.02 \mathrm{mg}$ per $\mathrm{mL}$ (95.7\% difference from initial), $0.01 \mathrm{mg}$ per $\mathrm{mL}$ (96.8\% difference from initial), and $0.02 \mathrm{mg}$ per $\mathrm{mL}$ (93.9\% difference from initial), respectively. The Km8-1 (A) and Km8-1 (C2) fermentations demonstrated a slightly different trend in the reduction of the reducing sugars as a function of time (Figure 13). 


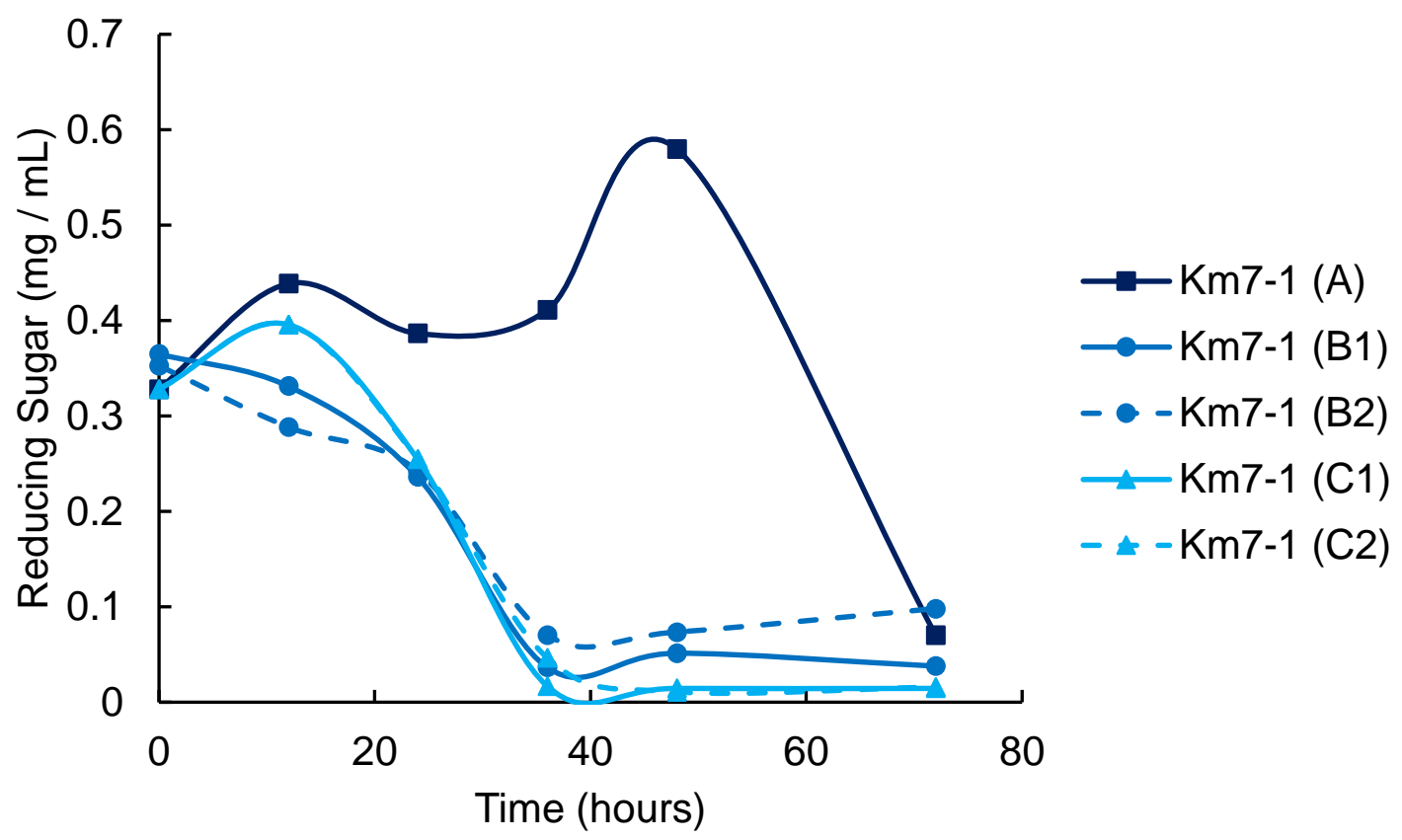

Figure 12. $K m 7-1$ fermentations: reducing sugar concentration as a function of fermentation time.

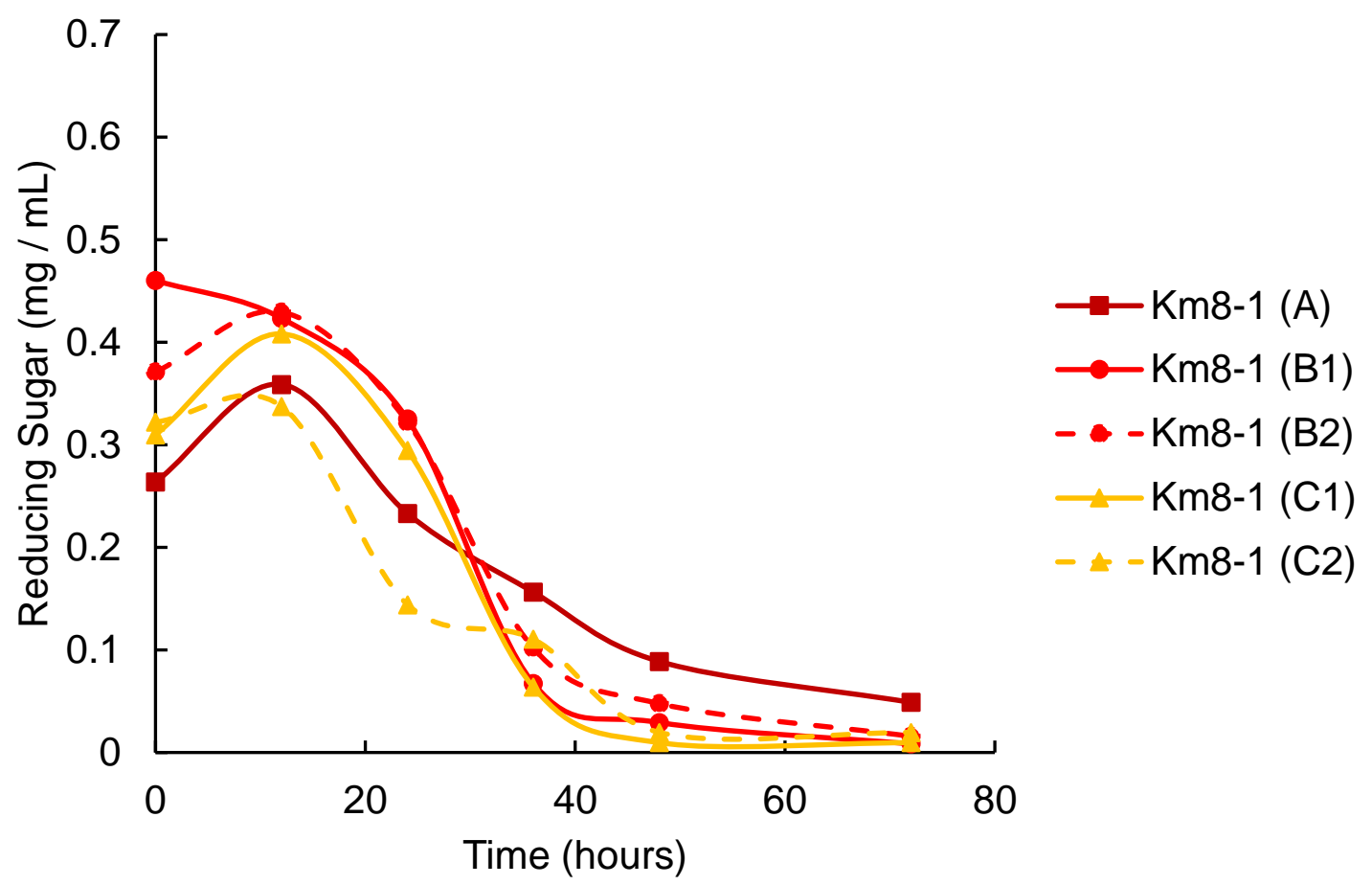

Figure 13. $K m 8-1$ fermentations: reducing sugar concentration as a function of fermentation time. 
The Km8-1 (A) fermentation demonstrated a more gradual reduction of reducing sugars not seen in the other fermentations with Kluyveromyces marxianus 8-1 in this study. The Km8-1 (C2) fermentation demonstrated a step wise reduction in reducing sugar with respect to fermentation time. Thus both these trends were unique but demonstrated the same general trend, shown by the 3 sets of fermentations, of a reduction of the concentration of reducing sugars as a function for fermentation time.

When all the respective fermentations reducing sugar concentrations were averaged as a function of fermentation time (Figure 14), it was observed that the averaged control fermentation demonstrated an increase of reducing sugars in the first 24 hours. The initial average Control fermentation reducing sugar concentration was $0.33 \pm 0.06 \mathrm{mg}$ per $\mathrm{mL}(\mathrm{n}=3)$ and became asymptotic at a concentration ranging from $0.41-0.43 \mathrm{mg}$ per $\mathrm{mL}$ from $24-72$ hours of fermentation. The increase in reducing sugar concentration observed in Figure 14 was likely due to spontaneous hydrolysis, due to the lack of CFU observed in the averaged control fermentation (Figure 14). The averaged Kluyveromyces marxianus 7-1 $(\mathrm{n}=5)$ and Kluyveromyces marxianus 8-1 $(\mathrm{n}=5)$ fermentations reducing sugar concentrations as a function fermentation time (Figure 14) demonstrate nearly identical trends. This trend indicates a sharp decrease in reducing sugar concentration after 12 hours of fermentation followed by an asymptotic region at the later time points of the fermentations. After 72 

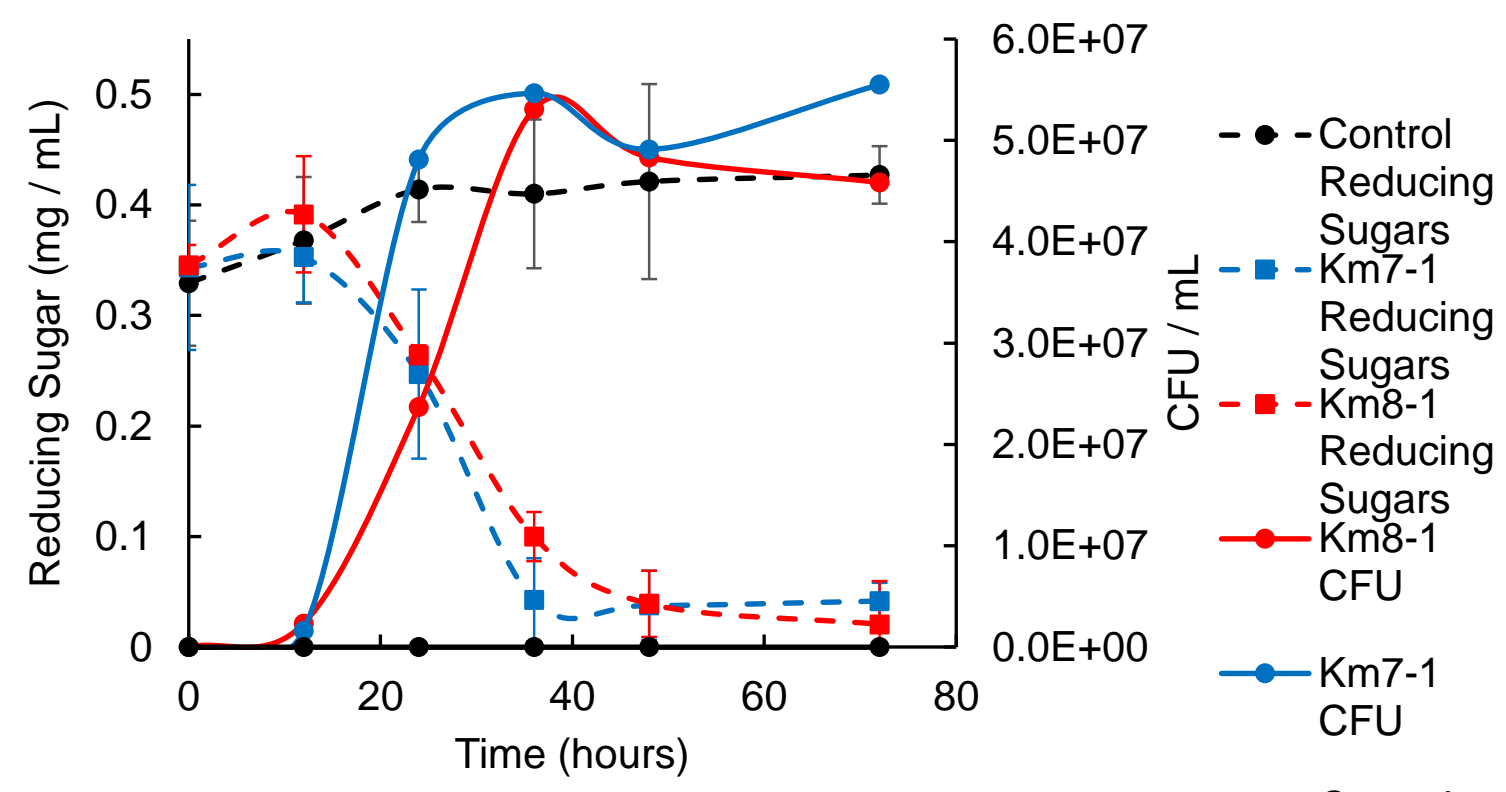

Figure 14. Averaged fermentation reducing sugar concentratton Control and CFU as a function of fermentation time.

hours of fermentation the averaged Kluyveromyces marxianus 7-1 and Kluyveromyces marxianus 8-1 fermentations final reducing sugar concentration was $0.04 \pm 0.04 \mathrm{mg}$ per $\mathrm{mL}(87.9 \%$ difference from initial) and $0.02 \pm 0.01 \mathrm{mg}$ per $\mathrm{mL}$ (94.0\% difference from initial), respectively. When the averaged reducing sugar concentrations and the averaged CFU of the respective fermentations are plotted together as a function of fermentation time (Figure 14), it is observed that as the yeast cells for both strains go into log phase (12 hours) the reducing sugar concentration begins to drop. After the yeast cells for both strains of yeast reach their respective stationary phases the reducing sugar concentrations become asymptotic at their respective minimum concentrations (Figure 14). The error bars in Figure 14 demonstrate the precision of the DNS assay between the respective yeast fermentations during this study. 


\section{FERMENTATION BROTH PH AND PROTEIN CONCENTRATION}

The $\mathrm{pH}$ of the fermentations demonstrated little to no change over the course of the entire fermentation for all fermentations during this study. For all fermentations the initial $\mathrm{pH}$ was $5.5-6$ and the final $\mathrm{pH}$ of the fermentations was 5.5-6 as well.

When the control fermentation broth protein concentration as a function of fermentation time is plotted (Figure 15), a horizontal trend is observed. The Control (C) fermentation demonstrates more variation in the protein concentration over time and is likely due to the handling of the sample prior to the assay. The initial concentration of protein for these Control (A, B and C) fermentations were $9.58 \mu \mathrm{g}$ per $\mathrm{mL}, 16.3 \mu \mathrm{g}$ per $\mathrm{mL}$, and $10.20 \mu \mathrm{g}$ per $\mathrm{mL}$ respectively. The final concertation of protein for the Control Fermentations (A, B,

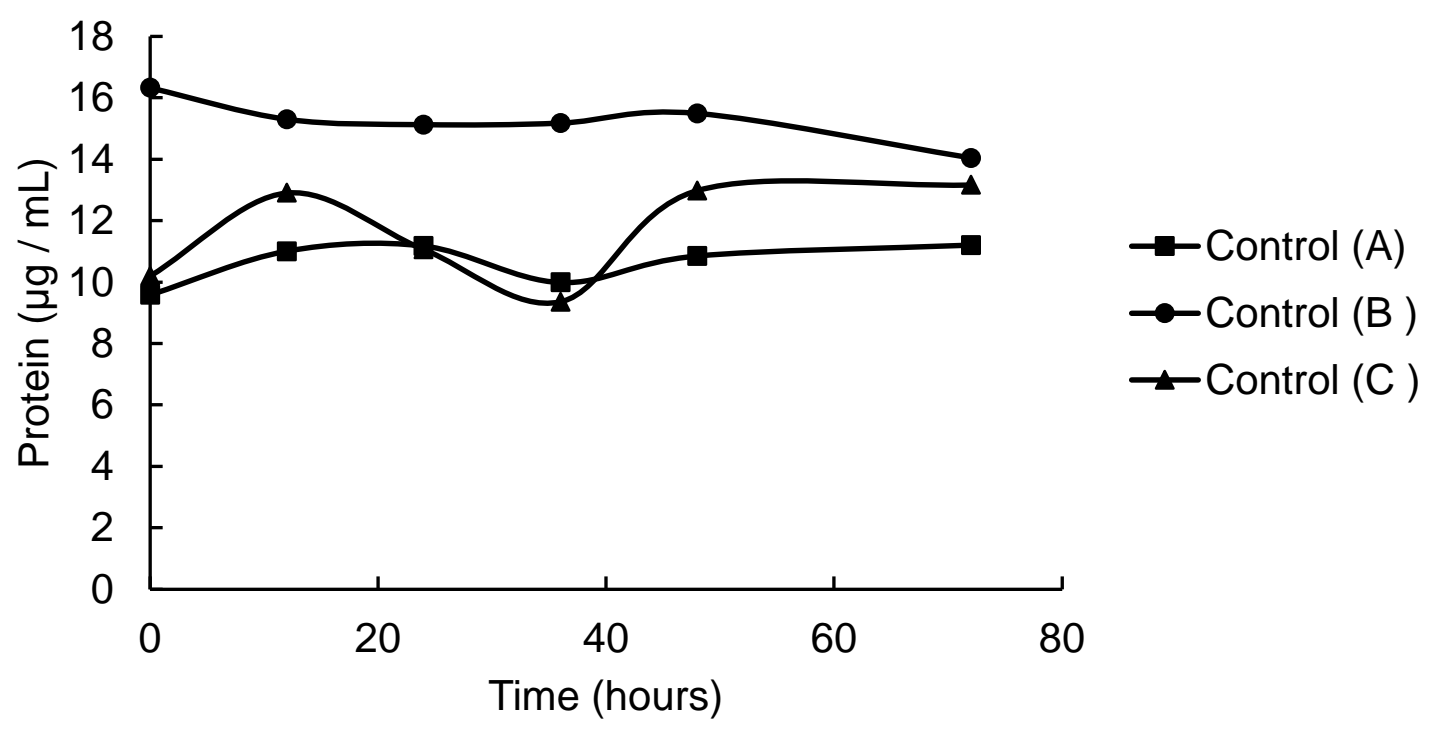

Figure 15. Control fermentations: protein concentration as a function of fermentation time. 
and C) were $11.2 \mu \mathrm{g}$ per $\mathrm{mL}$ (14.9\% difference from initial), $14.0 \mu \mathrm{g}$ per $\mathrm{mL}$ (14.0\% difference from initial), and $13.2 \mu \mathrm{g}$ per $\mathrm{mL}$ (22.9\% difference from initial), respectively.

When the Kluyveromyces marxianus 7-1 fermentation broth protein as a function of fermentation time is plotted (Figure 16), a general trend of the reduction in the concentration of protein as a function of fermentation time was observed. The Km7-1 (A), Km7-1 (B1), Km7-1 (B2), Km7-1 (C1), and Km7-1 (C2) fermentations had an initial protein concentration in the fermentation broth of $10.5 \mu \mathrm{g}$ per $\mathrm{mL}, 17.7 \mu \mathrm{g}$ per $\mathrm{mL}, 17.8 \mu \mathrm{g}$ per $\mathrm{mL}, 11.0 \mu \mathrm{g}$ per $\mathrm{mL}$, and $8.53 \mu \mathrm{g}$ per $\mathrm{mL}$, respectively. For all fermentations after 12 hour in the fermentation it was observed that the concentration of protein decreased until 24 hours of fermentation when most of the fermentation broths protein concentration became asymptotic at the lowest concentrations of protein for the respective fermentation (Figure 16). The $K m 7-1$ (B2) and $K m 7-1$ (C2) fermentation demonstrated a step wise trend, the first step had the same trend as the rest of the fermentations, but after 72 hours of fermentation it demonstrated another drop in protein concentration in the fermentation broth (Figure 16). The final concentration of protein in the fermentation broth for Km7-1 (A), Km7-1 (B1), Km7-1 (B2), 


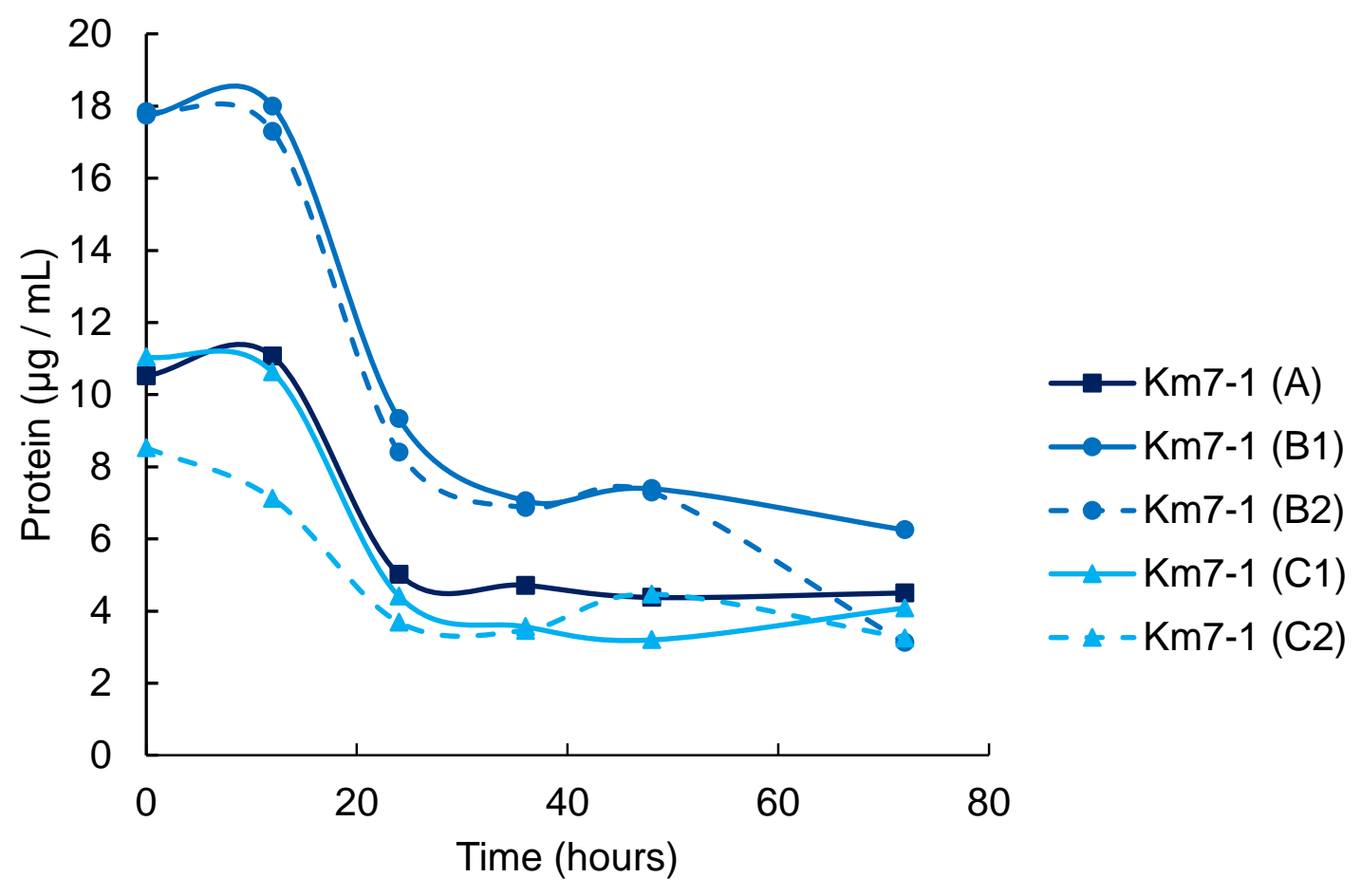

Figure 16. $K m 7-1$ fermentations: protein concentration as a function of fermentation time.

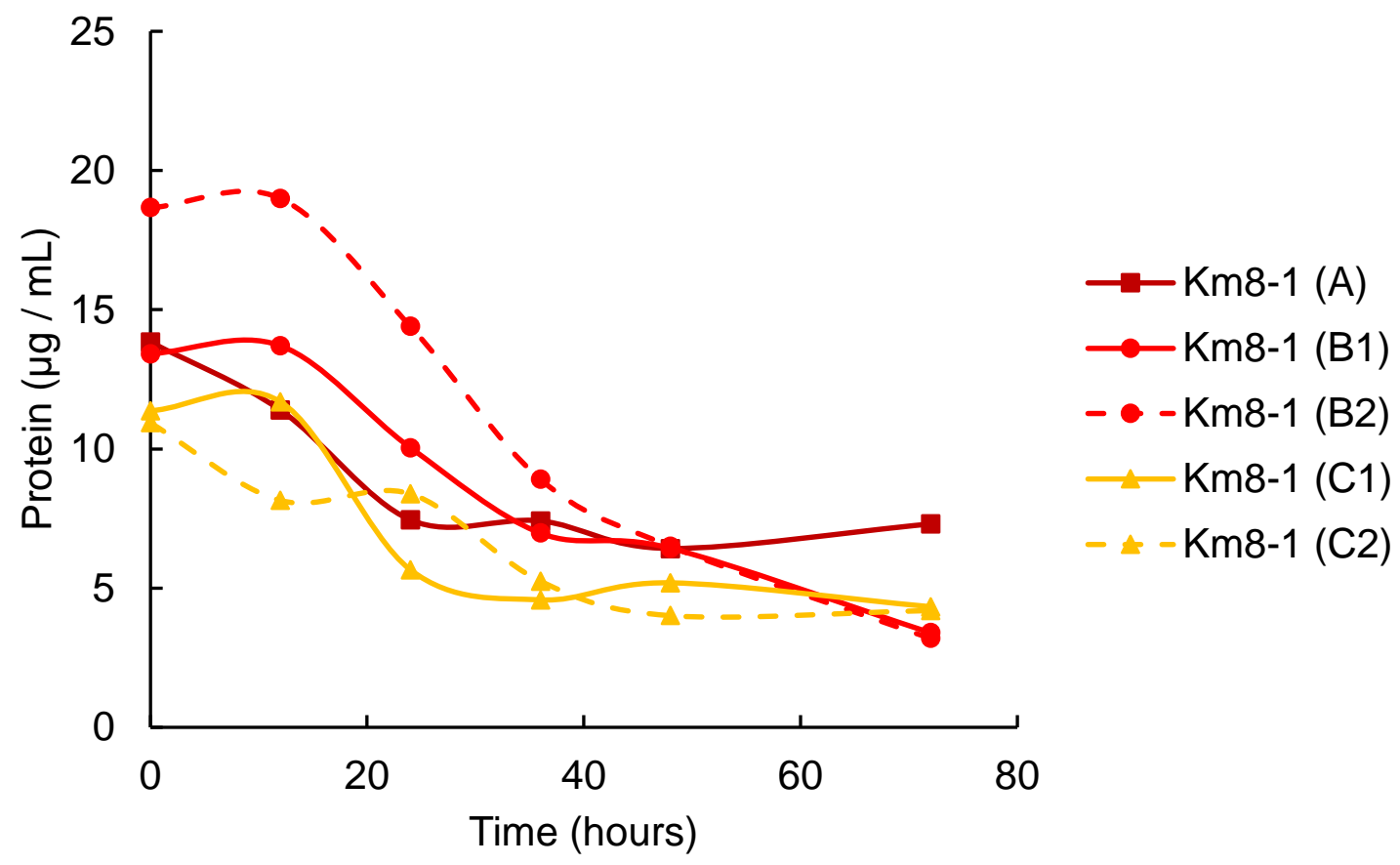

Figure 17. $K m 8-1$ fermentations: protein concentration as a function of fermentation time. 
Km7-1 (C1), and Km7-1 (C2) fermentations were $4.5 \mu \mathrm{g}$ per $\mathrm{mL}(58.4 \%$ difference from initial), $6.25 \mu \mathrm{g}$ per $\mathrm{mL}$ (64.8\% difference from initial), $3.13 \mu \mathrm{g}$ per $\mathrm{mL}$ (82.5\% difference from initial), $4.09 \mu \mathrm{g}$ per $\mathrm{mL}$ (71.0\% difference from initial), and $3.26 \mu \mathrm{g}$ per $\mathrm{mL}$ (47.6\% difference from initial), respectively.

When the Kluyveromyces marxianus 8-1 fermentation broth protein concentration as a function of fermentation time is plotted (Figure 17), a general trend of a step wise reduction in the concentration of protein as a function of fermentation time is shown. The $K m 8-1$ (A), Km8-1 (B1), Km8-1 (B2), Km8-1 (C1), and Km8-1 (C2) fermentations had an initial protein concentration in the fermentation broth of $13.8 \mu \mathrm{g}$ per $\mathrm{mL}, 13.4 \mu \mathrm{g}$ per $\mathrm{mL}, 18.7 \mu \mathrm{g}$ per $\mathrm{mL}, 11.4 \mu \mathrm{g}$ per $\mathrm{mL}$, and $10.9 \mu \mathrm{g}$ per $\mathrm{mL}$, respectively. After 12 hours of fermentation, the $K m 8-1$ (B1), the $K m 8-1$ (B2), and the $K m 8-1$ (C1) fermentations demonstrated a reduction in protein in the fermentation broth much like the Kluyveromyces marxianus 7-1 protein in the fermentation broths in this study. The Km8-1 (A) and Km8-1 (C2) fermentation demonstrated an immediate reduction of protein concentration in the fermentation broth unlike the other fermentations with Kluyveromyces marxianus 8-1 in this study. The final protein concentrations in the Km8-1 (A), Km8-1 (B1), Km8-1 (B2), Km8-1 (C1), and Km8-1 (C2) fermentation broths were $7.30 \mu \mathrm{g}$ per $\mathrm{mL}$ (53.6\% reduction from initial), $3.40 \mu \mathrm{g}$ per $\mathrm{mL}$ (74.7\% reduction from initial), $3.19 \mu \mathrm{g}$ per $\mathrm{mL}$ (82.9\% reduction from initial), $4.32 \mu \mathrm{g}$ per $\mathrm{mL}$ (54.4\% reduction from initial), and $4.19 \mu \mathrm{g}$ per $\mathrm{mL}(63.3 \%$ reduction from initial), respectively. 
When the protein concentrations of the Control $(n=3)$, Kluyveromyces marxianus 7-1 ( $(=5)$, and Kluyveromyces marxianus 8-1 $(n=5)$ fermentations are averaged and plotted with respective averaged CFU data (Figure 18), it was demonstrated that the averaged protein concentration and the averaged CFU have an inverse relationship. The concentration for protein in the fermentation broth for the Control fermentations demonstrated a slight increase in protein concentration from $12.0 \pm 3.73 \mu \mathrm{g}$ per $\mathrm{mL}$ to a final concentration of $13.6 \pm 1.65$ $\mu \mathrm{g}$ per $\mathrm{mL}$ (11.5\% difference). This was likely due to spontaneous hydrolysis of proteins from the Agave tequilana pieces because there were no CFU observed in these fermentations (Figure 18). The averaged protein concentration in the fermentation broths between the two strains of yeast were

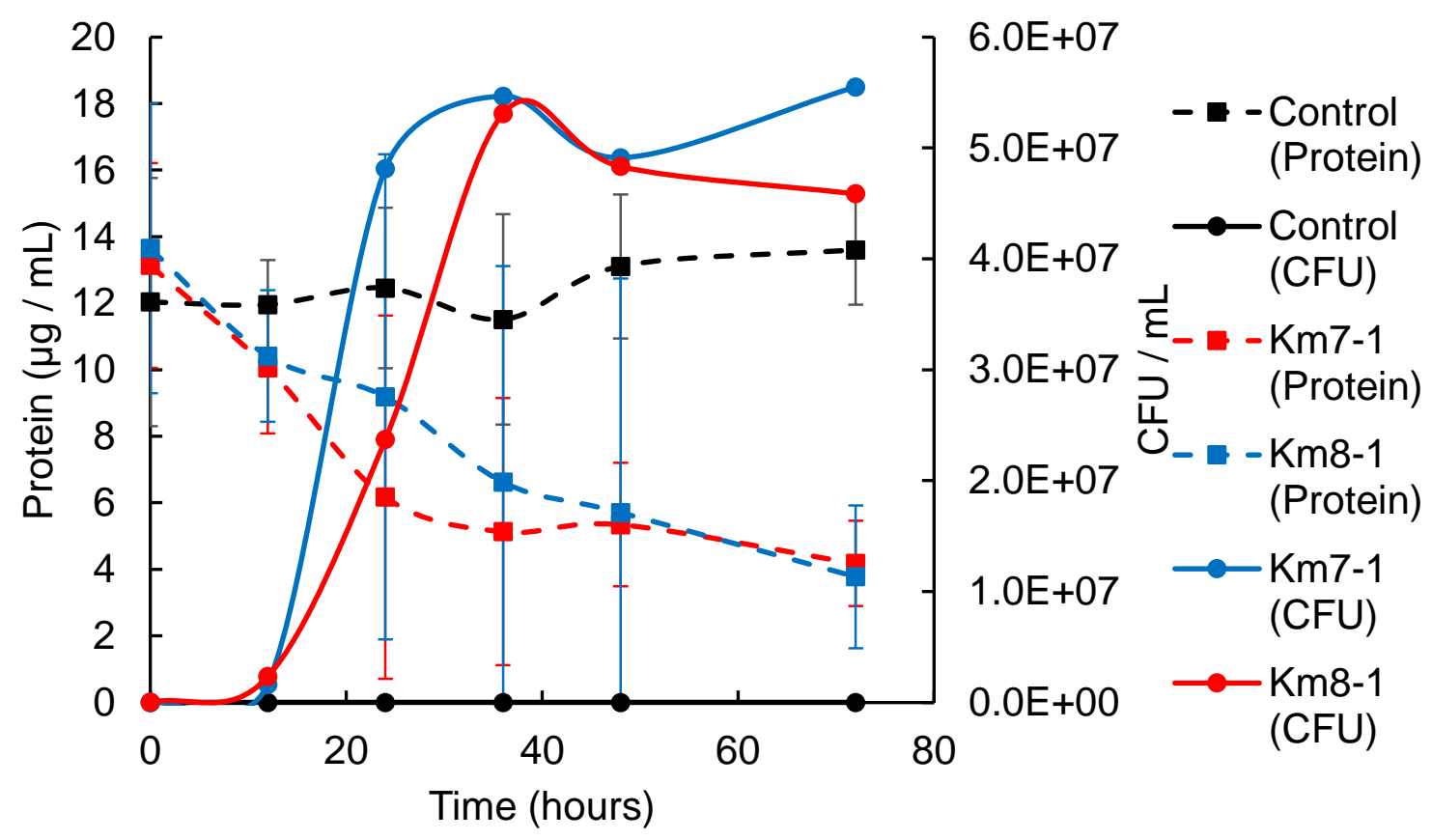

Figure 18. Averaged CFU and averaged protein as a function of fermentation time. 
similar and demonstrated the same general trend (Figure 18). The average initial protein concentration in the fermentation broths of Kluyveromyces marxianus 7-1 and Kluyveromyces marxianus 8-1 were $13.1 \pm 4.35 \mu \mathrm{g}$ per $\mathrm{mL}$ and $13.6 \pm 4.08$ $\mu \mathrm{g}$ per $\mathrm{mL}$, respectively. The average final protein concentration in the fermentation broths of Kluyveromyces marxianus 7-1 and Kluyveromyces marxianus 8-1 were $4.18 \pm 2.15 \mu \mathrm{g}$ per $\mathrm{mL}$ ( $68.2 \%$ difference from initial) and $3.78 \pm 1.28 \mu \mathrm{g}$ per $\mathrm{mL}(72.3 \%$ difference from initial).

\section{YEAST INULINASE PURIFICATION AND ACTIVITY}

Using a negative control (water + Bio-Rad reagent) as a spectrophotometric blank, the protein concentration was determined for the lyophilized DEAE bead decanted supernatant and the lyophilized dialyzed eluate. The lyophilized DEAE bead decanted supernatant had $20.0 \mu \mathrm{g}$ protein per $\mathrm{mL}$ while the lyophilized dialyzed eluate contained $15.6 \mu \mathrm{g}$ protein per $\mathrm{mL}$.

After incubation at $30^{\circ} \mathrm{C}$ for 7 days the various fractions collected from the protein purification were assayed for inulinase activity by the DNS method (35). Using the negative control (1.0\% inulin + water + DNS reagent) as a spectrophotometric blank, the DEAE bead decanted supernatant demonstrated no inulinase activity (reducing sugar concentration $0.0 \mu \mathrm{g} \mathrm{per} \mathrm{mL}$ ) and the dialyzed eluate demonstrated inulinase activity (reducing sugar concentration 
$31.9 \mu \mathrm{g}$ per $\mathrm{mL}$ ). A specific activity of $29.3 \times 10^{-4} \mu \mathrm{mol}$ product per min per $\mathrm{mg}$ protein was calculated for the dialyzed eluate.

The DEAE fractions were subjected to SDS-PAGE and post stained with Coomassie Blue; however no bands were detected. After using the silver stain on the SDS-PAGE gel (Figure 19), several small bands of high molecular weight protein were observed in the lanes containing the dialyzed eluate (Lanes: A, B, and $C$ ) that migrated with an $R_{f}$ similar to the standard inulinase enzyme (Lane H) that were not present in the DEAE bead wash loaded (Lanes D, E, F, and G). A high molecular weight band was observed in all lanes for all fractions (Figures 19 and 20). Figure 20, is the same gel as Figure 19, but the photo was converted to black and white, adjusted for contrast and brightness for ease of spotting bands using a program called Paint.net. Several protein bands for the standard inulinase (Figures 19 and 20; Lane H) from Aspergillus niger were observed with estimated molecular weights of 159 kDa, 134 kDa, 124 kDa, 102 kDa, 78 kDa, 60 $\mathrm{kDa}$ and $49 \mathrm{kDa}$. The dialyzed eluate in Lanes A, B, and C in Figures 19 and 20 demonstrate thin bands of protein with estimated molecular weights of $159 \mathrm{kDa}$, $148 \mathrm{kDa}, 137 \mathrm{kDa}, 131 \mathrm{kDa}$, and $115 \mathrm{kDa}$. 
Lanes:
A
B
C
D
$E$
$\mathrm{F}$
G
$\mathrm{H} \quad \mathrm{I}$

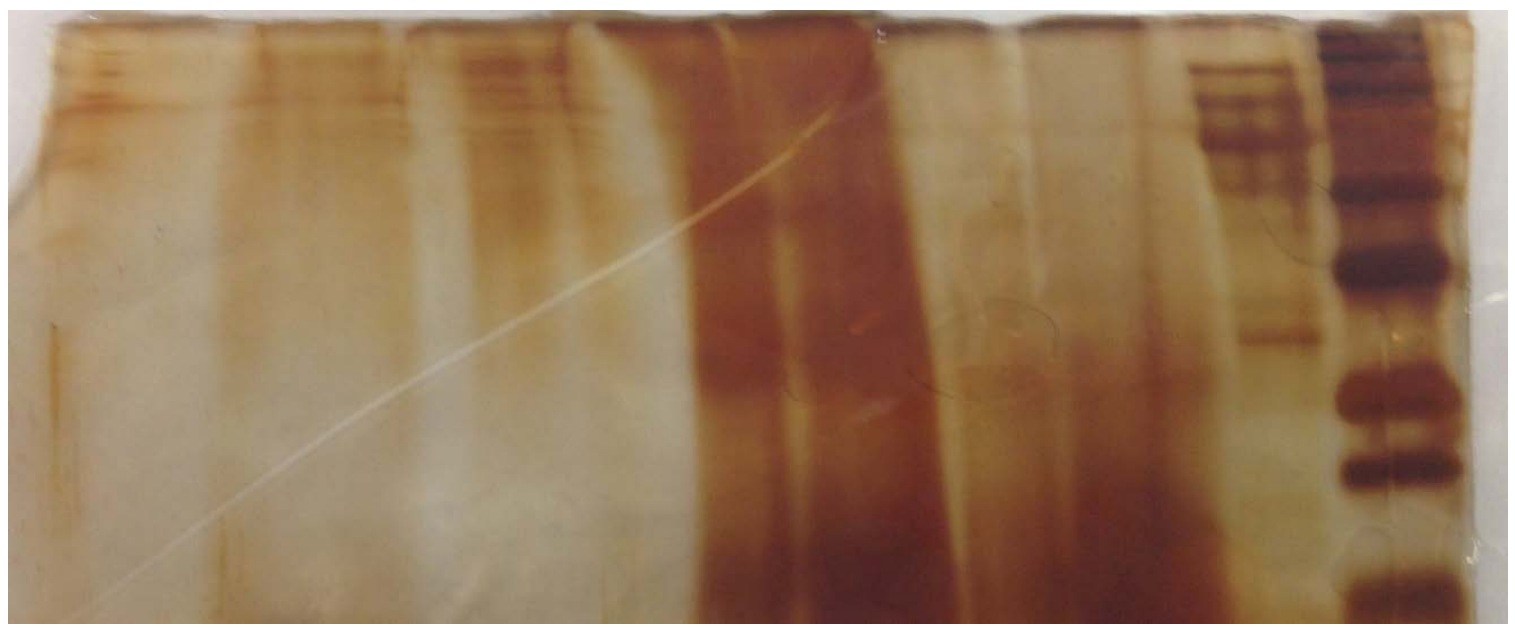

Figure 19. Silver stained SDS-PAGE gel. Dialyzed eluate, lanes A, B, and C; DEAE bead wash, lanes D, E, F and G; standard inulinase from Aspergillus niger, lane $\mathrm{H}$; molecular weight standards, lane I.

\section{Lanes:}
A
B
C
$\mathrm{D}$
E
$\mathrm{F}$
G
$\mathrm{H} \quad \mathrm{I}$

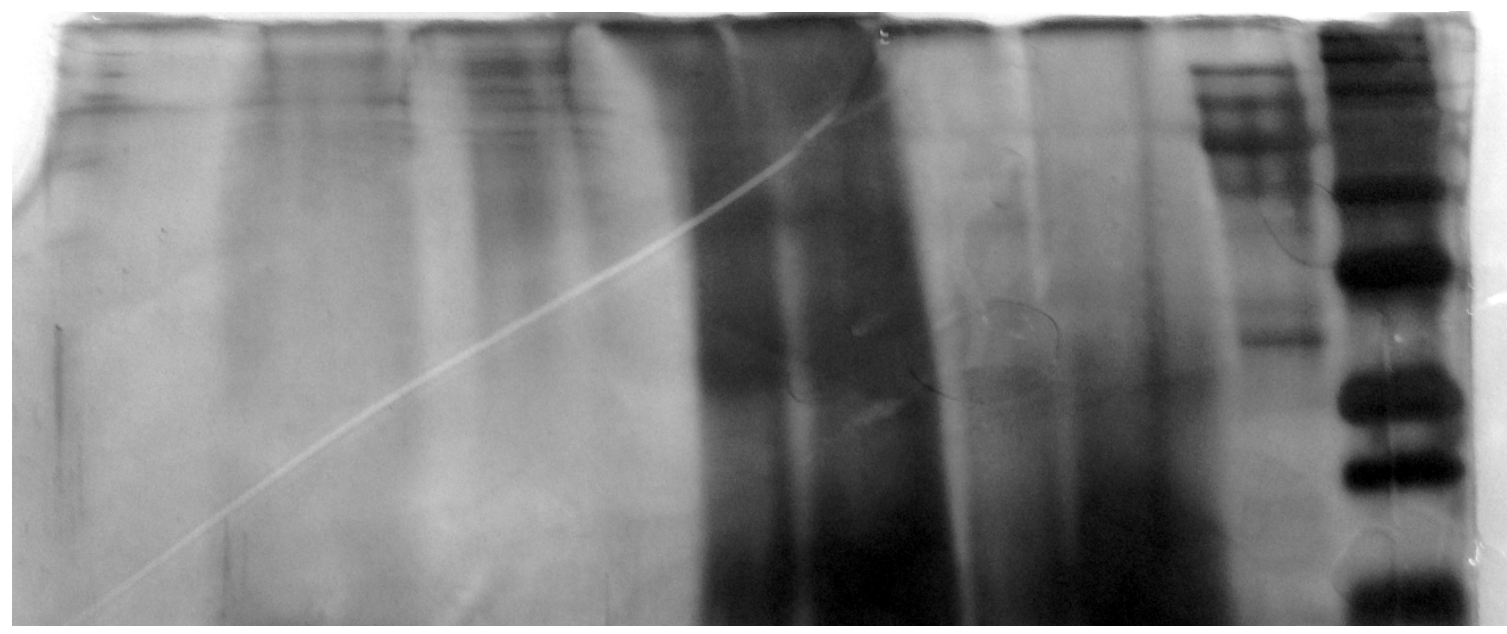

Figure 20. Same gel as Figure 19 with the image converted to black and white and the brightness and contrast adjusted. 


\section{MYCOSPORINE-LIKE-AMINO ACID EXTRACTION}

From the methanolic extracts using initial weights of $2.91 \mathrm{~g}$ and $3.16 \mathrm{~g}$ of dried seaweed, $0.47 \mathrm{~g}$ and $0.39 \mathrm{~g}$ of dried extract was obtained, respectively. On average, the extracts obtained were $14.1 \pm 2.69 \%(\mathrm{w} / \mathrm{w})$ of the original starting seaweed weight. From the methanolic extracts using initial weights of $4.68 \mathrm{~g}$, $30.9 \mathrm{~g}, 70.1 \mathrm{~g}$, and $117 \mathrm{~g}$ of Agave tequilana leaf skin, $0.76 \mathrm{~g}, 3.92 \mathrm{~g}, 7.40 \mathrm{~g}$, and $14.9 \mathrm{~g}$ of dried extracts, respectively, were obtained. On average, the dried extract obtained from Agave tequilana leaf skin was $13.1 \pm 2.35 \%(w / w)$ of the original starting material weight. The amounts of extracts obtain by percent weight were nearly identical between the seaweed and Agave tequilana skin.

\section{MYCOSPORINE-LIKE-AMINO ACID COLUMN PURIFICATION}

After column chromatography of the seaweed and Agave tequilana skin extracts, the interesting fractions were pooled. The seaweed extracts produced two spectrophotometrically interesting pools (Figure 21, dark blue spectrum and light blue spectrum) and the Agave tequilana skin extracts produced one (Figure 21, red spectrum). The seaweed pooled fractions demonstrated maximum absorbance values at $225 \mathrm{~nm}, 260 \mathrm{~nm}, 334 \mathrm{~nm}$ and $346 \mathrm{~nm}$ (Figure 21). The pooled Agave tequilana skin fractions demonstrated maximum absorbance values at $225 \mathrm{~nm}, 275 \mathrm{~nm}$, and 320-360 nm (Figure 21). 


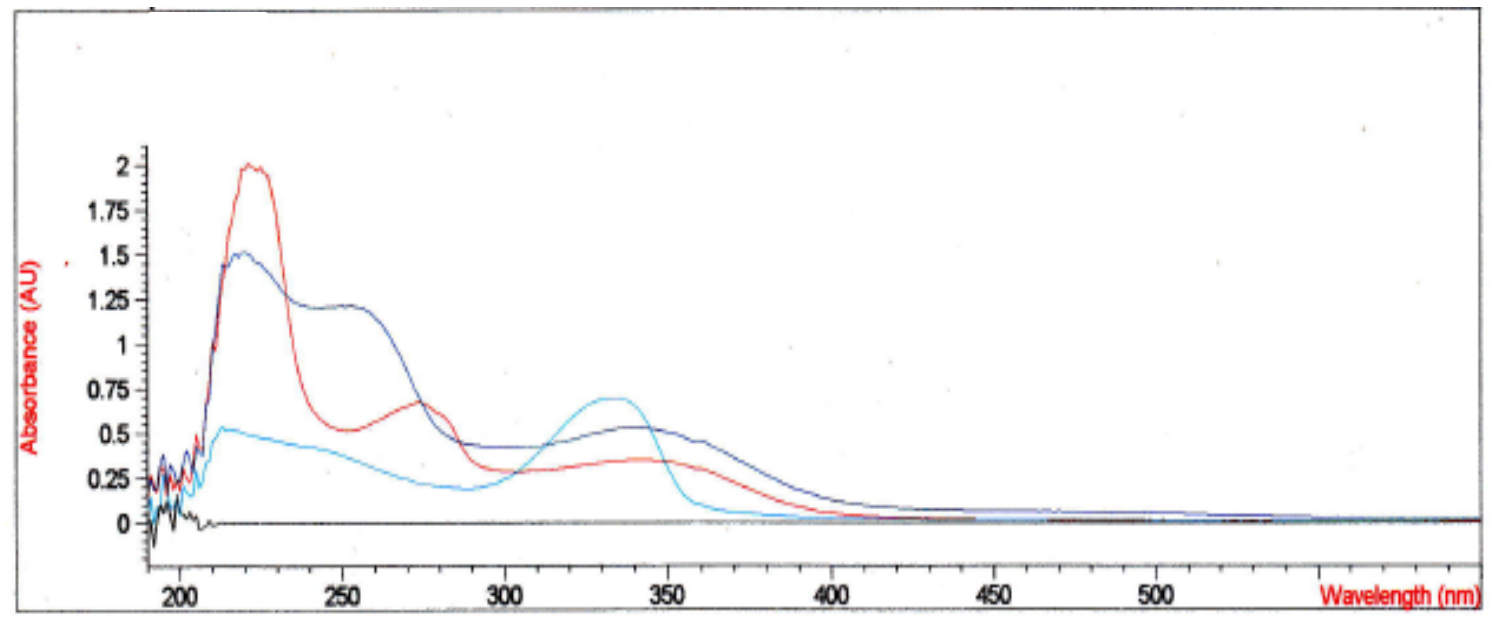

Figure 21. Overlaid UV-Vis spectra of pooled mycosporine-like-amino acid fractions from dried seaweed and the skin of the Agave tequilana. Two interesting pools of seaweed extracts (dark blue and light blue spectrum) and one pooled Agave tequilana extract (red spectrum) were obtained.

\section{TLC OF MYCOSPORINE-LIKE-AMINO ACID EXTRACTS}

The interesting pooled fractions from the column purification were spotted on a glass backed silica plate. Lanes A, B, and C of the glass backed silica plate were spotted with $0.5 \mu \mathrm{L}, 7 \mu \mathrm{L}$, and $5 \mu \mathrm{L}$, respectively. Figures 21 and 22 are of the same plate after sequential use of two different detection sprays. Lane A and Lane B of Figures 21 and 22 are from the seaweed, while Lane $C$ is from the Agave tequilana skin. Lane A of Figures 21 and 22 were from the light blue spectrum observed in Figure 20 and Lane B is from the dark blue spectrum observed in Figure 20.

In Figure 22, the plate was sprayed with ninhydrin detection spray, which turns pink, violet, or yellow in the presence of amines. The pink and purple 
observed at the origin of the plate is likely from the amines in proteins that are unable to travel up the plate. In Lane A of Figure 22, one pink spot that had a purple spot at the bottom of the pink spot was observed $\left(R_{f}=0.73\right)$. In Lane $B$ of Figure 22, one faint pink spot was observed $\left(R_{f}=0.73\right)$. In Lane $C$ of Figure 22, a light spot that was half pink and half purple $\left(R_{f}=0.73\right)$, an isolated purple spot $\left(R_{f}=0.60\right)$, and a faint purple spot $\left(R_{f}=0.50\right)$ were observed.

In Figure 23, the plate was sprayed with sulfuric methanol spray after the ninhydrin spray, which detects the presence of hydrocarbons after heating. The charred spots observed at the origin of the plate are likely from the hydrocarbons in proteins that are unable to travel up the plate. In Lane A of Figure 23 , one light charred spot was observed with the same $R_{f}$ as the spot observed in Figure 21 using the ninhydrin detection spray $\left(R_{f}=0.73\right)$. In Lane B of Figure 23 , one faint charred spot was observed at $R_{f}=0.50$ which was not present after the ninhydrin spray. In Lane C of Figure 23, a dark spot that had an $R_{f}=0.88$ was observed which was not present after the ninhydrin spray, as well as a light charring spot at $R_{f}=0.73$ and $R_{f}=0.60$ which where the ninhydrin detection spray gave a response. 


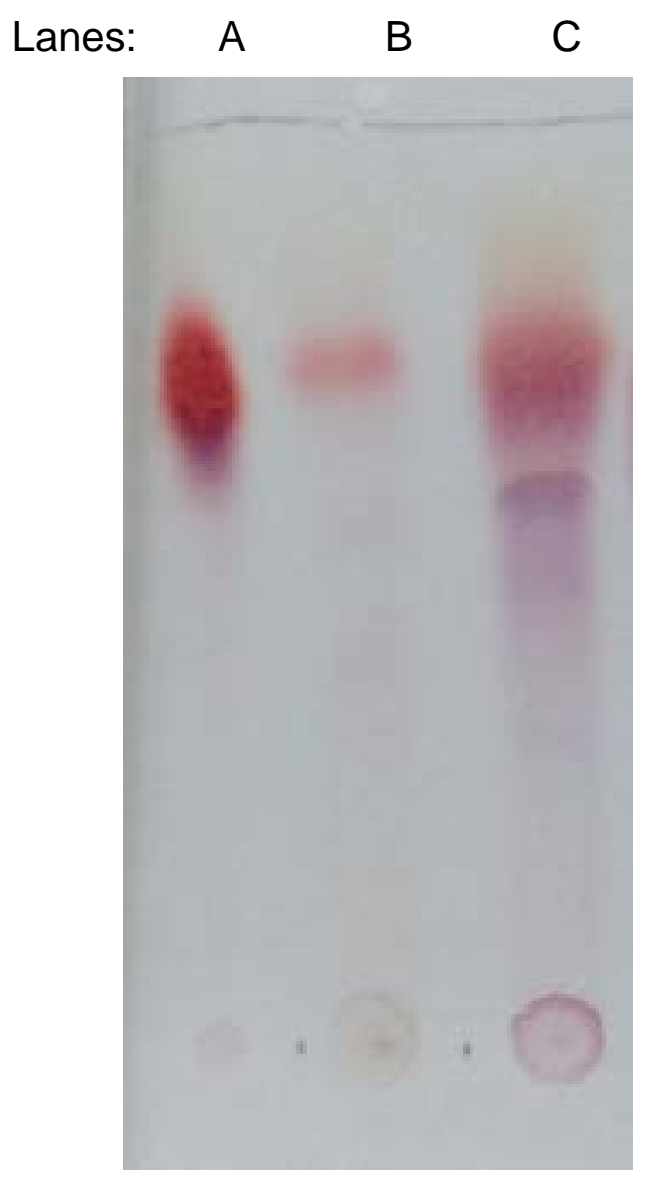

Figure 22. TLC of mycosporine-like-amino acid extracts from seaweed (lanes A and B) and Agave tequilana skin (lane C) after ninhydrin detection spray for amines.
Lanes: A B

C

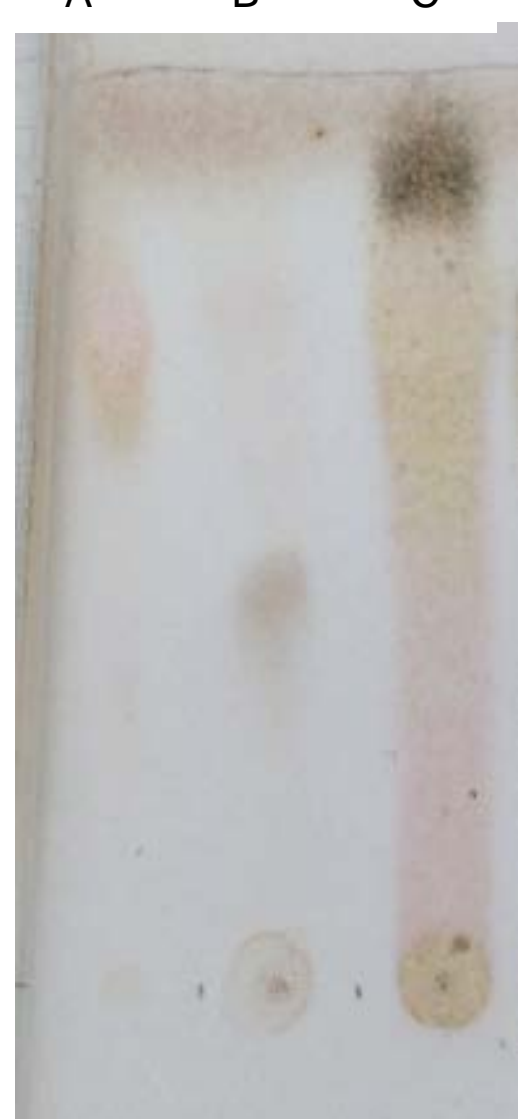

Figure 23. TLC of mycosporinelike-amino acid extracts from seaweed (lanes A and B) and Agave tequilana skin (lane $\mathrm{C}$ ) after sulfuric methanol detection spray for hydrocarbons.

\section{HPLC OF MYCOSPORINE-LIKE-AMINO ACID EXTRACTS}

The HPLC separation for the seaweed mycosporine-like-amino acid extracts with the DAD set to $320 \mathrm{~nm}$ as a function of elution time (Figure 24) using a gradient elution of $0.2 \%$ acetic acid $(\mathrm{v} / \mathrm{v})$ and acetonitrile: methanol: $0.2 \%$ 
acetic acid ( $/ \mathrm{v})$ at a ratio of 25: $25: 50(\mathrm{v} / \mathrm{v} / \mathrm{v})$ demonstrated one resolved peak at 2.85 mins and a partially resolved peak at 3.85 mins. The peak at 2.85 had an absorbance of $2480 \mathrm{mAU}$ and a peak area of $61500 \mathrm{mAU}^{2}$. The peak at $3.85 \mathrm{had}$ an absorbance of $307 \mathrm{mAU}$ and a peak area of $9900 \mathrm{mAU}^{2}$.

The HPLC separation for the Agave tequilana skin mycosporine-likeamino acid extracts with the DAD set to $320 \mathrm{~nm}$ as a function of elution time (Figure 25) demonstrated several peaks with retention time, peak absorbance, and peak area that are shown in Table 2. Both the Agave tequilana skin and seaweed had compounds with similar retention times of 2.84 mins (Agave tequilana skin), 3.65 mins (Agave tequilana skin), 2.85 mins (seaweed), and 3.85 $\min$ (seaweed).

Table 2. Retention Times, Peak Absorbance, and Peak Area of HPLC Separation of Mycosporine-Like-Amino Acid Extracts From the Skin of the Agave tequilana Monitored at $320 \mathrm{~nm}$

\begin{tabular}{|ccc|}
\hline Peak Retention Time $(\mathrm{min})$ & Peak Absorbance $(\mathrm{mAU})$ & Peak Area $\left(\mathrm{mAU}^{2}\right)$ \\
\hline 2.84 & 56.0 & 433 \\
3.65 & 113 & 5290 \\
20.6 & 30.7 & 742 \\
24.9 & 90.6 & 2990 \\
26.2 & 393 & 8960 \\
26.9 & 325 & 8390 \\
30.9 & 140 & 5840 \\
32.4 & 104 & 4840 \\
\hline
\end{tabular}




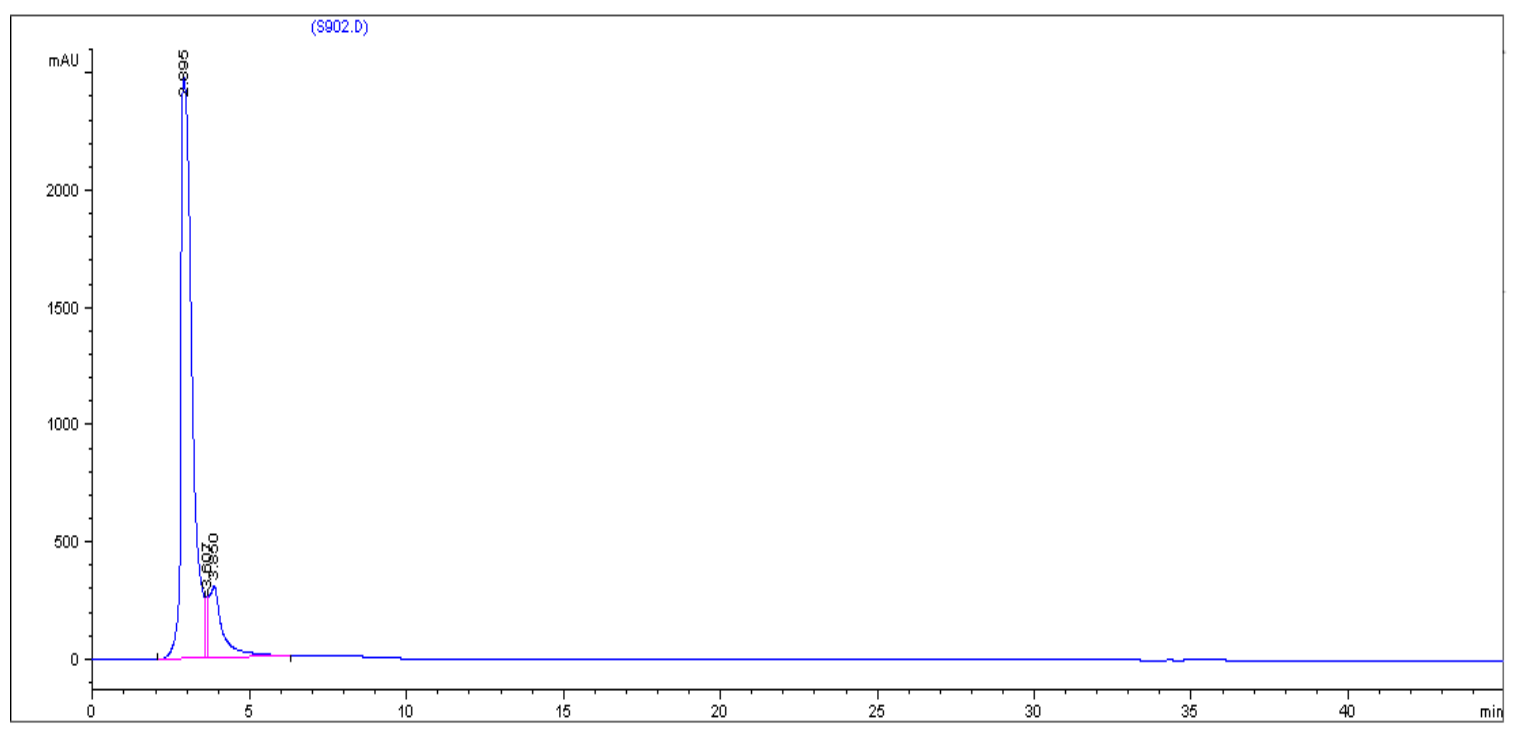

Figure 24. HPLC separation of seaweed

mycosporine-like-amino acid extracts $(320 \mathrm{~nm})$.

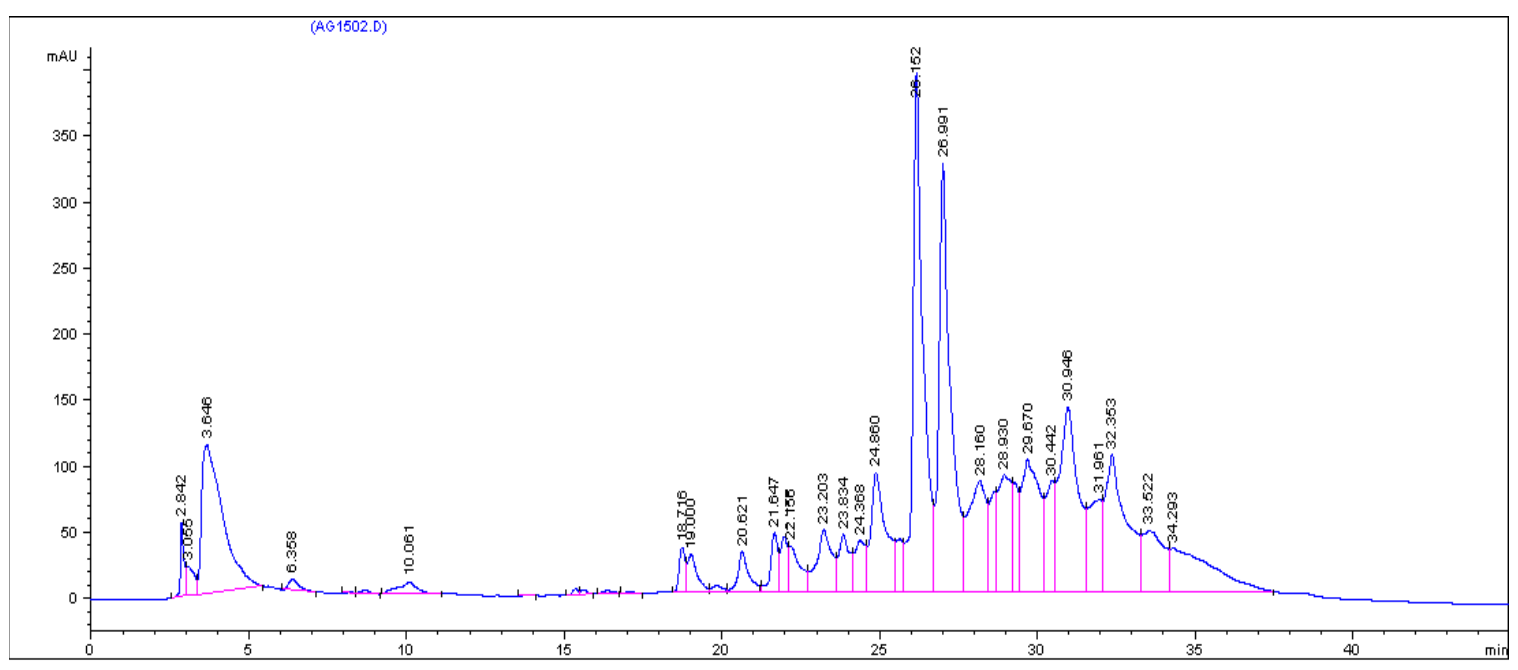

Figure 25. HPLC separation of Agave tequilana skin mycosporine-like-amino acid extracts $(320 \mathrm{~nm})$. 


\section{CHAPTER IV \\ CONCLUSIONS AND FUTURE WORK \\ FERMENTATION}

For all Control fermentations carried out in this study no CFU were observed in the undiluted plated fermentation broths. This demonstrates that only the yeast inoculated into the respective fermentations were responsible for the observed CFU data reported in this study. Both Kluyveromyces marxianus 7-1 and Kluyveromyces marxianus 8-1 were able to grow on sterilized pieces of leaves from the Agave tequilana in water under anaerobic conditions at room temperature under constant shaking. Using statistically identical weights of Agave tequilana leaf pieces (Table 1), both Kluyveromyces marxianus 7-1 and Kluyveromyces marxianus 8-1 were able to produce about the same CFU $U_{\max }$ after 36 hours of fermentation (Figure 10). Kluyveromyces marxianus 7-1 demonstrated an average CFU maximum of $5.47 \times 10^{7}$ viable cells per $\mathrm{mL}$ and Kluyveromyces marxianus 8-1 had an average CFU maximum of $5.31 \times 10^{7}$ viable cells per $\mathrm{mL}$ (2.90\% difference). The overlapping standard deviations observed in Figures 9 and 10 demonstrate that both strains of yeast grow nearly identically. Kluyveromyces marxianus 7-1's growth kinetics (slope during log phase) were $3.87 \times 10^{6}$ viable cells per hour (12-24 hours of fermentation) and 
Kluyveromyces marxianus 8-1's growth kinetics (slope during log phase) were $2.00 \times 10^{6}$ viable cells per hour (12-36 hours of fermentation), which was a 20.7\% difference, during the log phase. When the fermentation times are adjusted so that all fermentations are entering log phase at the same time (Figure 9), the Kluyveromyces marxianus 7-1 average CFU maximum was $5.47 \times 10^{7}$ viable cells per $\mathrm{mL}$ and Kluyveromyces marxianus 8-1 average CFU maximum was $5.22 \times 10^{7}$ viable cells per $\mathrm{mL}$, which is a $4.57 \%$ difference. These data demonstrate the high similarity of the growth curves between the Kluyveromyces marxianus 7-1 and Kluyveromyces marxianus 8-1 in this study.

When compared to CFU data of these same yeast strains grown on standard media from previous work (23) as shown in Table 3, it can be determined that Kluyveromyces marxianus 7-1 and Kluyveromyces marxianus 8-1, growing on the leaves of the Agave tequilana, grew to approximately the same CFU maximum as their respective fermentations on 1.0\% standard inulin (w/v). The CFU of the fermentations of Kluyveromyces

\section{Table 3. Comparison of Fermentations of Kluyveromyces marxianus 7-1} and Kluyveromyces marxianus 8-1 on Various Media

\begin{tabular}{|cccc|}
\hline Strain & Medium $^{*}$ & $\begin{array}{c}\text { CFU }_{\text {max }}^{*} \\
(C F U / m L)\end{array}$ & $\begin{array}{c}\text { Percent Difference from } \\
\text { CFU }\end{array}$ \\
\hline$K m 7-1$ & $1.0 \%$ Inulin (w/v) & $5.0 \times 10^{7}$ & $8.59 \%$ \\
$K m 8-1$ & $1.0 \%$ Inulin (w/v) & $5.0 \times 10^{7}$ & $5.83 \%$ \\
$K m 7-1$ & YP + 1.0\% Inulin (w/v) & $2.4 \times 10^{8}$ & $77.2 \%$ \\
$K m 8-1$ & YP + 1.0\% Inulin (w/v) & $2.7 \times 10^{8}$ & $80.3 \%$ \\
$K m 7-1$ & YPD & $1.9 \times 10^{8}$ & $71.2 \%$ \\
$K m 8-1$ & YPD & $2.5 \times 10^{8}$ & $78.8 \%$ \\
\hline
\end{tabular}

${ }^{*}$ Galindo-Leva et al. (23) 
marxianus 7-1 and Kluyveromyces marxianus 8-1 grown on the leaves of the Agave tequilana were 4.4 and 5.1 times less than that of the fermentation CFU maximum reported with YP $+1.0 \%$ standard inulin $(\mathrm{w} / \mathrm{v})$ standard medium respectively (23). The CFU of the fermentations of Kluyveromyces marxianus 7-1 and Kluyveromyces marxianus 8-1 grown on the leaves of the Agave tequilana were approximately $75.0 \%$ less than that of the fermentation CFU maximum reported with YPD standard medium (23). The growth curves for Kluyveromyces marxianus 7-1 and Kluyveromyces marxianus 8-1 on $1.0 \%$ standard inulin (w/v) reported by Galindo-Leva et al. (23) demonstrated a log phase trend that is different than the respective fermentations observed with the Agave tequilana leaves. The log phase trend that was reported in previous work demonstrated a step wise growth pattern on $1.0 \%$ standard inulin (w/v) (23). The fermentation growth trend observed in this study by both Kluyveromyces marxianus 7-1 and Kluyveromyces marxianus 8-1, more closely mimics the growth pattern reported for these strain on YP + $1.0 \%$ standard inulin (w/v) reported by Galindo-Leva et al. (23).

In conclusion, both strains of yeast can grow on pieces of leaves of the Agave tequilana, but Kluyveromyces marxianus 7-1 demonstrated a shorter lag time. Both yeast strains yielded nearly the same CFU and CFU maxima were at the same magnitude as when grown on $1.0 \%$ standard inulin $(w / v)$ previously reported by Galindo-Leva et al. (23). The shorter lag time demonstrated by Kluyveromyces marxianus 7-1 makes it the "better" choice for an industrial 
application due to it being more efficient at fermenting the leaves of the Agave tequilana with respect to time.

\section{REDUCING SUGARS}

The averaged Control fermentation broth reducing sugar concentration ( $\mathrm{n}$ = 3) demonstrated an average initial concentration of $0.34 \pm 0.06 \mathrm{mg}$ per $\mathrm{mL}$ reducing sugars and a final concentration of $0.43 \pm 0.04 \mathrm{mg}$ per $\mathrm{mL}$. The concentration of reducing sugars increased with fermentation time until it became asymptotic after 24 hour (Figure 14). The increase in the concentration of reducing sugars in the control fermentation broths was accompanied by zero CFU with undiluted fermentation broth (Figure 14). This demonstrates that the increase in reducing sugars for the Control fermentations were due to slow spontaneous hydrolysis.

When averaged, the reducing sugar concentrations of the Kluyveromyces marxianus 7-1 $(n=5)$ and Kluyveromyces marxianus 8-1 $(n=5)$ fermentation broths respectively demonstrate nearly the same trend over the same time frame (Figure 14). The average initial concentrations of reducing sugars for the Kluyveromyces marxianus 7-1 $(n=5)$ and Kluyveromyces marxianus 8-1 $(n=5)$ fermentation broths were $0.34 \pm 0.02 \mathrm{mg}$ per $\mathrm{mL}$ and $0.35 \pm 0.07 \mathrm{mg}$ per $\mathrm{mL}$, respectively. The average reducing sugar concentration for the Kluyveromyces marxianus 7-1 and Kluyveromyces marxianus 8-1 fermentation broths had an 
inverse relationship with the average CFU observed in the respective fermentations with time (Figure 14). This indicates that the yeast were able to consume the reducing sugars in the fermentation broth from the leaves of the Agave tequilana. The lowest concentrations of reducing sugars in the fermentations broths coincided with the CFU stationary phase demonstrating that when the yeast consumed the majority of the reducing sugars available, the yeast strains stopped dividing (Figure 14). The final concentration of reducing sugars in the Kluyveromyces marxianus 7-1 and Kluyveromyces marxianus 8-1 fermentation broths were $0.04 \pm 0.04 \mathrm{mg}$ per $\mathrm{mL}$ (87.9\% reduction from initial) and $0.02 \pm 0.01 \mathrm{mg}$ per $\mathrm{mL}(94.0 \%$ reduction from initial). On average Kluyveromyces marxianus 8-1 was able to consume $6.10 \%$ more reducing sugar $(w / v)$ than Kluyveromyces marxianus 7-1 when grown on pieces of leaves from the Agave tequilana.

\section{PROTEIN CONCENTRATION}

The averaged Control fermentation broth protein concentration $(n=3)$ demonstrated an average initial concentration of $12.0 \pm 3.72 \mu \mathrm{g}$ protein per $\mathrm{mL}$ protein and a final concentration of $13.6 \pm 1.65 \mu \mathrm{g}$ protein per $\mathrm{mL}(11.5 \%$ increase). The increase in the concentration of protein in the control fermentation broths was accompanied by zero CFU with undiluted fermentation broth (Figure 18). This demonstrates that the increase in protein concentration for the 
Control fermentations was due to an increased release of protein from the Agave tequilana plant material, likely by diffusion from the interior of the leaves into the fermentation broth.

The concentration of protein in the fermentation broth decreased with fermentation time (Figure 18). When averaged the protein concentrations of the Kluyveromyces marxianus 7-1 $(n=5)$ and Kluyveromyces marxianus 8-1 $(n=5)$ fermentation broths respectively demonstrate nearly the same trend over the same time frame (Figure 18). The average initial concentrations of protein for the Kluyveromyces marxianus 7-1 $(n=5)$ and Kluyveromyces marxianus 8-1 $(n=5)$ fermentation broths were $13.1 \pm 4.35 \mu \mathrm{g}$ per $\mathrm{mL}$ and $13.6 \pm 3.08 \mu \mathrm{g}$ per $\mathrm{mL}$, respectively. The average protein concentration for the Kluyveromyces marxianus 7-1 and Kluyveromyces marxianus 8-1 fermentation broths had an inverse relationship with the average CFU observed in the respective fermentations (Figure 18). This indicates that the yeast were using the protein in the fermentation broth over the course of the fermentation. The lowest concentrations of protein in the fermentations broths coincided with the CFU stationary phase demonstrating that when the yeast consumed the majority of the protein available, the yeast strains stopped dividing (Figure 18). The final concentration of protein in the Kluyveromyces marxianus 7-1 and Kluyveromyces marxianus 8-1 fermentation broths were $4.18 \pm 2.14 \mu \mathrm{g}$ per $\mathrm{mL}$ (a $68.2 \%$ reduction from initial) and $3.78 \pm 1.28 \mu \mathrm{g}$ per $\mathrm{mL}$ (a $72.3 \%$ reduction from initial). Thus the Kluyveromyces marxianus 7-1 and Kluyveromyces marxianus 8-1 
fermentations consumed about the same amount of protein over the course of the fermentations in this study. It is of interest to note that both accessible protein and reducing sugars were reduced by approximately $50.0 \%$ by the two strains of yeast at about the same time implying the yeast were not using these two sources of energy sequentially but simultaneously.

The large error bars (standard deviation, Control fermentations $n=3$, $K m 7-1$ fermentations $\mathrm{n}=5$ and $K m 8-1$ fermentations $\mathrm{n}=5$ ) demonstrate the uncertainty in the reported protein concentrations. The undiluted protein concentrations of the fermentation broths were at the lower limits of detection for this assay, which is $5 \mu \mathrm{g}$ protein per $\mathrm{mL}$, for fermentation time points after 12 hours and likely the source of the large standard deviation. This suggests that protein supplementation to these fermentations could potentially increase CFU and harvesting protein from the fermentation broth will not be advised under the fermentation conditions used in this study. This analysis ignores all protein within the yeast cells because the yeast cells were pelleted by centrifugation prior to the protein assay. If yeast intracellular proteins were assayed, the trends in protein concentration would likely modestly increase with time due to the increase in CFU over the course of fermentation. 


\section{YEAST INULINASE PURIFICATION}

Several protein bands for the standard inulinase (Figures 19 and 20; Lane H) from Aspergillus niger were observed with estimated molecular weights of $159 \mathrm{kDa}, 134 \mathrm{kDa}, 124 \mathrm{kDa}, 102 \mathrm{kDa}, 78 \mathrm{kDa}, 60 \mathrm{kDa}$ and $49 \mathrm{kDa}$. This indicates the presence of either fragments of inulinase, subunits of inulinase or multiple inulinase type enzymes from the yeast. The several small bands seen in the Figures 19 and 20 Lanes A, B, and C, are potentially due to the heterogeneity of the molecular weight of proteins. It has been reported that inulinase can by glycosylated, which can account for this homogeneity in molecular weight (24, 25). The average and standard deviation $(n=5)$ estimated for molecular weight of bands seen in the dialyzed salt eluate (Figures 19 and 20; Lanes A, B, and C) was $138 \pm 17 \mathrm{kDa}$. This standard deviation of the averaged dialyzed protein molecular weights was within the molecular weights of the $159 \mathrm{kDa}, 134 \mathrm{kDa}$, and $124 \mathrm{kDa}$ bands seen with the standard inulinase enzyme. The estimated molecular weight $(138 \pm 17 \mathrm{kDa})$ of the purified protein does not match the reported values for other inulinases purified from Kluyveromyces marxianus (endo-inulinase $66 \mathrm{kDa}$ and exo-inulinase $250 \mathrm{kDa}$ ) but are within the reported range of molecular weights of inulinases $50-250 \mathrm{kDa}$ of other organisms $(24,25)$. A specific activity of $29.3 \times 10^{-4} \mu \mathrm{mol}$ product per min per mg protein was calculated for the dialyzed eluate. This specific activity was 1-2 orders of magnitude smaller than reported specific activities for inulinase between $10.7 \times 10^{-3}$ and $24.2 \times 10^{-2} \mu \mathrm{mol}$ product per min per mg protein (24). With the 
observed inulinase activity, and an estimated molecular weight near that of standard inulinase, it can be concluded that the reported "batch" type anion extraction can be used to partially purify inulinases from the fermentation broths of Kluyveromyces marxianus 7-1 and Kluyveromyces marxianus 8-1 on the Agave tequilana. We can also conclude that the inulinase is a very robust enzyme since there were several steps, over several days, yet enzyme activity was still detected.

\section{MYCOSPORINE-LIKE-AMINO ACID EXTRACTION AND PURIFICATION}

From the $80.0 \%$ methanol $(\mathrm{v} / \mathrm{v})$ extracts using initial weights of $2.91 \mathrm{~g}$ and $3.16 \mathrm{~g}$ of dried seaweed, $0.47 \mathrm{~g}$ and $0.39 \mathrm{~g}$ of dried extract was obtained, respectively. On average the extracts obtained were $14.1 \pm 2.69 \%(\mathrm{w} / \mathrm{w})$ of the original starting material weight. The $80.0 \%$ methanol $(\mathrm{v} / \mathrm{v})$ extracts using initial weights of $4.68 \mathrm{~g}, 30.9 \mathrm{~g}, 70.1 \mathrm{~g}$, and $117 \mathrm{~g}$ of Agave tequilana leaf skin, yielded $0.76 \mathrm{~g}, 3.92 \mathrm{~g}, 7.40 \mathrm{~g}$, and $14.9 \mathrm{~g}$ dried extract, respectively. On average the dried extracts obtained from Agave tequilana leaf skin was $13.1 \pm 2.35 \%(\mathrm{w} / \mathrm{w})$ of the original starting material weight. Thus similar yields of dried extracts were obtain with both the seaweed and Agave tequilana leaf skin. The dried seaweed extracts were orange to red in color, while the Agave tequilana skin extracts were yellow to orange in color. The extractions of Vegicaps soft capsules by Torres et al. were reported to be pale yellow in color (42). 
After column chromatography, the seaweed extracts produced two spectrophotometrically interesting pools (Figure 21, dark blue spectrum and light blue) and the Agave tequilana skin extracts produced one (Figure 21, red spectrum). The seaweed pooled fractions demonstrated maximum absorbance values at $225 \mathrm{~nm}, 260 \mathrm{~nm}, 334 \mathrm{~nm}$ and $346 \mathrm{~nm}$ (Figure 21). The peak seen in the light blue spectrum in Figure 21 at $334 \mathrm{~nm}$ indicates that the positive control extraction of prophyra-334 was successful using the modified method of Torres et al. (42). The peaks for the seaweed extracts at $225 \mathrm{~nm}$ and $275 \mathrm{~nm}$ in Figure 21 are typical absorbance regions for hydrocarbons and aromatic compounds. The broad absorbance from $310-390\left(\lambda_{\max }=345 \mathrm{~nm}\right)$ is an unknown/reported compound. The pooled Agave tequilana skin fractions demonstrated maximum absorbance values at $225 \mathrm{~nm}, 275 \mathrm{~nm}$, and $345 \mathrm{~nm}$ (Figure 21, red spectrum). The peaks for the Agave tequilana skin extracts at $225 \mathrm{~nm}$ and $260 \mathrm{~nm}$ in Figure 21 are typical absorbance regions for hydrocarbons and aromatic compounds. The Agave tequilana skin extracts also demonstrated a broad absorbance from $310-390\left(\lambda_{\max }=345 \mathrm{~nm}\right)$ that also is an unknown/reported compound.

\section{TLC AND HPLC OF MYCOSPORINE-LIKE-AMINO ACID EXTRACTS}

In Figures 22 and 23, the Lanes A, B, and C, of the glass backed silica plate were spotted with $0.5 \mu \mathrm{L}, 7 \mu \mathrm{L}$, and $5 \mu \mathrm{L}$ on the plate, respectively. Lane A 
of Figures 22 and 23 were from the light blue spectrum observed in Figure 20 and Lane B is from the dark blue spectrum observed in Figure 20.

The plate in Figure 22, was sprayed with ninhydrin detection spray, which turns pink, violet, or yellow in the presence of amines. The pink and purple observed at the origin of the plate is likely from the amines in proteins that are unable to travel up the plate. In Lane A of Figure 22, one pink spot that had a purple spot at the bottom of the pink spot was observed $\left(R_{f}=0.73\right)$. In Lane $B$ of Figure 22, one faint pink spot was observed $\left(R_{f}=0.73\right)$. In Lane $C$ of Figure 22 , a light spot that was half pink and half purple $\left(R_{f}=0.73\right)$, an isolated purple spot $\left(R_{f}=0.60\right)$, and a faint purple spot $\left(R_{f}=0.50\right)$ were observed.

In Figure 23, the plate was sprayed with sulfuric methanol spray after the ninhydrin spray, which detects the presence of hydrocarbons after heating. The charred spots observed at the origin of the plate are likely from the hydrocarbons in proteins that are unable to travel up the plate. In Lane A of Figure 23, one light charred spot was observed with the same $R_{f}$ as the spot observed in Figure 22 using the ninhydrin detection spray $\left(R_{f}=0.73\right)$. In Lane B of Figure 23 , one faint charred spot was observed at $R_{f}=0.50$ which was not present after the ninhydrin spray. In Lane C of Figure 23, a dark spot that had an $R_{f}=0.88$ was observed which was not present after the ninhydrin spray, as well as a light charring spot at $R_{f}=0.73$ and $R_{f}=0.60$ which where the ninhydrin detection spray gave $a$ response. 
When comparing the HPLC peak retention times monitored at $320 \mathrm{~nm}$ it was demonstrated that both the Agave tequilana skin and seaweed had compounds with similar retention times of 2.84 mins (Figure 25, Agave tequilana skin), 3.65 mins (Figure 25, Agave tequilana skin), 2.85 mins (Figure 24, seaweed), and 3.85 min (Figure 24, seaweed). The seaweed extract peak at 2.85 mins (Figure 24) demonstrated a peak area that was 142 times larger than that of Agave tequilana peak area at 2.84 mins (Figure 25). This indicates that this compound is at much higher concentrations in the seaweed than the Agave tequilana skin. This conclusion is also supported by the amount of sample required for the observed spotting of TLC plates in Figures 22 and 23. The Agave tequilana skin extracts demonstrate several HPLC peaks with retention times (Figure 25) that the seaweed (Figure 24) did not. Most notable were the peaks seen at 26.2 mins and 26.9 mins (Figure 25). These peaks were the largest peaks observed in the HPLC chromatogram. The peaks in Figure 25 with retention times at 26.2 mins and 26.9 mins had peak absorbance values of $393 \mathrm{mAU}$ and $325 \mathrm{mAU}$, respectively. These peaks demonstrated nearly the same peak areas, $8960 \mathrm{mAU}^{2}$ (Figure 25, retention time 26.2 mins) and $8390 \mathrm{mAU}^{2}$ (Figure 25, retention time 26.9 mins), demonstrating that these compounds were nearly the same concentrations. 


\section{FINAL CONCLUSIONS}

Kluyveromyces marxianus 7-1 and Kluyveromyces marxianus 8-1, can be used to ferment the leaves of the Agave tequilana as an initial fermentation for the proposed bioremediation process (8). Kluyveromyces marxianus 7-1, demonstrated a shorter lag time than Kluyveromyces marxianus 8-1 and thus is the "better" strain for this process (Figure 9). Otherwise, both strains of yeast grew and used the available protein and reducing sugars almost identically (Figures 10,14, and 18). If the skin of the leaves of the Agave tequilana were removed prior to fermentation potentially economically valuable UV-absorbing compounds could be extracted. After fermentation, inulinases from the yeast can be purified providing another economically valuable product from the fermentations of the Agave tequilana leaves with Kluyveromyces marxianus 7-1 or Kluyveromyces marxianus 8-1.

\section{FUTURE WORK}

In previously reported CFU data by Galindo-Leva et al. (23), the addition of yeast extracts and peptone increased the $1.0 \%$ Inulin (w/v) CFU maximum by 4.8 and 5.4 times for Kluyveromyces marxianus 7-1 and Kluyveromyces marxianus 8-1, respectively. This strongly suggests that the yeast "starved" for nitrogen have limited growth. Thus future work should be done to test the effect of adding yeast extracts and/or peptone to the fermentations of leaves of the 
Agave tequilana with Kluyveromyces marxianus 7-1 and Kluyveromyces

marxianus 8-1. Adding yeast extracts and/or peptone to the fermentations to these fermentations should increase the CFU maxima that are reported in this study. Other work including optimization of the inoculation size and Agave tequilana leaf weight to water ratio need to be tested to explore potential avenues to improve CFU maxima. Also pressing the Agave tequilana leaves to release the "juice" may be an additional method to boost yeast growth; however this would add substantial labor costs prior to fermentations.

Determining the composition of carbohydrates as a function of fermentation time by TLC would give some insight into what carbohydrates in the Agave tequilana Kluyveromyces marxianus 7-1 and Kluyveromyces

marxianus 8-1 are being used for growth. Standard carbohydrates such as inulin, fructose, glucose, and sucrose would be used for comparison to the fermentation broths using the mobile phase for separating carbohydrates reported by GalindoLeva et al. (23).

Further characterization of the mycosporine-like-amino acid extracts of the skin of the Agave tequilana, and using seaweed as the positive control, is of particular interest because mycosporine-like-amino acids, to my knowledge, have not been reported as natural Agave tequilana products. Mass spectrometry of these extracts needs to be done to determine the molecular masses of the compounds separated by HPLC to help identify compounds isolated. 


\section{REFERENCES}

1. Industry at a Glance [Internet].: IBISWorld; 2015 [cited 1/11/2016]. Available from:

http://clients1.ibisworld.com.libproxy.lib.ilstu.edu/reports/us/industry/ataglanc e. aspx?entid=290.

2. General Declaration for Protection of the DOT [Internet].: Consejo Regulador del Tequila [cited 1/14/2016]. Available from:

http://www2.crt.org.mx/index.php?option=com_content\&view=article\&id=169 \&ltemid=178\&lang=en.

3. History [Internet].: Consejo Regulador del Tequila [cited 1/16/2016]. Available from: https://www.crt.org.mx/index.php/tequila/history.

4. Norma Oficial Mexicana NOM-006-SCFI-2005, Bebidas Alcohólicas-TequilaEspecificaciones [Internet].: Norma Oficial Mexicana [cited 1/11/2016]. Available from: https://www.crt.org.mx/images/Documentos/NOM-006-SCFI2005.pdf.

5. Producción Total: Tequila y Tequila 100\% [Internet].: Consejo Regulador Del Tequila [cited 1/11/2016]. Available from: https://www.crt.org.mx/EstadisticasCRTweb/.

6. Iñiguez CG, Bernal CJ, Ramírez MW, Villalvazo NJ. Recycling Agave Bagasse of the Tequila Industry. Adv Chem Eng Sci. 2014;4:134-42.

7. Iñiguez-Covarrubias G, Díaz-Teres R, Sanjuan-Dueñas R, AnzaldoHernández J, Rowell R. Utilization of By-Products from the Tequila Industry. Part 2: Potential Value of Agave tequilana Weber azul Leaves. Bioresource Tech. 2001(77):101-8.

8. Hughes S. Complete Conversion of Agave Waste to Aromatic Prescursors of Kevlar in a Gen2 Energy Two-Stage Biorefinery. Personal Communications 2014.

9. Agave tequilana F.A.C Weber tequila agave [Internet].: United States Department of Agriculture [cited 1/16/2016]. Available from: http://plants.usda.gov/core/profile?symbol=AGTE7. 
10. Blue agave [Internet].: Department of Employment, Economic Development and Innovation Biosecurity Queensland [cited 1/16/2016]. Available from: https://www.daf.qld.gov.au/_data/assets/pdf_file/0016/53116/IPA-BlueAgave-Risk-Assessment.pdf.

11. Salinas M, Ogura T, Soffchi L. Irritant Contact Dermatitis Caused by Needlelike Calcium Oxalate Crystals, Raphides, in Agave tequilana Among Workers in Tequila Distilleries and Agave Plantations. Contact Dermatitis. 2001;44(2):94-6.

12. Cedeño-Cruz, M.; Alvarez-Jacobs, J. Production of Tequila from Agave: Historical Influences and Contemporary Processes. [Internet].: [cited 1/16/2016]. Available from: http://www.scocia.com/newsite/Tequila.pdf.pdf.

13. Vijayaraghavan K, Yamini D, Ambika V, Sravya Sowdamini N. Trends in Inulinase Production - A Review. Crit Rev Biotechnol. 2009;29(1):67-77.

14. Lopez M, Mancilla-Margalli N, Mendoza-Diaz G. Molecular Structures of Fructans from Agave tequilana Weber var. azul. K Agric Food Chem. 2003;51:7835-40.

15. Mancilla-Margalli N, López M. Water-Soluble Carbohydrates and Fructan Structure Patterns from Agave and Dasylirion Species. J Agric Food Chem. 2006.

16. Waleckx E, Gschaedler A, Colonna-Ceccaldi B, Monsan P. Hydrolysis of Fructans from Agave tequilana Weber var. azul During the Cooking Step in a Traditional Tequila Elaboration Process. Food Chem. 2008;108:40-8.

17. Nelson D, Cox M. Glycolysis, Gluconeogenesis, and the Pentose Phosphate Pathway. In: Lehninger Principles of Biochemistry. 5th ed. New York, New York: W.H. Freeman and Company; 2008. p. 527-59.

18. Lappe-Oliveras $P$, Moreno-Terrazas R, Arrizón-Gaviño J, Herrera-Suárez T, García-Mendoza A, Gschaedler A. Yeasts Associated with the Production of Mexican Alcoholic Nondistilled and Distilled Agave Beverages. FEMS Yeast Research. 2008;8(7):1037-52.

19. Amaya-Delgado L, Herrera-lópez E, Arrizon J, Arellano-Plaza M, Gschaedler A. Performance Evaluation of Pichia kluyveri, Kluyveromyces marxianus and Saccharomyces cerevisiae in Industrial Tequila Fermentation. World J Microbiol Biotechnol. 2013(29):875-87. 
20. Lane MM, Burke N, Karreman R, Wolfe KH, O'Bryrne CP, Morrissey JP. Physiological and Metabolic Diversity in the Yeast Kluyveromyces marxianus. Antonie van Leeuwenhoek. 2011;100(4):507-19.

21. Lertwattanasakul N, Rodrussamee N, Suprayogi, Kimtong S, Thanonkeo P, Kosaka T, Yamada M. Utilization Capability of Sucrose, Raffinose, and Inulin and it's Less-Sensitiveness to Glucose Repression in Thermotolerant Yeast Kluyveromyces marxianus DMKU 3-1042. AMB Express. 2011;1(20).

22. Hughes S, Bang S, Bischoff K, Cote G, Cox E, Cedeño D, Doran-Peterson J, Gibbons W, Jones M, Kurtzman C, Liu S, López-Núñez J, Nelson D, Ochwat K, Pinkleman R, Qureshi N, Riaño-Herrera N, Rodriguez-Valencia N, Schoepke A. Automated UV-C Mutagenesis of Kluyveromyces marxianus NRRL Y-1109 and Selection for Microaerophilic Growth and Ethanol Production at Elevated Temperature on Biomass Sugars. Journal of Laboratory Automation. 2013;18(4):276-90.

23. Galindo-Leva L, Hughes S, López-Núñez J, Jarodsky J, Erickson A, Lindquist M, Cox E, Bischoff K, Hoecker E, Liu S, Qureshi N, Jones M. Growth, Ethanol Production and Inulinase Activity on Inulin Substrates by Mutant Kluyveromyces marxianus Strains NRRL Y-50798 and NRRL Y-50799. J Ind Microbiol Biotechnol. Accepted February 2016.

24. Inulinase [Internet].: Brenda Enzymes [cited 1/25/2016]. Available from: http://www.brenda-enzymes.org/enzyme.php?ecno=3.2.1.7.

25. Fructan beta-fructosidase [Internet].: Brenda Enzymes [cited 1/25/2016]. Available from: http://www.brenda-enzymes.org/enzyme.php?ecno=3.2.1.80.

26. Ethanol Futures [Internet].: Nasdaq [cited 2/11/2016]. Available from: http://www.nasdaq.com/markets/ethanol.aspx?timeframe=10y.

27. Singh S, Kumari S, Rastogi R, Singh K, Sinha R. Mycosporine-Like-Amino Acids (MAAs): Chemical Structure, Biosynthesis and Significance as UVAbsorbing/Screening Compounds. Indian J Exp Biol. 2008;46:7-17.

28. Mystery of Natural Sunscreen Solved [Internet].: Royal Society of Chemistry; 2011 [cited 1/21/2016]. Available from: http://www.rsc.org/chemistryworld/News/2011/February/25021103.asp.

29. Maeda H, Dudareva N. The Shikimate Pathway and Aromatic Amino Acid Biosynthesis in Plants. Annu Rev Plant Biol. 2012;63:73-105.

30. Plack P, Fraser N, Grant P, Middleton C, Mitchell A, Thomson R. Gadusol, an Enolic Derivative ofCyclohexane- 1,3-dione Present in the Roes of Cod and 
Other Marine Fish. Isolation, Properties and Occurrence Compared with Ascorbic Acid. Biochem J. 1981;199:741-7.

31. Carreto J, Carignan M. Mycosporine-Like-Amino Acids: Relevant Secondary Metabolites. Chemical and Ecological Aspects. Mar Drugs. 2011;9:387-446.

32. Böhm G, Pfleiderer W, Böger P, Scherer S. Structure of a Novel Oligosaccharide-Mycosporine-Amino Acid Ultraviolet A/B Sunscreen Pigment from the Terrestrial Cyanobacterium Nostoc commune. J Biol Chem. 1995;270(15):8536-9.

33. Reisch M. Burning Issues. C\&EN. 2015;93(20):10-5.

34. GEN 2 Energy Company, Inc. [Internet]. [cited 1/21/2016]. Available from: http://www.gen2energycompany.com/index.html.

35. Miller GL. Use of Dinitrosalicylic Acid Reagent for Determination of Reducing Sugars. Analytical Chemistry. 1958;31(3):426-8.

36. Tullo A. DuPont, ADM Unveil Route To Biobased Polyester. C\&EN. 2016;94(4):6.

37. Inulinase from Aspergillus niger [Internet].: Sigma Aldrich [cited 1/21/2016]. Available from: http://www.sigmaaldrich.com/catalog/product/sigma/i2017?lang=en\&region= US.

38. Bradford MM. A Rapid and Sensitive Method for the Quantitation of Microgram Quantities of Protein Utilizing the Principle of Protein-Dye Binding. Analy. Biochem. 1976;72:248-54.

39. Kushi R, Monti R, Contiero J. Production, Purification and Characterization of an Extracellular Inulinase from Kluveromyces marxianus var. bulgaricus. J Indust Microbio \& Biotech. 2000(25):63-9.

40. Laemmli U. Cleaveage of structural Proteins During the Assembly of the Head of Bacteriophage T4. Nature. 1970(227):680-5.

41. Kerényi L, Gallyas F. Über Probleme der Quantitativen Auswertung der mit Physikalischer Entwicklung Versilberten Agarelektrophoretogramme. Clin Chim ACta. 1973;47(3):425-36.

42. Torres A, Claes E, Hochberg M, Srebnik M. Porphyra-334, A Potential Natural Source for Protective Sunscreens. Photochem Photobiol Sci. 2006(5):432-5. 
43. Takano S, Nakanishi A, Uemura D, Hirata Y. Isolation and Structure of a 334 nm UV-Absorbing Substance, Porphyra-334 from the Red Alga Porphyra tenera Kjellman. Chem Letters. 1979:419-20.

44. Robyt J, White B. Amino Acids, Peptides and Proteins. In: Biochemical Techniques Theory and Practice. Prospect Heights, Illinois: Waveland Press, Inc.; 1987. p. 227-30.

45. Carreto J, Carignan M, Montoya N. Comparative Studies on MycosporineLike-Amino Acids, Paralytic Toxins and Pigment Profiles of the Toxic Dinoflagellates Alexandrium tamarense, A. catenella and A. minutum. Mar Ecol Prog Ser. 2001;223:49-60.

46. Shick J, Dunlap W. Mycosporine-Like-Amino Acids and Related Gadusols: Biosynthesis, Accumulation, and UV-Protective Functions in Aquatic Organisms. Annu Rev Physiol. 2002(64):223-62. 


\section{APPENDIX A}

\section{SELECTION OF REPORTED STRUCTURES OF}

MYCOSPORINE-LIKE-AMINO ACIDS

(MODIFIED FROM REF. 46)
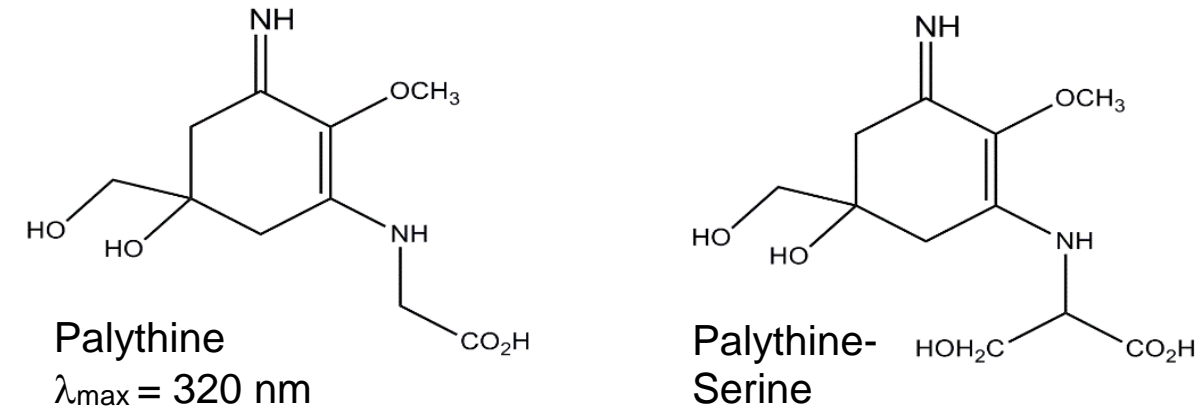

Serine

$\lambda_{\max }=320 \mathrm{~nm}$<smiles>[R]C1C(=O)C(OC)=C(O)CC1(O)CO</smiles>

Gadusol, $\mathrm{R}=\mathrm{OH}$

Deoxygadusol, $\mathrm{R}=\mathrm{H}$

$\lambda_{\max }=268 \mathrm{~nm}\left(\mathrm{H}^{+}\right), \lambda_{\max }=294 \mathrm{~nm}\left(\mathrm{OH}^{-}\right)$
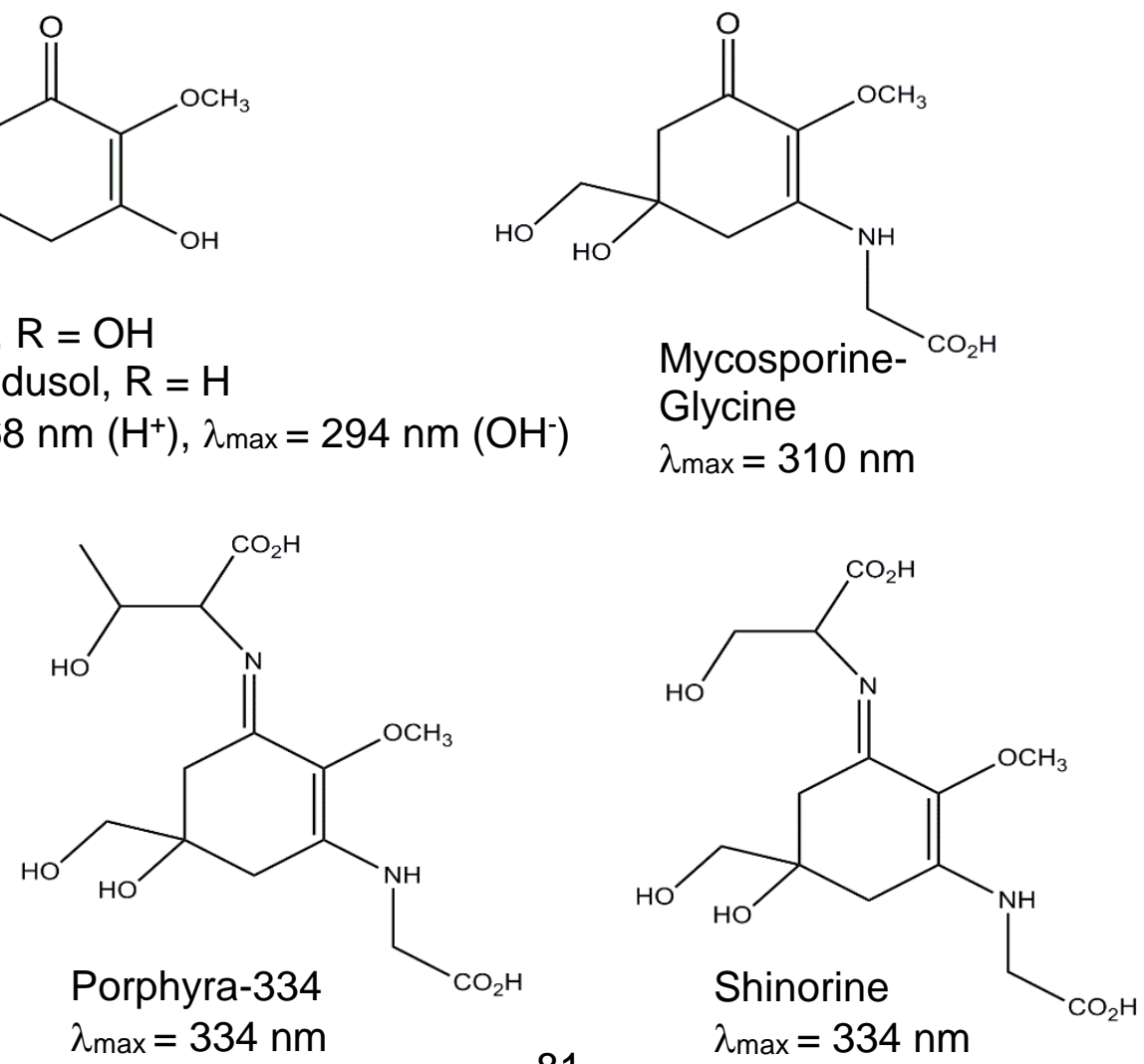


\section{APPENDIX B}

\section{REPORTED BIOSYNTHETIC ROUTES OF}

\section{MYCOSPORINE-LIKE-AMINO ACIDS}

(MODIFIED FROM REF. 27)

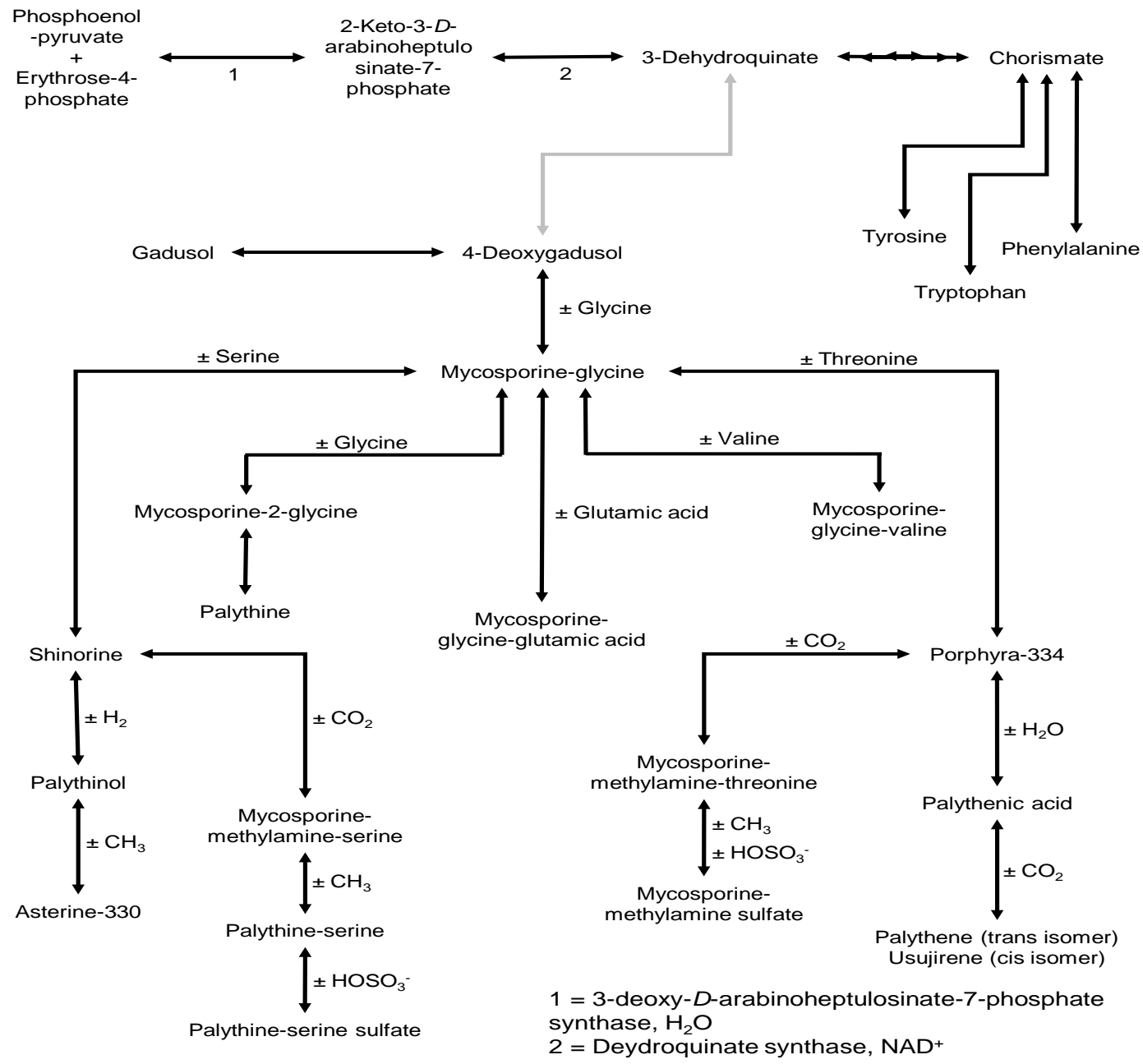




\section{APPENDIX C}

\section{THE PROPOSED GENERALIZED BIO-NYLON 6 AND}

\section{BIO-KEVLAR SYNTHETIC PATHWAYS}

(MODIFIED FROM REF. 8)

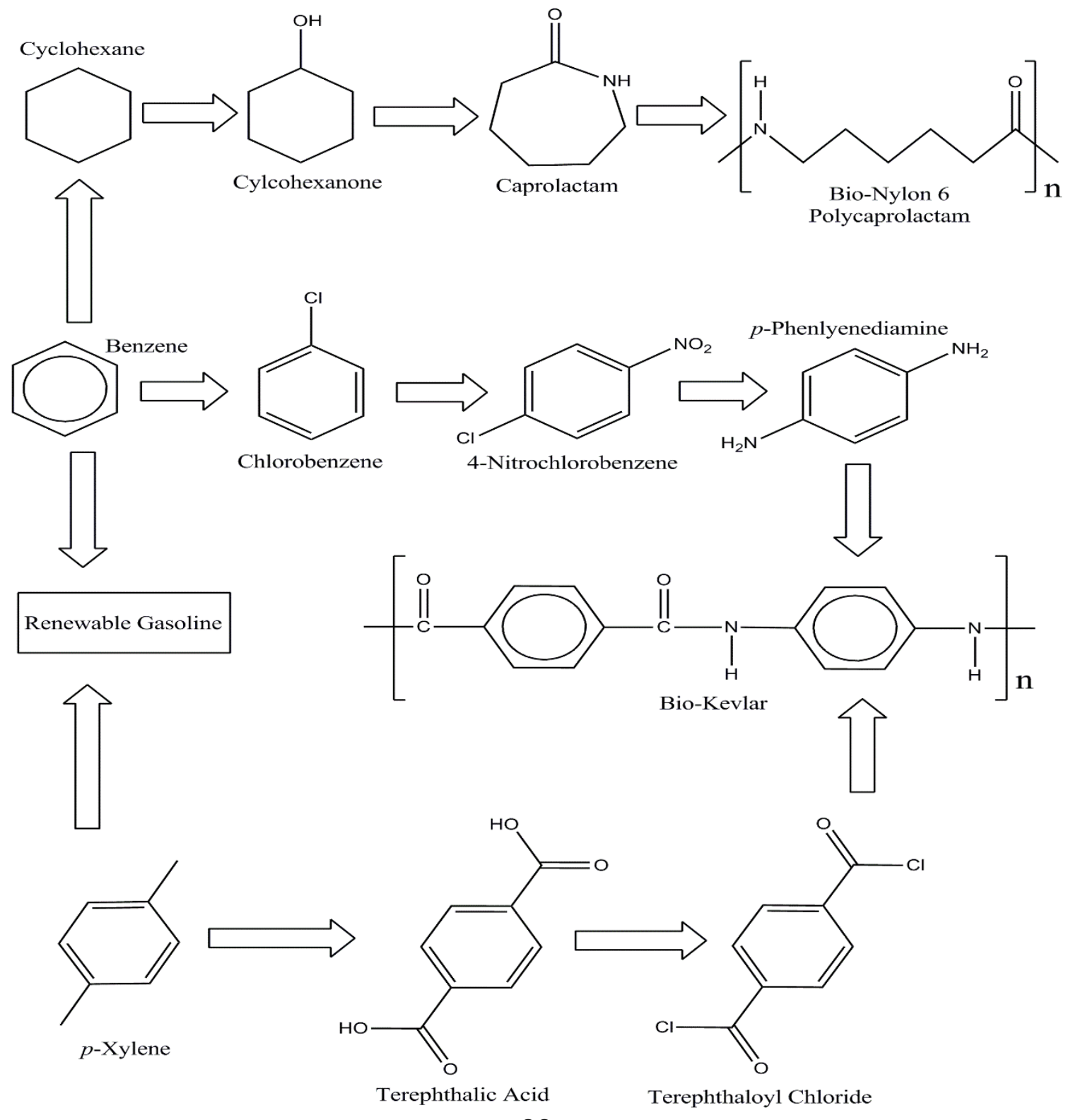

